\title{
Systemic complications in the preterm fetus after asphyxia : studies of cardiovascular and blood flow responses
}

Citation for published version (APA):

Quaedackers, J. S. (2006). Systemic complications in the preterm fetus after asphyxia : studies of cardiovascular and blood flow responses. [Doctoral Thesis, Maastricht University]. Maastricht University. https://doi.org/10.26481/dis.20060420jq

Document status and date:

Published: 01/01/2006

DOI:

10.26481/dis.20060420jq

Document Version:

Publisher's PDF, also known as Version of record

Please check the document version of this publication:

- A submitted manuscript is the version of the article upon submission and before peer-review. There can be important differences between the submitted version and the official published version of record.

People interested in the research are advised to contact the author for the final version of the publication, or visit the DOI to the publisher's website.

- The final author version and the galley proof are versions of the publication after peer review.

- The final published version features the final layout of the paper including the volume, issue and page numbers.

Link to publication

\footnotetext{
General rights rights.

- You may freely distribute the URL identifying the publication in the public portal. please follow below link for the End User Agreement:

www.umlib.nl/taverne-license

Take down policy

If you believe that this document breaches copyright please contact us at:

repository@maastrichtuniversity.nl

providing details and we will investigate your claim.
}

Copyright and moral rights for the publications made accessible in the public portal are retained by the authors and/or other copyright owners and it is a condition of accessing publications that users recognise and abide by the legal requirements associated with these

- Users may download and print one copy of any publication from the public portal for the purpose of private study or research.

- You may not further distribute the material or use it for any profit-making activity or commercial gain

If the publication is distributed under the terms of Article 25fa of the Dutch Copyright Act, indicated by the "Taverne" license above, 
SYSTEMIC COMPLICATIONS IN THE PRETERM FETUS AFTER ASPHYXIA

Studies of cardiovascular and blood flow responses

Josine Johanna Serafina Leonarda Theresia Quaedackers 
(c) Josine Quaedackers, Maastricht 2000

\section{Druk}

Schrijen-Lippertz-Huntjens

\section{Vormgeving en Layout}

D\&L graphics

www.digraphics.nl

ISBN-1 0: 90-8590-012-3

ISBN-13: $978-90-8590-012-2$ 


\section{SYSTEMIC COMPLICATIONS IN THE PRETERM FETUS AFTER ASPHYXIA}

\section{Studies of cardiovascular and blood flow responses}

\section{Proefschrift}

ter verkrijging van de graad van doctor aan de Uniwersiteit Maastricht, op gezag van de Rector Magnificus, Prof. Mr. G.P.M.F. Mols, ingevolge het besluit van het College van Decanen, in het openbaar te verdedigen op donderdag 20 april 2006 om 12.00 uur

door

Josine Johanna Serafina Leonarda Theresla Quaedackers

geboren op 26 januari 1976

te Heerlen 


\section{Promotores}

Prof. Dr. J. de Haan

Prof. Dr. E. Heineman

\section{Copromotores}

Dr. L. Bennet (University of Auckland, NZ)

Dr. A.J. Gunn (University of Auckland, NZ)

\section{Beoordelingscommissie:}

Prof. Dr. C.E. Blanco (voorzitter)

Prof. Dr. D.A. Giussani (University of Cambridge, UK)

Prof. Dr. J.G. Nijhuis

Prof. Dr. H.A.J. Struijker Boudier

Prof. De. L.J.L. Zimmermann 


\section{CONTENTS}

$\begin{array}{ll}\text { Abbreviations } & 7\end{array}$

$\begin{array}{lll}\text { Chapter } 1 & \text { General introduction }\end{array}$

Chapter 2 The premature fetus: not as defenceless as we thought, but still paradoxically vulnerable?

Developmental neuroscience, $2001,23(3): 175-9$.

Chapter 3 An evaluation of methods for grading histologic injury following ischemia/reperfusion of the small bowel.

Transplantation Proceedings. 2000 Sep,32/6):1307.10.

Chapter $4 \quad$ The effect of asphyxia on superior mesenteric artery blood flow in the premature sheep fetus.

Journal of Pediatric Surgery. 2000 Jan,35(1):34-40.

Chapter 5 The role of the sympathetic nerwous system in post-asphyxial intestinal hypoperfusion in the preterm sheep fetus.

The Journal of Physiology (London). 2004 Jun;557(Pt 3): 103344.

Chapter 6 Polyuria and impaired renal blood flow after asphyxia in preterm fetal sheep. American joumal of physiology. Regulatory, integrative and comparative phystology. 2004 Mar;286(3):R576-83.

Chapter 7 Cardiovascular and endocrine effects of a singie course of maternal dexamethasone treatment in preterm fetal sheep.

British journal of obstetrics and gynaecology. 2005 Feb; $112(21: 182-91$.

Chapter $8 \quad$ General discussion and future perspectives

Chapter 9 Summary

Samenvatting

List of publications

Curriculum Vitae

Dankwoord 


\section{LIST OF ABBREVIATIONS}

ACTH adrenocorticotropic hormone

A/R EDF

ANP

absent or reversed end diastolic flow in the umbilical artery

ARF

atrial natriuretic peptide

acute renal fallure

$\mathrm{BE}$

base excess

BP

blood pressure

$\mathrm{CaBF}$

carotid artery blood flow

CaVR

carotid artery vascular resistance

$\mathrm{CBF}$

cerebral blood flow

$\mathrm{ClCr}$

creatinine clearance

CNS

central nervous system

$\mathrm{CVO}$

comibined ventricular output

$D A B$

diaminobenzidine tetrahydrochloride

DEX

dexamethasone

ECG

electrocardiogram

$\mathbb{E E G}$

electroencephallogram

EMG

electromyogram

$\mathrm{FE}_{\mathrm{Na}}$

$\mathrm{FE}_{\mathrm{K}}$

fractional excretion of sodium

fractional excretion of potassium

FBF

FHR

femoral artery blood flow

fetal heart rate

FHRV

fetal heart rate variability

Fiv

femoral artery vascular: resistance

GA

GFR

gestational age

glomerular filtration rate

$H \& E$

haematoxylin and eosin stajn

HPA

hypothalamic-pituitary-adrenal axis

$1 / \mathrm{R}$

ischemia / reperfusion

MAP

mean arterial pressure

MVP

mean venous pressure

Na,K-ATPase sodium-potassium adenosine-triphosphate,

(enzyme part of the cell membrane sodium potassium pump)

NEC

necrotising enterocolitis

NICU

neonatal intensive care unit 
NO

nitric oxide

$\mathrm{OR}$

Odds Ratio

$\mathrm{PaO}_{3} \quad$ arterial partial pressure of oxygen

$\mathrm{PaCO}_{2}$ arterial partial pressure of carbon dioxide

$\mathrm{pH}$

PRA

plasma renin activity

RBF

renal artery blood flow

RIA

radioimmunoassay

RVR

renal artery vascular resistance

SMA

superior mesenteric artery

SMABF

superior mesenteric artery blood flow

SMAVR

superior mesenteric artery vascular resistance

SNS

sympathetic neryous system

TUNEL terminal deoxynucleotidyl transferase-mediated dUTP-biotin in situ nick end labelling

UO

urine output 


\section{THE PRETERM INFANT}

Five to ten percent of all births in the western world occur before term $(37$ weeks gestation) $(1,2)$. Although by definition prematurely born infants represent only a relatively small percentage of births, they represent $70 \%$ of all neonatal mortality and about $75 \%$ of neonatal morbidity. The majority of these complications occur in the most premature infants, at less than 32 weeks gestation (3).

Preterm birth can be caused by a multitude of factors leading to either spontaneous labour ( $50 \%$ ), premature rupture of membranes (30\%) or iatrogenic delivery due to maternal or fetal distress (20\%). There seems to be a poorly defined association with intrauterine infection in some cases $(4,5)$. Currently there is no effective treatment to prevent or stop impending premature delivery, and thus treatment must be directed at minimising morbidity and mortality associated with prematurity. The only effective preventative therapeutic intervention at present is the administration of corticosteroids; acute complications are treated as they arise.

Advances in neonatal care have seen the survival of the most vulnerable low birth weight babies improve significantly over the last two decades. Unfortunately, there has not been a corresponding improvement in age specific morbidity. Indeed, the increasing success of newborn intensive care has actually been associated with a moderate rise in the childhood prevalence of cerebral palsy (6). In the USA, the direct costs of caring for premature infants were estimated in 1992 to be 7.4 billion USD/year, double the direct costs of AIDS (7), and acute and chronic costs remain substantial $(8,9)$.

\section{COMPLICATIONS OF PREMATURITY}

Although much recent research has been focused on neurodevelopmental disability, the major issues that confront premature infants and their carers immediately after birth are primarily related to systemic complications, which, as well as respiratory distress syndrome, include frequent early gastrointestinal dysfunction, with an increased risk of later severe complications such as necrotising enterocolitis (NEC), and renal impairment, including acute renal failure (10). In turn adverse neurodevelopmental outcomes are highly associated with systemic complications including NEC $(11,12)$. Acute renal failure (ARF) is estimated to occur in $8-24 \%$ of neonates that spend time in neonatal intensive care units (NICU) $(13,14)$. Gastrointestinal dysfunction is very common in premature infants and subsequent NEC occurs in up to $10 \%$ of all premature infants, with incidence inversely related to gestational age and birth weight (15).

The premature infant may be more vulnerable to these diseases simply due to immaturity, such as incomplete structural or functional development of organ systems. However, impaired perfusion seems to be a key factor that links many perinatal events such as exposure to hypoxia (low oxygen levels) around the time of birh, growth retardation, exposure to prostaglandin inhibitors and postnatal surgery, with early gastrointestinal and renal dysfunction in prematurely born infants (16-21). A further complicating factor is antenatal treatment with synthetic glucocorticoids such as dexamethasone and betamethasone which have many systemic effects, including an acute increase in vascular resistance as discussed below. Although a single course of these agents shows a consistent dose related reduction in perinatal morbidity and improved long-term development (22), there is now some experimental and clinical evidence that prophylactic treatment with glucocorticoids may have long-term cardiovascular consequences such as increased blood pressure (23), although others have not found this (24). At present, there is little information on the specific mechanisms that control gut and renal perfusion in the very immature fetus and newborn. Surprisingly, the majority of studies on the effects of glucocorticoids have used experimental models that best represent a relatively mature stage of development, equivalent to the term human. 


\section{HYPOXIA AND PREMATURE BIRTH}

Asphyxia, derived from two Greek words "a" (not) and "sphuxis" (heartbeat), literally means pulseless. Clinically and experimentally asphyxia is defined as a state of hypoxia and hypercapnia, due to impaired gaseous exchange, accompanied by an "oxygen debt" as shown by metabolic acidosis (25). Cinically it can be very difficult to assess with precision whether a fetus or neonate has suffered an asphyxial nisult, as well as it"s timing and depth due to the wide scope of insult severity and differences in response (26). Currently there are no specific markers to qualify asphyxia. Fetal heart rate variability during labour, postnatal Apgar score and umbilical cord blood $\mathrm{pH}$ and base excess levels lack specificity and sensitivity, except in severe cases (27). Although there is no precise degree of severity at which injury can occur, an approximate threshold has been defined by the increased incidence of complications in infants whose umblical artery base deficit is $10.12 \mathrm{mmol} / \mathrm{L}$, or higher (28). Perinatal asphyxia can occur for a number of reasons some of which are shown in Table 1.

Table 1: Some causes of acute severe asphyxia.

\section{Causes of acute asphyxia}

Prolapsed unbilical cord

Ulerne upture

Abrupto placentae

Amniotic flud embolism

Acute neonatal haemorhage

Acute matemal haemonnage

Moderate to severe asphyxia is not uncommon at term, occurring in approximately $3 / 1000$ births. There is strong evidence that hypoxia is much more common in infants born prematurely than at term (29), and frequently begins before the onset of labour (30). The incidence of such severe hypoxia [asphyxia) is approximately ten fold higher in preterm deliveries (30), and similarly to term infants is highly associated with an increased incidence and severity of systemic complications at birth $(30,31)$.

Further evidence comes from early serial electroencephalographic (EEG) and imaging studies, which suggest that preterm neural injury occurs in the immediate perinatal period in approximately two thirds of cases, while up to a third of cases may occur antenatally, and cases in the chronic postnatal period are the least common (32-34). Further, worse outcomes are strongly associated with exposure to perinatal hypoxia, active labour, abnormal heart rate traces in labour and subsequent low Apgar scores (34-37). Thus, antenatal and perinatal hypoxia is a common adverse event in premature birth.

\section{EXPERIMENTAL MODELS OF THE FETAL RESPONSE TO ASPHYXIA}

Experimental models are essential to study the effects of asphyxia on the fetus. The chronically instrumented fetal sheep is by far the most commonly used experimental approach for fetal studies, because it allows for the systematic recording of parameters such as heart rate and blood pressure over time, without the confounding effects of anaesthesia. It also allows parameter measurement during and after experimental interventions, such as asphyxia (Figure 1). 
Most previous experimental studies have focused on the responses to moderate hypoxemia. These limited studies suggest that premature fetal sheep at 100 days $(0.7)$ gestation or less show iminature responses to isocapnic hypoxia (38) or haemorrhagic hypotension (39) with no evidence of the bradycardia and peripheral vasoconstriction that are seen in the mature fetus. Similarly, it is reported that release of cortisol during moderate hypoxia is greatly attenuated at 100 days and earlier (40). Furthermore, although the 0.6 gestation fetus was able to increase cerebral blood flow (CBF) during moderate hypoxia, in contrast to the near-term fetus, this was not sufficient to fully maintain oxygen availability to the brain. Cerebral oxygen consumption was therefore sustained in part by an increase in fractional oxygen extraction (41). These data have led to the hypothesis that peripheral vasomotor control starts to develop at 0.7 gestation, coincident with maturation of neuro-hormonal regulators and chemoreceptor function, thus, that the premature fetus and newborn are really too 'immature' to defend themselves from hypoxia (42).

However, an important methodological issue for studies of hypoxic stress is that preterm fetuses have a much greatel" anaerobic capacity and lower aerobic requirements than at term (43-45), and thus may actually not experience true hypoxic stress until a much lower partial pressure of oxygen than at term. These considerations led us to hypothesize that the previous experiments in the preterm fetus using mild or brief hypoxic insults were misleading because they may not have been sufficient to elicit appropriate chemoreflex responses, and that responses comparable with those seen in the term fetus could be elicited by a severe insult. Chapter 2 provides a detailed dissection of how maturity affects fetal responses to asphyxia.

These considerations led us to use the chronically instrumented fetal sheep model of asphyxia (i.e. very severe hypoxemia accompanied by progressive metabolic acidosis) for our studies, as a tool to examine systemic blood flow responses.

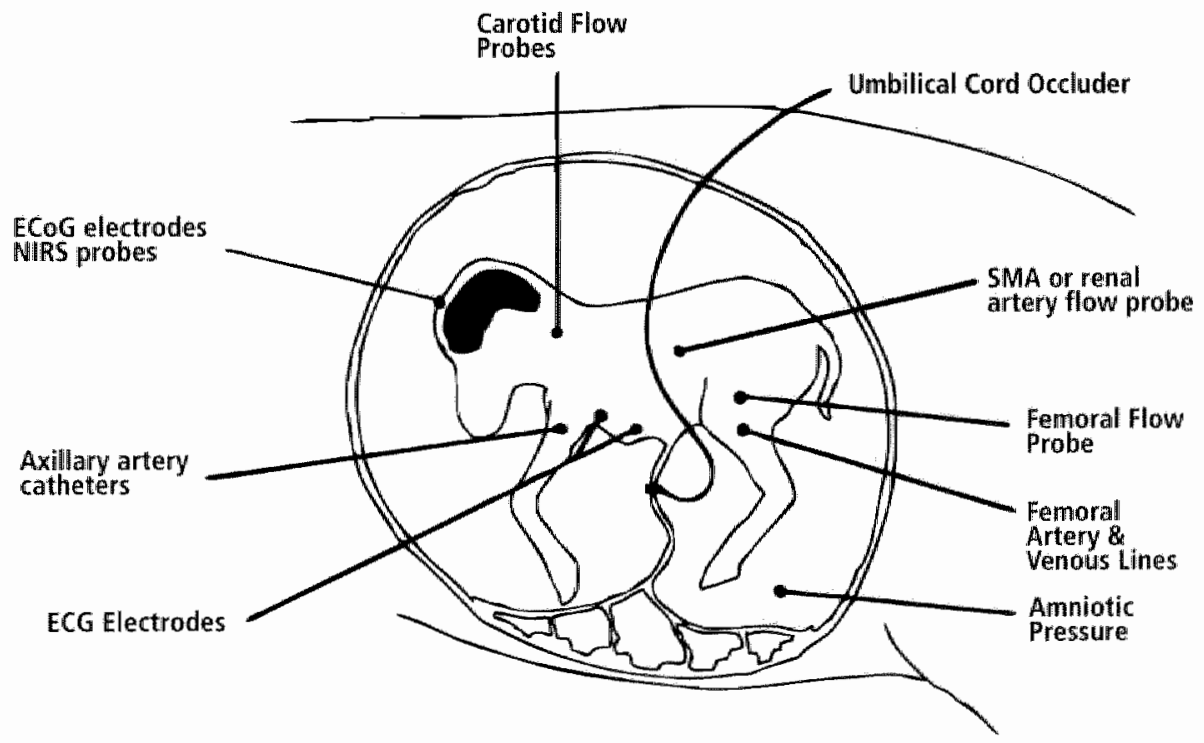

Figure 1: Schematic drawing of chronically instrumented fetal sheep 


\section{GUT DYSFUNCTION AFTER PREMATURE BIRTH}

By 20 weeks of gestation the human gastrointestinal tract is structurally complete. Functional development of both digestion and absorption occurs throughout the last third of gestation and continues for several years after birth (46). Small bowel contractile activity begins to develop at 25 weeks and reaches a mature pattern close to term $(47)$. The transition from intrauterine to extrauterine life represents a major change for the digestive tract. What is effectively parenteral nutrition from the placenta through the umbilical vein stops and the gut becomes responsible for nutrient absorption and digestion. Furthermore, the digestive tract has to function as an immunological barrier for the host of foreign bodies to which it is exposed to from birth onwards.

Early initiation of enteral feeding facilitates more rapid maturation of intestinal motility patterns in the preterm infant (48). However, increasing feeding volumes increases the risk of NEC (49), possibly because food combined with immature motility may increase bacterial overgrowth, in a gut which is susceptible to bacterial translocation due to immature immune function (50).

Premature birth is associated with a high rate of impaired postnatal intestinal adaptation during the first days of life, with delay in tolerating enteral feeding and ultimately NEC (51). NEC is the most common life-threatening gastro-intestinal disease in the neonates (15). Mortality rates can be as high as 20 to $40 \%(15,52)$. Treatment is limited to conservative management with parenteral feeding and intravenous antibiotics or surgical removal of necrotic bowel segments, which may result in short bowel syndrome (53).

The aetiology of NEC is much more complex than that of the earlier symptoms of feeding intolerance, and involves a triad of hypoperfusion, enteral feeding and bacterial invasion $(50,52,54)$ (Figure 2). The importance of all three factors is highlighted by the consistent observation that $95 \%$

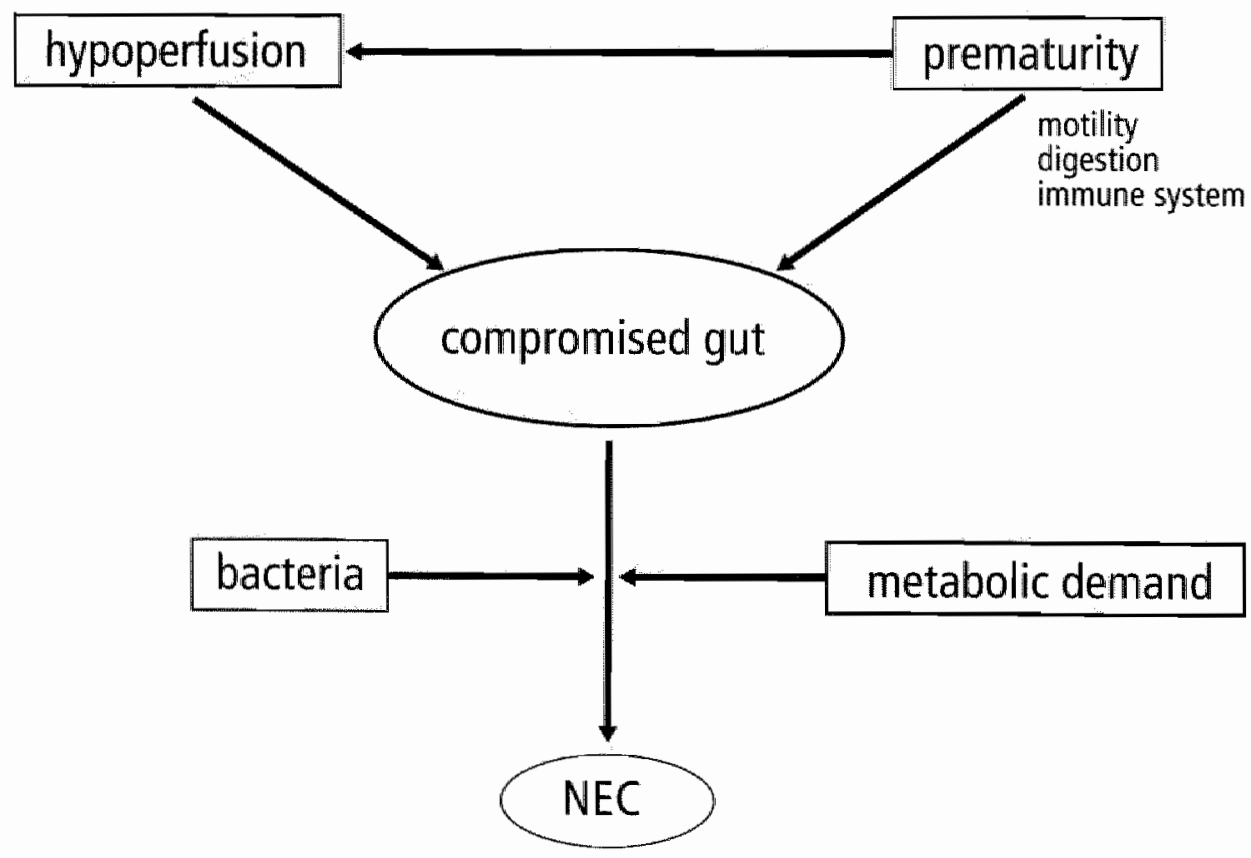

Figure 2: Hypothesised pathogenesis of necrotising enterocolitis. 
of preterm infants who develop NEC have received enteral feeding, and it does not develop in utero, prior to colonization by bacteria (50). Our studies focused on the initiating element, hypoperfusion, which seems to be the key link between a wide variety of disparate clinical problems and early gastrointestinal dysfunction $(16,17,20,21)$. Currently, there is little information on the specific mechanisms that control gut perfusion in the perinatal period.

\section{Evidence for hypoperfusion}

The histopathologic changes that occur in NEC, such as mucosal oedema, haemorrhage and necrosis, are strongly suggestive of ischaemic injury. Furthermore, this injury is most often found in the watershed areas between the superior and inferior mesenteric artery, the ileum and proximal colon. The timing of this injury has been the subject of considerable debate (55). Postnatally the premature infant is at higher risk of intestinal hypoperfusion and subsequent mucosal injury compared to the term infant due to their high incidence of hypotension, peripheral vasoconstriction and thrombosis particularly in the presence of a patent ductus arteriosus or umbilical artery catheter (52). However; both epidemiological and clinical evidence points towards at least some cases being triggered by prenatal and perinatal events, as discussed below.

Epidemiologically, NEC is closely associated with prematurity or low birth weight (56), but also with a number of other factors including exposure to antenatal glucocorticoids, vaginal delivery, need for mechanical ventilator support, treatment for patent ductus arteriosus with indomethacin, treatment for hypotension and low Apgar score at 5 minutes $(3,57-59)$. In turn, most of these factors imply an association with either hypoxia or with hypoperfusion - or both.

Clinically, several studies have shown a close association between absent or reversed end diastolic flow in the umbilical artery (A/R EDF; i.e. reduced uteroplacental perfusion) before birth in low birth weight infants and subsequent NEC. For example, Bhatt and colleagues found that A/R EDF in infants born weighing less than $2000 \mathrm{~g}$ has a positive predictive value for NEC of $52.6 \%$ (RR 30.2; OR 264) (60), with a subsequent mortality from NEC of $50 \%$. Conversely, when umbilical artery velocimetry was not reduced, there were no cases of NEC or mortality. This was a highly selected, retrospective analysis, however, others have also found an increased risk of perinatal complications including INEC and non specific feeding problems such as delayed meconium passage, abdominal distension, bilious vomiting and a delay in tolerating enteral feeding in growth restricted. infants with impaired uteroplacental blood flow $(20,61-66)$. This association appears to be independent of other variables such as degree of growth retardation and prematurity (20).

Strikingly, fetuses with $A / R$ EDF also had abnormal mesenteric artery pulsatility on Doppler measurements, which was in turn associated with NEC (66). These prenatal events affect postnatal gut perfusion, with evidence that low birth weight infants have reduced postprandial gut blood flow. Those who fail to increase blood flow in response to feeding have a very high risk of feeding intolerance $(67,68)$. Further, impaired intestinal blood flow in the neonate is also highly associated with an increased risk for subsequent necrotising enterocolitis (17).

This intestinal hypoperfusion precedes the development of NEC. Once NEC is present several groups have reported that mesenteric (gut) blood flow velocity is consistently increased $(19,69)$. Interestingly, however, and consistent with the studies above, gut perfusion had been decreased or non-responsive to feeding in the days before the onset of NEC in several infants whose flow had coincidentally been measured at that time (19). These clinical studies strongly imply that hypoxiarelated blood flow disturbances precede and contribute to the development of NEC. 


\section{The effect of severe hypoxia on the immature gut}

There is some, limited, experimental data on the acute effects of hypoxia or asphyxia on gastrointestinal blood flow, mostly in term models. In the near-term sheep fetus studies using microsphere blood flow measurements reported that gut blood flow is maintained or increased during moderate hypoxia or asphyxia, whereas during severe asphyxia there is a redistribution of blood flow away from peripheral organs, such as the gut, in favour of central organs (70-72). In contrast, partia! compression of the umbilical cord did not decrease intestinal blood flow in the mid-gestation sheep fetus (38), however, as discussed in chapter 2 , this may reflect the greater anaerobic capacity of the preterm fetus. Further, studies in the newborn piglet intestine have shown that sustained reduction of intestinal blood flow caused a decrease in production of the vasodilator nitric oxide and an increased response to vasoconstrictors in the 3 day old but not the 35 day old piglet, suggesting the immature intestine is more vulnerable to secondary hypoperfusion $(73,74)$. Again it is critical to appreciate that this represents a mature, term equivalent model. Thus, surprisingly there are no experimental data on adaptation of gut blood flow during, or after severe hypoxia in the preterm fetus or newborn.

\section{Mechanisms of mesenteric hypoperfusion}

Some data in the adult suggest that both central and peripheral secondary hypoperfusion after hypoxiaischaemia in other organ systems is related to impaired endothelial control of blood flow (75.78), while others suggest that it is actively mediated, reflecting reduced metabolic requirement $(79,80)$. Although there is no specific information in the fetus, several lines of evidence suggest the hypothesis that alphaadrenergic sympathetic nervous system (SNS) activity may play a key role in regulating gut perfusion during recovery after an asphyxial insult. The fetal gut is innervated by the autonomic nervous system from very early in development (81), and the autonomic nervous system is an important regulator of intestinal blood flow under a variety of physiological and pathological conditions (82-87). Redistribution of blood flow away from the peripheral organs such as the gut during hypoxia and asphyxia in utero is, for example, largely mediated by alpha-adrenergic receptors $(83,88,89)$, and sympathectomy in the sheep fetus resuits in increased meconium passage (90). This hypothesis was tested in the studies described in chapter 6.

\section{ACUTE RENAL FAILURE IN PREMATURITY}

In acute renal failure (ARF) there is a rapid and sustained reduction in renal function resulting in oligurla and accumulation of waste products, such as urea, in the body as well as an inability to control fluid and ion balance (91). In broad terms, there are three types of causes of ARF; prerenal, intrinsic and post-renal (91). In prerenal cases low glomerular filtration rate (GFR) is secondary to low renal blood flow due to low mean arterial blood pressure (91). Intrinsic ARF describes complications in the renal tissue, such as acute tubular necrosis, and post-renal cases are a result of obstruction of the downstream collecting system $(91)$.

The fetal kidney is structurally complete by 34 weeks of gestation. The fetus produces increasing amounts of urine throughout gestation thereby supplying most of its amniotic fluid volume. Studies in fetal sheep have shown that fetal kidneys receive a much lower percentage of cardiac output than at term $(2 \%$ ws. 15\%) (92). Thus, fetal glomerular filtration rate is low relative to the newborn and increases with gestational age. While it is well known that preterm infants are at an increased risk of transient fluid and electrolyte disturbances and of overt ARF compared to term neonates, there is little direct experimental evidence for the mechanism. 
Because GFR is preterm infants is low, and very close to renal blood flow, it has been suggested that even small reductions in renal blood flow will impair GFR. Largely on these theoretical grounds it has been proposed that $85 \%$ of cases of ARF in premature neonates may be due to prerenal causes (14). However, this must be contrasted with other studies suggesting that the majority of neonatal renal fallure in both term and preterm infants is associated with perinatal hypoxia/asphyxia $(21.93)$, and therefore could be a result of effects of asphyxia in organs other than the kidney, ischaemic renal damage or because of altered perfusion unrelated to mean arterial blood pressure $(13,94,95)$. Consistent with the hypothesis that intrinsic mechanisms such as ischaemic injury are important, a small long term study of preterm neonates that suffered ARF shortly after birth showed 9 out of 20 at the age of seven had worsening glomerular filtration rate (GFR) consistent with impaired renal function (96).

\section{CORTICOSTEROID THERAPY FOR IMPENDING PREMATURITY}

The use of antenatal glucocorticoids to prevent or reduce respiratory distress syndrome was originally reported by Liggins and Howie (97), and has been recommended for all preterm deliveries (98). Recent meta-analysis has shown that antenatal steroid administration for fetal maturation is also associated with a reduced incidence of early neonatal mortality, intraventricular haemorrhage and necrotising enterocolitis and improved postnatal cardiovascular stability (99). These beneficial effects have been associated with evidence of long-term neurodevelopmental improvement (22).

Recent experimental data raise the troubling possibility that even a short-term course of steroids may detrimentally alter fetal cardiovascular function. In near-term fetal sheep glucocorticoids have been shown to cause a significant reduction in cerebral blood flow [100], sustained elevation of blood pressure (101, 102), increased central and peripheral vascular resistance (100-102), and altered vascular sensitivity to endothelium-derived factors $(103,104)$. In late-gestation rats dexamethasone results in altered cardiac innervation and myosin heavy-chain isoforms $(105,106)$. Further, there is experimental evidence to show that there are altered perinatal responses to hypoxia, which potentially could compromise perinatal adaptation to labour (107-109). It is of concern that there are now data suggesting that infants exposed to a single course of corticosteroids more than 7 days before birth may have increased perinatal mortality $(110)$.

While these data argue strongly that even a single course of steroids may cause significant, and potentially harmful, changes in cardiovascular development, interpretation of these studies is problematic due to a number of methodological considerations; in particular the route of administration and degree of maturity. Many of the experimental studies, for example, utilised a direct infusion or injection to the fetus. This direct and constant exposure is quite different from the profile of clearance seen after maternal administration (111-113). Several studies have shown that the rotite of administration critically affects how the fetus responds to glucocorticoids. Organ maturation is significantly different between maternal and direct administration to the fetus (114) and neonatal blood pressure changes after antenatal treatment have been shown to be both route and dosedependent (115). Maternal administration of dexamethasone in late gestation induced only transient cardiovascular effects (111), while a lower dose in preterm sheep had no effect on blood pressure (116). In contrast, maternal betamethasone in the preterm baboon caused an acute elevation of fetal blood pressure for at least 24 hours (117), although the subsequent changes are unknown. While there may be differences related to the type of steroid used, these and other data (118) suggest that maturity at the time of exposure is also important and this is supported by clinical observations (119).

In summary, the cardiovascular effects of treatment with synthetic glucocorticoids on the preterm fetus remain highly controversial. 


\section{EXPERIMENTAL AIMS}

In conclusion, perinatal asphyxia is not uncommon for the preterm neonate and there is increasing clinical data to suggest that it results in an extended period of decreased blood flow to the organ beds. This reduction in flow is hypothesized to contribute to the high risk of systemic complications and in particular NEC and acute renal failure (21). Furthermore, paradoxically, the only effective treatment for prematurely delivered infants, prophylactic administration of systemic glucocorticoids, has also been suggested to cause increased blood pressure and reduced blood flow in many organs, which might further complicate the infant's course, and lead to long-term cardiovascular abnormalities. The mechanism of this increase in vascular resistance is speculated to be mediated primarily via sympathetic nervous release of noradrenalin at alpha-1 adrenergic receptors $(120)$. However, there have been no studies to date that have directly measured the changes in vascular resistance or blood flow pre, during and after- asphyxia.

Thus, the experimental goal of this thesis was to systematically dissect how hypoxia and corticosteroids affect the cardiovascular system and organ blood flow in the preterm fetus. By understanding the underlying processes that are involved in the fetal system, a more educated interpretation can be made of the pathogenesis of systemic complications in the preterm neonate.

Chapter 2 will explore in more depth the complex, paradoxical relationship between maturation and fetal responses to asphyxia which is briefly touched on above. Chapter 3 describes the validation of the specific system used to examine the development of intestinal injury in the experimental study reported in subsequent chapters. Chapters 4 to 7 report the results of specific experiments, which are discussed in detail in Chapter 8. 


\section{REFERENCES}

1. Wen SW, Smith G, Yang O, Waker M. Epideniology of preterm birh and heonatal outcome. Semin Feris? Neonatal Med 2004, $9161,429-35$.

2. Stoehorst GM, Rikken M, Martens SE, Brand R, den Ouden AL, Wit IM, et al. Changes in neonatolog: comparison of wo cohorts of very preterm infants (gestational age $<32$ weeks): the Project on Preterm and 5 mall for Gestational Age Infants 1983 and the Leiden Follow. Up Project on Prematurty 1996-1997. Pedathos $2005 ; 115121: 396 \cdot 405$.

3. Lemons IA, Gauer CR, On W, Korones SB, Paple LA, Stoll B, et al. Very low birth weightoutcomes of the National Institute of Child healih and human development neonatal research network, January 1005 through Decenber 1990. NICHD Neonatal Research Network. Pediatrics 2001;107/1:E1.

4. Goldenberg RL, Rouse DJ. Prevention of premature birth. N Engl J Med 1998;339151:313-20.

5. Halam R, Mortensen JH, Wollen AL. Preterm delivery an overwew. Acta Obstet Gynecol Scand 2003:82/81:687-704.

6. Bhushan V, Paneth N, Kiely IL. Impact of improved survival of very low birth weight infants on recent secular trends in the prevalence of cerebral palsy. Pediatrics 1003;01101:1094.100.

7. Lewit EM, Bakel: LS, Coman H, Shiono PH. The direct cost of low birth weight. Future Child 1995;511):35.56.

8. Petrou S, Mehta Z, Hockley C, Cook-Mozafari P, Henderson I, Goldacre M. The impact of preterm birth on hospital inpatient admissions and costs during the first 5 years of life. Pediatrics 2003;112(6 Pt 1]:12907.

9. Rogowsk IA, Horbar JD, Plsek PE, Baker LS, Deterding J, Edwards WH, et al. Economic implications of neonata! intensive care unit collaborative quality improvement. Pediatrics $2001 ; 10711 ; 239$.

10. Wand RM, Beachy JC. Neonatal complications following preterm birth. BH / Obstef Gyhaecol $2003 ; 110$ Suppl 20:816 .

11. Vohr BR, Wright LL, Dusick AM, Mele L, Verter J, Steichen IJ, et al. Neurodevelopmental and functional outcomes of extremely low birth weight infants in the National Institute of Child Health and Human Development Neonatal Research Network, 1993-1994. Pediatics 2000;105101:121626.

12. Hintz SR, Kendrick DE, Stoll BI, Vohr BR, Fanaroff AA, Donovan EF, et al. Neurodevelopmental and growth outcomes of extremely low bith weight infants alter necrotizing enterocolitis. Pediatrics 2005;1 15/3):690703.

13. Drukker A, Guignard JP. Renal aspects of the term and preterm infant: a selective update. Carr Opin Pediatr $2002 ; 14(2): 175-82$.

14. Toth-Heyn P. Drukker A, Guignard JP. The stressed neonatal kidney: from pathophysiology to clincal manggement of neonatal vasomotor nephropathy. Pediat Nephol 2000:14(3):227-39.

15. Stoll B1. Epidemiology of necrotizing enterocolits. Ch Perhato 1994:21(2):205-18.

16. Coombs RC, Morgan ME, Durbin GM, Booth IW, McNeish AS. Gat blood low velocities in the newbon: effects of patent ductus arteriosus and parenteral indomethacin. Arch Dis Chid 1990;651 10 Spec No, 1067 -1071.

17. Coombe RC, Morgan ME, Durbin GM, Booth IW, MCNeish AS. Abnomal gut blood flow welocttes in neonates at risk of necrousing enterocolitis. I Pediat Gastoenterol Nutr 1902;1511 1:13.9.

18. Kempley ST, Camsu HR, Vyas S, Nicolaides K. Effects of intrateme growth retardation on postratal wicenal and cerebral blood flow velocily. Arch Dis ChHd $1901 ; 60110$ Spec Nol:11158.

19. Kempley ST", Gamsu Hi. Superior mesenteric artery bload flow velocity in necrotising enterocolitis. Arh Dis Chid 1092,6717 Spec Noj:7936.

20. Malcolm G, Ellwood D, Devonald $K$, Beilby $R$, Henderson Smart D. Absent or reversed end diastolic flow velocity in the umbillical artery and necrotising enterocolitis, Arch Dis Child 1991;6617 Spec Nol805-807.

21. Akinbi H, Alubasi S, Hilpert PI., Bhutani VK. Gastrointestinal and renal blood flow velocity profile in neonates with birth asphyxia. I Pedatr 1904;125141:625-7.

22. Doyle LW, Ford GW, Rickards AL, Kelly EA, Davis NM, Callanan C, et al Antenatal corticosteroids and outcome at 14 years of age in children with birth weight less than 1501 grams. Pedatrics 2000;10011:E2. 
23. Doye LW, Word GW, Davis NM, Calanan C. Artenatal corticosterold herapy and blood pressure at 14 years of agrin inctem childer. Cin Sci Lond $2000,98(2): 137.42$.

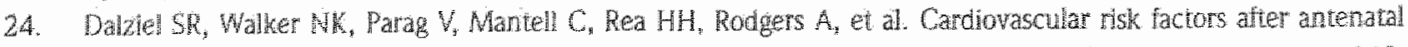

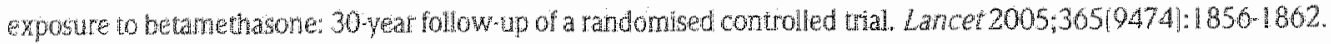

25. Gunn A, Guan, Bennet L. Neuroprotective trechanistus atter asphria. In. Stevenson DK, Sunshine P, ediors. Fetal and Neonatal Bran Imury: Mechanisms, Management, and the Risk of Practice. 2nd ed. Cambridge: Carmbridge Universty Press 2003 . p. Chapter $36,715.734$.

20. Low IA Intrapartum feta asphyxia: definition, diagnosis, and classification. Am / Obstet Onecol $1007 ; 17651: 95790$

27. Goodwin TM, Betai 1, Hernandez P, Durand M, Paul RH. Asphyxial complicatons in the tem newbon with severe umbilical acidemia. Am J Obste Cynecol 1992;16716):1506-12.

28. Low $\mathrm{A}$, Lindsay $\mathrm{BG}$, Derrick El. Theshold of metabolic acidosis associated with newbom complications. Am Obstet Gynecol 1907; $177(6): 1391-4$.

29. Low IA Determining the contribution of asphyxia to bain damage in the neonate. Obstet Gyaecol Res 2004,3014127606

30. Low JA, Killen $H$, Derrick E. Antepartum fetal asphyxia in the preterm pregnancy. An / Obsiet Ghecol $2003 ; 1882121.461 \cdot 465$.

31. Low JA. Reflections on the accurrence and significance of antepartum tetal asphyxia. Best Pract Res Chn Obstet Gyraecol $2004: 18(3): 375 \cdot 82$.

32. Watanabe $\mathrm{R}$, Hayakawa F, Okumura A. Neonatal EEG: a powerful tool in the assessment of brain damage in pretern infants. Brain Dev 1099;21101:361-72.

33. Hayakawa Okumura $A$, Kato $T$, Kuno K, Watanabe K. Disorganized patterns: chronic-sitage EEG abnomalicy of the late neonatal period following severely depressed $\mathrm{EEG}$ activities in eariy preterm infants. Neuropedatrics $1097 ; 28(5): 2725$.

34. de Vties LS, Eken P, Groenendaal F, Radenaker $\mathrm{Q} J$, Hoogervorst B, Bruinse HW. Antenatal onset of haemorrhagic and/or ischaemic lesions in preterm infants: prevalence and associated obstetric wariables. Arch Dis Chid Fetal Neonatal Ed 1998;78[1]:F51\%.

35. Low JA, Ranaglotopoulos C, Derrick El. Newborn complications ater intrapartum asphyxia with metabolic acidosis in the preterm fetus. An I Obster Gynecol 1995;172(3):805-10.

36. Weinberge: B. Anwar M, Hegyi T, Hiatt M, Koons, A, Paneth N. Antecedents and neonatal consequences of lows Apgar scores in preterm newbons: a population study. Arch Pediat Adolesc Med2000:154(3):294-300.

37. Osbopm DA, Evans $N$, Kluckow $M$. Hemodynamic and antecedent risk factors of early and late

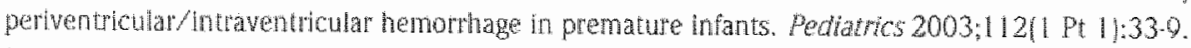

38. I wamoto HS, Stucky E, Roman CM. Effect of graded umbilical cord compression in fetal sheep at 0.60 .7 gestation. An J Bhystol $1901 ; 26114$ PL 2)H1268-H1274.

30. Samonowicz W, Walker AM, Yu W, Stewant ML, Cannata J, Cussen L. Regional cerebral blood flow alter herrowrhagic hypotension in the preterm, nearterm, and newbom lamb. Pediat Res 1000;28[4]:361-306.

40. Akagi K. Chatis IR. Homonal and biophysical responses to acute hypoxemia in fetal sheep at $0.7-0.8$ gestation. Can / Phwiol thamacol $1900,0812115271532$.

4. Gleason CA, Hamm C. Jones MD, Ir. Effect of acute hypoxemia on brain blood flow and oxygen metabolism in

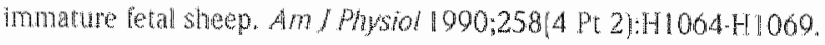

42. Hanson MA. Do we now understand the control of the fetal circulation? Eur J Obstet Gynecol Reprod Brot $1907,7511,55,61$.

43. Mot IC. The ability of young mammals to withstand total oxvgen lack. Br Med Bull 1961;17:144:8.

44. Dawes GS. Mott IC, Shelley HI. The importance of cardiac glycogen for the maintenance of life in foetal lambs and newborn animats during anoxia. I Physol (Lond 1959; 46(3):516.38. 
45. Shelley HI. Carbohydrate Reserves in the Newbon intant. Br Mad / 1964,5378:273-5:

46. Trahair $J F_{*}$ Robinson PM. Permatal development of the small intestine of the sheep Roprod Nutr Dew $1986,261011255 \cdot 1263$.

47. Dumont RC, Rudolph CD. Development of gastrointestimal motility in the intant and child. Gastoenterol Cw North Am 1994;23[4):655-7].

48. Berseth CL. Effect of early feeding on maturation of the preterm infants small intestine. / Pediat 1992;12016):947.53.

49. Berseth $\mathrm{CL}$, Bisquera $\mathrm{JA}$, Paje VU. Prolonging small feeding volumes early in life decreases the incidence of necrotizing enterocolitis in very low birth weight indants. Pedatics 2003;1113):52034.

50. Claud EC, Waiker WA. Hypothesis: inappropriate colonization of the premature intestine can cause neonatal necrotzing enterocolitis. FASEB /2001; 15(8):1398-403.

51. Robe-Tilig E, Vogtmann C, Bennek ]. Prenatal hemodmamic disturbances - pathophysiological background of intestinal motility disturbances in small for gestational age infants. Eur, pediatr Surg 2002;12(3):175-9.

52. Kosioske AM. Epidemiology of necrotizing enterocolitis. Acta Paediatr Supp/ 1994;396:27.

53. Kanto WP, Jk, Hunter JE, Stoll BJ. Recognition and medical management of necrotizing enterocolitis. Chin Perinatol 1994:2 (2):335-40.

54. Caplan MS, Mackendrick W. Necrotzing enterocolitis: a rewiew of pathogenetic mechanisms and implications for prevention. Pediatr Pathol 1993; 13:3/,357.69.

55. Nowicki PT, Nankervis CA. The role of the circulation in the pathogenesis of necroting enterocolits. Clin Perinatol 1994:21121:219.34.

56. Llanos AR, Moss ME, Pinzon MC, Dye T, Sinkin RA, Kendig JW. Epidemiology of neonatal necrotising enterocolitis: a population-based study. Faedatr Perinat Eptdeniol 2002; 10141:342-9.

57. Guthrie SO, Gordon PV, Thomas V, Thorp IA, Peabody I, Clark RH. Necrotizing enterocoltis among neonates in the United States. J Perinatol 2003;23[4):27885.

58. Grosfeld JL, Chaet M, Molinari F, Engle W, Engun SA, West KW, elt al. Increased risk of necrotzing enterocolitis in premature infants with patent ductus arteriosus treated with indomethacin. Ann Surg 1996;224/37:350-5; discussion 355.7 .

59. The Canadian Neonatal Network. Variations in Incidence of Necrolizing Enterocolitis in Canadian Neonatal Intensive Care Units. / Fediatr Gastroentero/ Nur 2004;39(4):360.372.

60. Bhatt $A B$, Tank PD, Barmade KB, Damania KR. Abnomal Doppler fow velocmetry in the growth restricted foetus as a predictor for necrotising enterocolitis. / Postgrad Med 2002;4813:1825; discussion 185 .

61. Soregaroli $M$, Bonera $R$, Danti $L$, Dinolio D, Taddei F, Valcamonico $A$, el ad. Prognostic role of umbilical artery Doppler velocinetry in growth lestricted fetuses. M Aatem Fotal Neonatal Med 2002; 1 1131:190-203.

62. Craigo SD, Beach ML, Haryey-Wikes KB, D'Alton ME Lltrasound predictors of neonatal outcome in intraterne growth restriction. Am / Perinatol 1990;13(8):465 71.

63. Seyan YS, AI-Mahmeid MS, AJ Tamini HR. Umbillical attery Dopples flow velocimetry in in traterine growth restriction and its relation to perinatal outcome. Int / Gyaecol Obstet 2002;77(2):131-7.

64. Kirsten GF, wan Zy] N, Smith M, Odendat H. Necrotizing enterocolits in infants born to women with severe early preeclampsia and absent end diastolic umbilical artery doppler llow velocity waveforms. An f Penthatot $1999 ; 16(6): 309-14$.

65. Robel-Tilig E, Vogmann C, Faber R. Postnaral incestinal disturbances in smallorgestational age premature infants after prenatall haemodynamic disturbances. Acta Paediatr 2000;89(3):324\%30.

60. Korszun P, Dubiel M, Breborowicz G. Danska $A_{4}$ Gudmundsson S. Fetal superior mesenteric artery blood low velocimetry in nomal and high risk pregnancy. I Pernat Med 2002; 30131:235-41.

67. Fang S, Kempley ST, Gamsu HR. Prediction of early rolerance to enteral feedisg in pretern infants by measuremebt of superior mesenteric artery blood flow velocity. Arch Dis Child Fetal Neonalal Ed 2001:8511):1425. 
68. Pezzat M, Dani $C$, fronchin M, Fippi L. Rogsi $S$, Rubaltell FF. Prediction of early tolerance to enterai feeding

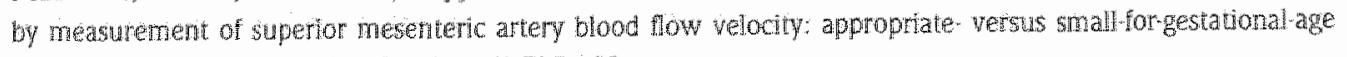

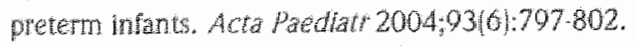

69. Degg $2 H$, Rupprechi T, Schmid E. Doppler sonographic detection of increased flow velocites in the cellac trunk and superior mesenteric artery in infants wh necrouzing enterocolits. Pediatr Radiol 1003;23/81:578-82.

70. Ftrkovitz 1, LaGama EF, Rudoph AM. Effects of cond comptession on tetal blood flow distribution and 02

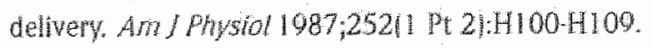

71. Yaffe H, Paret JT, Biock BS, Llanos A1. Cardiorespiratory responses to graded reductions of uterne blood flow in the sheep fetus. / Dev Phystol 1987;9(4):325-336.

72. Jensen $A$, Hohmann $M$, Kunzel W. Redistribution of fetal circulation during repeated asphyia in sheep: efiects on skin blood flow, transeutaneous. PO2, and plasma catecholamines. / Dew Physol 1987;91 1:41.55.

73. Nowicki PT. Effects of sustarned low.flow perfusion on the response to vasoconstrictor agents in postnatal intestine. An / Physiol 1909;27610 Pt 1):C1408-10.

74. Nowicki PT, Milter CE. The effects of systemic hypotension on posmatal intestinal hemodynamics and oxygenation. Pediatr Res 1906;39(1): 105.11.

75. Reber KM, Nankervis CA, Nowick PT. Newbom intestinal cinculation. Physiology and pathophysiology. Chin Perinatol 2002;29(1):23-30.

76. Ten VS, Pinsky D. Endothelial response to hypoxia: physiologic adaptation and pathologic dysfunction. Curr Opin Gill Care 2002;8(3):242.50.

77. Karimova A, Pinsky DJ. The endothelial response 10 oxygen deprivation: biology and dinical implications. Intenswe Care Med 2001;27(1):19.31.

78. Hossmann KA, Reperfusion of the brain after global ischemia: hemodynamic disturbances. Shack 1907;821:95-101.

79. Michenfelder ID, Milde JH. Postischemic canine cerebral blood flow appears to be detemined by cerebral metabolic neds. J Cereb Blow Flow Metab 1990;10(1):71-6.

80. Gold L, Lauritzen M. Neurona deactivation explains decreased cerebellar blood flow in response to local cerebral ischenia or suppressed neocortical function. Proc Natl Acad Sci U S A 2002;99111 1:7699-704.

81. Read JB, Bumstock $G$. Developement of the adrenergic innervation and chromaffin cells in the human fetal gut. Dev Biol $1970,22131: 513-34$.

82. Jensen A, Kunzel W, Kastendieck E. Fetal sympathetic activity, transcutaneous PO2, and skin blood flow during repeated asphyxia in sheep. / Dev Phystol 1987;9(4):337-346.

83. Jensen $A$, Lang U. Foetal ciculatory responses to arrest of uterine blood flow in sheep: effects of chenical sympalihectomy. / Dev Ihysiol 1092;17(2):75-80.

84. Nuwayhid B, Brinkman CR, Su C, Bevan JA, Assali NS. Dewelopment of autononic controt of retal circulation. Am I Plystol $1975,228121337.344$.

85. Rouwet EV, De Mey JG, Shaf DW, Heineman F, Ramsay G, Le Noble FA, Development of vasomotor responses in fetal mesenteric artertes. An / Physiol Hear Circ Physiol 2000;279(3):H1:097-105.

80. Paulick RP, Meyers RL, Rudolph CD, Rudolph AM. Hemodynamic responses to alphad adrenergic blockade during hypoxemia in the fetal lamb. I Dev PHywlol 1901;16121:63-69.

87. Mulder AL, Medema A, De Mey 1G, Giussani DA, Bianco CE. Spmpathetic control of the cardiovascular response to acute hypoxemia in the chick embryo. Am J Physiol Regul Jntegr Comp Physiol 2002;282141:R1150-R1103.

88. Gussani DA, Spencer JA, Moore PJ. Bennet L, Hanson MA. Afferent and efferent components of the cardiovascular reflex responses to acule hypoxia in tem fetal sheep. / Phystot/Lond/ 1993:461:431-49:431-449.

89. Wwanoto HS, Rudolph AM, Mirkin BL, Keil LC. Circulatory and humoral responses of sympathectomized fetal sheep to hypoxemia. And Physol $1983 ; 24515$ Pi 1]:H767-H772.

90. Westgate JA, Bennet L, Gunn A. Meconium and fetal hypoxia: some experimental observations and clinical relewance. Br / Obstet Ginaecol 2002; 109(10):1171-4. 
Q1. Lameire $\mathrm{N}$. The pahophysiology of acute renal failure. OHt Can am 20052121107210.

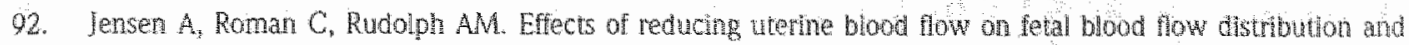
orygen delivery. IDey Physiol 1991;15(6):309323.

93. Agras PI, Tarcan A, Baskin E, Cengiz N, Gurakan B, Satci U. Acute renal falure in the neonatal period. Run Fan $2004 ; 26 ; 3 ;: 305-9$.

Q4. Chevalier RL, Campbel F, Brenbridge AN. Prognostic factors in neonatal achte fenal failure. Peodathos $1984 ; 74(2): 265-72$.

95. Koima T, Kobayashi I, Matsuzaki $S$, Iwase $S_{3}$ Kobayashi Y. Effects of perinatal asphyxia and myoglobinuria on development of acute, neonatal renal failure. Arch Dis Child 1985;001101:908812.

90. Abitbol CL, Bauer CR, Montane B, Chandar J, Duara S, Znleruelo G. Longtem follow tip of extremely low birth Weight infants with neonatal renall falure. Pediatr Nephrol 2003;1891:887-93.

97. Liggins GC, Howie RN. A controlled trial of antepartum glucocorticoid treatment for prevention of the respiratory distress syndrome in premature infants. Perifatics 1972,50441:515-525.

98. NIH Consensus. Effect of corticosteroids for fetal maturation on perinatal outcomes. NiH Consensus Development Panet on the Erfect of Corticosteroids for Fetal Maturation on Perinatal Outcomes. JAMA 1995;273(5):413-8.

99. Halliday HL, Ehrenkranz RA, Doyle LW. Early postnatal $<90$ hours corticosteroids for preventing chronic fung disease in preterm infants. Cochrane Database Syst Rev 2003[1]:CD001140.

100. Schwab M, Roedel M, Anwar MA, Muller T, Schubert H. Buchwalder Lf; et al. Effects of betamethasone administration to the fetal sheep in late gestation on fetal cerebral blood flow. I Physlof (Lond) 2000,528 (Pt 3).619.632.

101. Derks IB, Giussani DA, Jenkins SL, Wentworth RA, Visser GH, Padbury JF, et all. A comparative study of cardovascular, endocrine and behavioural effects of betamethasone and dexamethasone administration to fetat sheep. / Physiol (Lond) 1997;499(Pt 11:217-226.

102. Fletcher A, McGarigle HH, Edwards CM, Fowden AL, Giussani DA. Effects of low dose dexamethasone treatment on basal cardovascular and endocrine function in fetal sheep during late gestation. f Physiol Lond" 2002;545ip: 2]:049-60.

103. Anwar MA, Schwab M, Poston L, Nathanjelsz PW. Betamethasone mediated vascular dysfunction and changes in hematological profile in the ovine felus. Am I Physiof 1999;276(4 Pt 2):H1 $137-11143$.

104. Docherty CC, Kalmar-Nagy I, Engelen M, Koenen SV, Nijland M, Kuc RE, et al. Effect of in wivo fetal infusion of dexamethasone at $0.75 \mathrm{GA}$ on fetal ovine resistance artery responses to ET:1. Amp physiol Regul Integr Comp Physiol 2001;281(1):R251-R208.

105. Bian $X$, Seidler F, Slotkin TA. Fetal dexamethasone exposure interferes with estabishment of cardiac noradrenergic inmerwation and sympathetic activity. Teratology $1093 ; 47(2): 100-17$

100. Bian X, Briggs MM, Schachat FH, Seidfer F], Slotkin TA. Gucocorticolds accelerate the ontogenetic trangition of cardiac ventricular myosin heavy-chain isoform expression in the rat: promotion by prenatal exposure to a low dose of dexamethasone. J Dev Physol 1992;18(1):35-42.

107. Erwin MC, Padbury JF, Polk DH, Ikegami M, Berry LM, Jobe AH. Antenatal glucocorticolds alter premature newbom lamb neuroendocrine and endocrine responses to hypoxia. Am / Pfysiol Regul htegr Conp Fhysto $2000 ; 279(3): R 830 R 838$.

108. Fetcher $A$, Gardner DS, Edwards CM, Fowden AL, Giussani DA. Cardiovascular and endocine responses to acute hypoxaemia during and following dexamethasone infusion in the ovine fetus. $/$ Physiof / Lond/ 2003,549 (Pt $1]: 27 \llbracket-87$.

100. Kauffman KS, Seidler F, Slokin TA. Prenatal dexamethasone exposure causes loss of neonatal hypoxia tolerance: Cellutar mechanisns. Pediat Res 1994;35(5):515-22.

110. McLaughin KJ, Crowther CA, Walker $\mathrm{N}$, Harding JE. Effects of a single course of conticosteroids given more than 7 days before bith: a systematic review. Aust $N Z$ J Obstet Guacco 2003;4321:101.0. 
111. Bennet L, Kotuna S, McGurrgle HHG, Harson MA. Temporal changes in fetal cardiowascular, behawoural, metaboic and endocrine responses ho maternally administered de amethasone in the late gestation fetal sheep. Br J Obster Gyracol $1909 ; 10044) 331339$

12. Anderson DF, Stock MK, Ranhin JH. Placental tansfer of dexamethasone in nearterm sheep. / Dev Physiof $1979 ; 160: 4310$.

113. Krean 1. Mulay S, Fukushima DK, Solomon S. Determination of plasma dexamethasone in the mother and the newborn after adminisiation of the hormone in a clincal trial. 1 Cln Endochino Metao 1983;5611:127-33.

114. Newnham JP, Evans SF, Godfrey M, Huang W, Ikegami M, Jobe A. Maternal, but not letal, administration of coricosteroids restricts fetal growth. Jatern. Fetal Med 1909;8(31:81-87.

15. Jobe AH. Wada $N$, Berry LM, Tkegami M, Enw MG. Single and repetiive natemal glucocorticoid exposures reduce letal growth in sheep [see comments]. Am / Obstet Oyneco 1908;178151880-885.

116. Hai CM; Sadowska $G$, Francois L, Stonestreet BS. Maternal dexamethasone treatment alters myosin isoform expression and contracile dymamics in letal arteries. Am / Phystol Heart Che Physol 2002;283151:417439.

117. Koenen SW, Mecenas CA, Smith GS, Jenkins S, Nathanelsz PW. Effecis of maternal betamethasone administration on fetal and maternal blood pressure and heart rate in the baboon at 0.7 of gestation. Am / obstet Cynecol $2002 ; 180[41: 812 \%$

118. Dodic M, May CN, Wintour EM, Coghlan JP. An early prenatal exposure to excess glucocoricold leads to

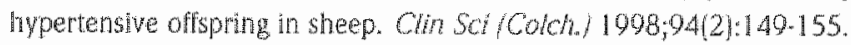

119. Mulder El, Koenen SV, BHom I, Visser GH. The effects of antenatai betamethasone administration on fetal heart rate and behaviour depend on gestational age. Early Hum Dev 2004;76(1):65-77.

120. Bennet L, Westgate J, Guckman PD, Gunn AI. Fetal responses to asphyxia. In: Stevenson DK, Sunshine P, editors. Fetal and Neonatal Britin Injury: Mechanisms, Management, and the Risks of Practice. 2 ed. Cambridge: Cambridge Unversity Press; 2003. p. $83-110$. 



\section{ABSTRACT}

Traditionally it has been believed that the cardiovascular and hormonal responses to aspiyxia in preterm fetuses are immature, and that this contributes to their apparent vulnerability to neural injury. These data however were derived from studies using relatively mild insults, which did not allow for the greater cardiac glycogen reserves and anerobic capacity of the brain near mid-gestation. In the present article we review the maturation of the cardiovascular and cerebrovascular and cerebral responses to asphyxia and how these relate to the apparent vulnerability of the premature brain. Most such studies have been performed in the chronically instrumented fetal sheep. Recent studies have demonstrated that the premature fetus has highly adaptive, and relatively mature responses to asphyxia, and that in absolute terms the preterm brain is very resistant to asphyxial injury. These data suggest that the premature fetus is able to survive much more prolonged periods of asphyxia than the nearterm fetus, but that paradoxically such survival is associated with exposure to prolonged periods of hypotension and hypoperfusion and consequently greater risk of severe neural damage. 


\section{THE IMPORTANCE OF FETAL HYPOXIA}

Neural injury of the preterm fetus and infant continues to be a significant problem. As recently reviewed, it is now clear that more than $70 \%$ of cerebral palsy is related to prepartum events, much of which occurs in the mid-gestational period [1]. Further, the improved care of very premature infants in intensive care units has led to a progressive improvement in survival that has not been matched by a corresponding improvement in age specific morbidity. Thus the number of premature infants surviving with neurodevelopmental impairment has increased [2]. In many premature infants, the very early development of cerebra] lesions after birth implicates a prenatal insult [3].

Periventricular white matter injury ("periventricular leucomalacia' or PVL) and hernorrhage into white matter (periventricular-intraventricular hemorrhage) are the major contributors to mortality and neurodevelopmental impairment in premature infants $|4|$. Such white matter damage is strongly associated with impairment of cortical development [5]. Established clinical associations include evidence of hypoxic-ischemic insults such as asphyxia, hypotension or hypocarbia (which causes cerebral vasoconstriction] and exposure to chorioamnionitis [4]. The current paradigm of neural injury in the premature infant may be termed 'the vulnerable fetus', as illustrated in Figure 1. In this paradigm, the fetus is exposed to potential adverse events at a critical period of cardiovascular and cellular immaturity $[4 ; 6]$.

The present review will highlight recent data that suggest an alternative view of the role of the fetal responses. We hypothesize that the premature fetus has both high cardiac and neural tolerance to asphyxia but that these adaptations permit the fetus to survive extra-ordinarily prolonged insults, which result in exposure to severe hypotension and hypoperfusion, and that it is the increased duration of the resulting hypoxia-ischemia which is the significant link with an increased risk of neural injury.

\section{MATURATIONAL CHANGES IN FETAL RESPONSES TO ASPHYXIA}

Limited previous data have suggested that there are maturational differences in the fetal responses to hypoxia; however the insults used in early studies was relatively moderate. In the premature fetal sheep before 100 days (0.7) gestation isocapnic hypoxia $|7|$ and hemorrhagic hypotension [8] are not associated with the hypertension, bradycardia and peripheral vasoconstriction which are seen in the near-term fetus. Similarly, hypoxic release of cortisol also appears to be greatly reduced before 100 days $[9]$. Furthermore, although the 0.6 gestation fetus was able to increase cerebral blood flow $[\mathrm{CBF}]$ during moderate hypoxia, in contrast to the nearterm fetus this was not sufficient to fully maintain oxygen availability to the brain. Cerebral oxygen consumption was therefore sustained in part by an increase in fractional oxygen extraction [10]. The mechanisms mediating this blunted hypoxic vasodilatation in immature fetuses are not known.

Based on these data, it has been suggested that peripheral vasomotor control starts to develop at 0.7 gestation, coincident with maturation of neurohormonal regulators and chemoreceptor function $[11 ; 12]$. However, when interpreting these results it is important to consider that the premature brain has both reduced basal oxygen consumption |13], as well as a much greater capacity to maintain cellular energy requirements through anaerobic metabolism [14]. It is likely that the degree of hypoxia attained in these earlier studies did not reduce tissue oxygen availability below the critical threshold for this developmental stage.

The responses to asphyxia depend on the severity of the insult. During moderate asphyxia the near- 
term fetus responds with redistribution of blood flow away from the periphery, to essential organs such as the brain and the heart [15]. During profound asphyxia however, corresponding with a severe reduction of uterine (or uribilical) blood flow to less than $25 \%$, the cardiowascular responses of the nomal fetus are substantially different. Bradycardia is sustained and there is a generalized vasoconstriction involving essentially all organs [15]. Under these conditions, CBF does not increase or may even fall despite initially increased fetal blood pressure. This restriction of $\mathrm{CBF}$ is due to a significant increase in cerebral vasoconstriction $[15 ; 16]$. This is accompanied by redistribution of blood flow within the brain, towards the brainstem, which speculatively may help maintain autonomic function at the expense of the cerebrum [12]. As asphyxia continues, the initial rise in blood pressure is followed by hypotension, with a parallel fall in CBF. The combination of impaired CBF and very low oxygen content severely reduces cerebral oxygen consumption [15].

Survival during profound asphyxia is a function of cardiac glycogen levels which are maximal near mid-gestation in the fetal sheep (and in man), and decline towards birth [17]. Typically the near-term fetus will survive 10 to 12 min of severe asphyxia [16]. In contrast, the premature fetus at 0.6 gestation can survive up to 30 minutes (Figure 2) [18;19]. While the premature fetal response to hypoxia appears

\section{The Vulnerable Fetus}

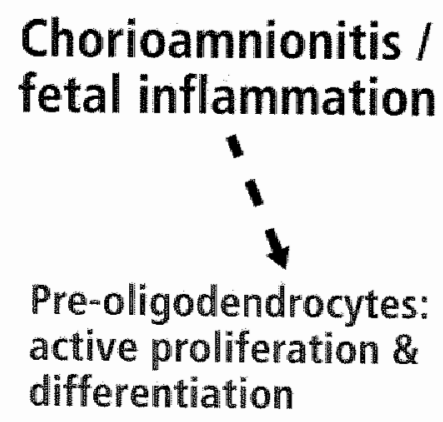

Hypoxia / Asphyxia

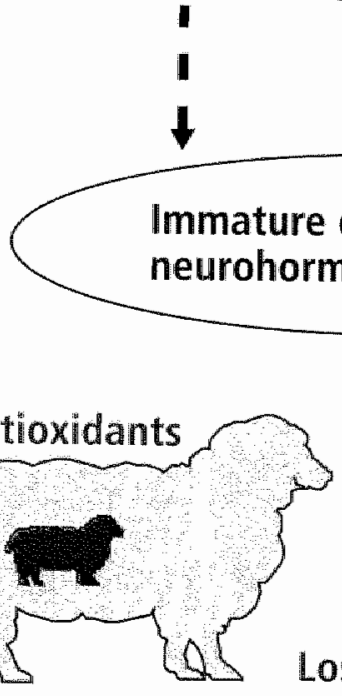

Hypotension

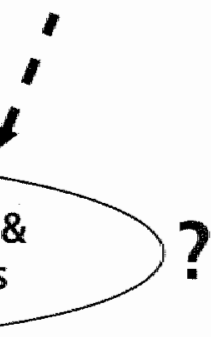

\section{Critical balance of cytokines vs grow th factors}

\section{Fragile capillaries / developmental end arterial zones}

Fugure 1. Schematic showing the current "vulnerable fews' paradigm for the high rate of neutal injury in the premature brain. The lerus is exposed to a number of adwerse factors including asphyxia, bypotension, and chorio-amuionitis. Limited fetal defences and critical developmental events occurning near midgestation such as active proliferation and differentiation of multipotential cels and preoligodendrocytes, in turn are postulated to increase the vulnerability of the fetws to cerebral damage. Immaturty of the fetal cardiovascular and cerebrowascular tesponses is believed to be an important factor compromising the ability of the preterm fetus to mantain oxygen detivery to the brain. We propose an alternative view of the contribution of these fetal responses to neural injury. 
to be different to that at term, the response to asphyxia was similar to that seen in more mature fetuses, with sustained bradycardia, accompanied by circulatory centralization, initial hypertension, then a progressive fall in blood pressure [16;19]. Similarly to the term fetus, there was no initial increase in blood flow to the brain and again this was due to a significant increase in vascular resistance rather than to hypotension [19].

As shown in Figure 2, once blood pressure begins to fall below baseline, CaBF falls in parallel, similarly to the near-term fetus $[16 ; 19]$. The fall in pressure is partly a function of failure of redistribution of blood flow at this time with a rise in femoral blood flow (FBF). The mechanisms mediating this loss of redistribution are unknown, but are likely to relate to profound local peripheral acidosis. In the latter half of a maximal interval of asphyxia in the preterm fetus, there is progressive failure of $\mathrm{CVO}$, with a fall in both central and peripheral perfusion. This phase is much less likely to be seen, for any significant duration, at term as glycogen stores in the term fetus are depleted more quickly [16]. Thus as a consequence of its extended survival, unlike the term fetus, the preterm fetus is exposed to profound and prolonged hypotension and hypoperfusion during ongoing asphyxia. This is the major difference in the responses to asphyxia between the term and preterm fetus.

It may be speculated that during this final phase of asphyxia in the preterm fetus there is a

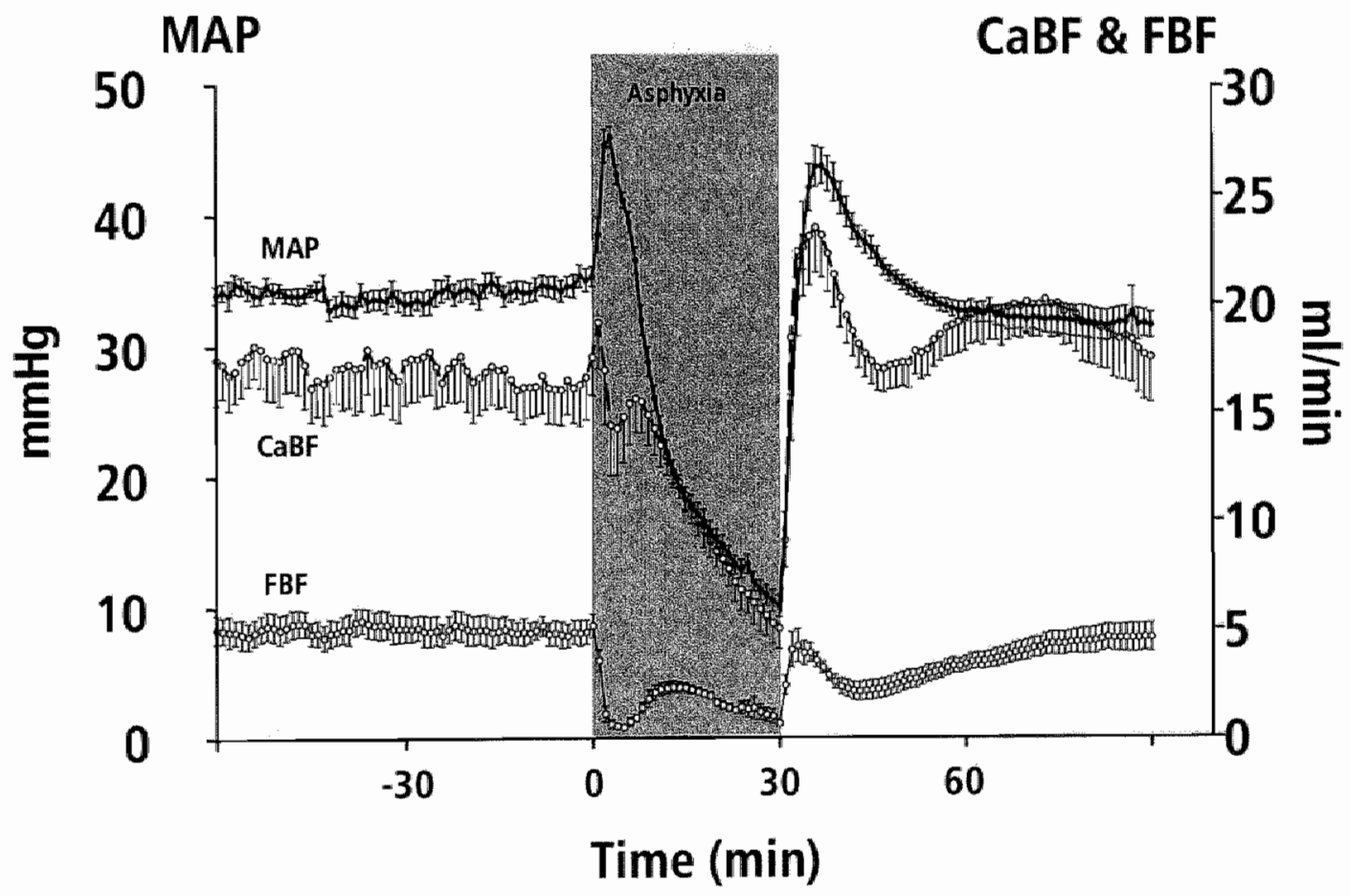

Figure 2. The relationship between mean arterial blood pressure (MAP) and carouid and femoral blood flow (CaBF and FBF) during complete umbilical cord occlusion for 30 min in the 0.6 gestation fetal sheep. The start and end of occlusion are shown by the shaded area. Note that the CaBF began to fall only when MAP was below baseline levels, and thereafter paralleled the changes in MAP very closely. It is interesting that this rapid decline in CaBF also corresponded with failure of peripheral vasoconstriction (shown by the secondary rise in $\mathrm{FBF}$ during occlusioni 11 \%). 
catastrophic failure of redistribution of blood flow within the fetal brain which places previously protected areas of the brain such as the brainstem at risk of injury. This hypothesis is consistent with clinical reports showing a pattern of subcortical injury after asphyxia in the preterm fetus $[20]$. Postasphyxia, a brief period of arterial hypertension and hyperperfusion is followed by a prolonged period of hypoperfusion, despite normalization of blood pressure. This secondary fall in carotid blood flow is paralleled by a reduction in total blood volume, as indicated by near-infrared spectroscopic measurements. Furthermore there is a transient reduction in cerebral oxygenation, indicating a true reduction in perfusion relative to cerebral requirements $\mid 19$. This post-asphyxial hypoperfusion and impaired cerebral oxygenation may contribute further to cerebral injury.

\section{CELLULAR MATURATION, AND SENSITIVITY TO INJURY.}

Surprisingly little work has been done to clasely define the precise effect of maturation on sensitivity to injury. The immaturity of oligodendrocytes and their precursors has been highlighted by many commentators since the period of greatest risk for periventricular leucomalacia in premature infants is at a time when oligodendrocyte precursors are actively proliferating and differentiating [4]. in vitro studies have suggested that developing oligodendroglia are particularly wulnerable to free radical toxicity, because of a developmental lack of antioxidant enzymes to mediate oxidative stress [21;22]. However, although this might affect the differential sensitivity between cell types, in isolation such data do not prove that the premature brain is necessarily more vulnerable to injury than near term or postnatally.

Indeed the reverse appears to be the case in short term studies of defined hypoxic-ischemic insults. The nearterm letal sheep develops severe selective hippocampal neuronal loss after just $10 \mathrm{~min}$ of umbilical cord occlusion [23]. In contrast, after 10 or even 20 min of cord occlusion at 0.6 gestation these was rapid recowery of EEG activity and no neuronal (or glial! loss \18;23!. However when asphyxia was continued for 30 min at 0.6 gestation, there was prolonged suppression of the EEG [1 9], and on preliminary analysis, selective neuronal and white matter injury in subcortical structures, but sparing of the cortex [24].

These differences are primarily related to neural maturation since a similar relationship is seen with pure ischemic insults, with greatly reduced neural injury in the preterm fetus after short periods of ischemia $[25 ; 26]$. At 0.65 gestation, a maturation approximately equivalent to the 28 week infant, 30 minutes of cerebral ischemia led to the development of subcortical infarction involving the deeper layers (V \& VI) of the cortex, and underlying white matter tracts [26]. In contrast, the same insult in the near-term fetal sheep leads to severe neuronal loss which is greatest in the superficial layers (II, II \& IVI of the cortex $|25|$. This difference is consistent with the stages of anatomical maturation. As neurons migrate into the cortex during development the deeper layers are populated first and thus mature first, while the superficial layers include immature, migrating neurons which are less metabolically active and are still using primarily anerobic pathways [27], and have less mature receptors
for excitatory neurotransmitters [28].

\section{LONG-TERM CONSEQUENCES.}

The studies discussed above examined relatively short term outcomes, typically 72 hours after asphyxia. There are only limited data on the long-term consequences of different insults. Clinically, 
apparently isolated PVL in premature infants is associated with markedly reduced grey matter volume at term [5]. It is likely that the impact of asphyxial insults near midgestation may be further amplified if, for example, immature and multipotential cell lines that can still divide are either lost, or undergo premature differentiation, or if the development of neuronal connections is affected. Consistent with this, moderate hypoxia near mid-gestation in the fetal sheep not only reduced neuronal numbers in the hippocampus and cerebellum after 35 days recovery but also reduced numbers of neural processes in regions that were still immature at the time of hypoxia, such as the cerebellum [29].

\section{CONCLUSIONS.}

There appears to be a paradoxical relationship between the vulnerability of the fetus to asphyxia, and neural injury. The data discussed above suggest that even the near-mid-gestation fetus demonstrates relatively mature and effective cardiovascular defences against asphyxia, and is able to survive much longer insults than is possible near-term, and furthermore the premature brain is surprisingly resistant. to defined ischemic or asphyxial insults. However, the greater cardiac glycogen reserves of preterm fetuses means that they are able to survive much longer periods of profound asphyxia. This ability to survive prolonged exposure to severe asphyxia with secondary cerebral hypoperfusion may paradoxically increase the risk of grey or white matter injury. It is critical that future studies examine the long-term impact of well defined prenatal insults on neural growth and development. 


\section{REFERENCES}

1. MacLennan A, The International Cerebral Palsy Jask Force: Gunn A. Benet L, Westgate JA A template for defining a causal relation beween acute intrapartum events and cerebral palsy: internatonal consensus statument. BMI 1999; 31917216): $1054 \cdot 1059$.

2 Hagberg B, Hagberg G, Zeterstrom R. Decreasing perinatal mortality-Increase in cerebral palsy motbidity. Acta Paedatir Scand 1989; $78: 604670$.

3 Ihakura A, Kurauch O, Hayakawa F, Matsuzawa K, Mizutani S, Tomoda Y. Timing of periventricular leukomalacia using neonatal electroencephalography. Int J Gynaecol Obstet 1996; 55(2):111-115.

4 Perlman M. White matter injury in the pretem intant: an important detemination of abnoma neurodevelopment outcome. Eariy Hum Dev 1998; 53[2]:99-120.

5 Inder TE, Huppi PS, Warfield S, Kkmis R, Zientara CP, Barnes PD et al. Perventricular white matter initury in the premature infant is followed by reduced cerebral cortical gray matter wolume at term. Ann Neurol 1909; 46(5):755 760 .

6 Volpe JJ. Brain injury in the premature infant - neuropathology, clinical aspects, pathogenesis, and prevention. Clin Perinatol 1997; 24131:567 ff.

7 Iwamoto HS, Stucky E, Roman CM. Effect of graded umbilical cord compression in fetal sheep at $0.6-0.7$ gestation. Am J Physiol $1991 ; 201(4 \mathrm{PL} 2): \mathrm{H} 1268-\mathrm{H}) 274$.

8 Szymonowicz W, Walker AM, Yu VY, Stewart ML, Cannata J, Cussen L. Regional cerebral blood flow after hemorhagic hypotension in the preterm, nearterm, and newbom lamb. Pediar Res 1990; 28(4):361-366.

9 Alkagl $K$, Chalis JR. Hormonal and biophysical responses to acute hypoxemia in fetal sheep at 0.70 .8 gestation. Can J Physiof phamacol 1900; 68(12):1527-1532.

10 Gleason CA, Hamm $\mathrm{C}$, Jones MDI. Elfect of acute hypoxemia on brain blood flow and oxygen metabolism in immature felal sheep. An / Physiol $1900 ; 258(4 \mathrm{Pt} 2): \mathrm{H} 1064$ - 41069.

11 Hanson MA. Do we now understand the control of the retal circulation? Eur / Obster Gynerol Reprod biol 1 go7; $7511]: 5501$.

12 Jensen A. The brain of the asphyxiated fetus - basic research. Eur J Obset Ghecol Reprod 1996; 65/11:19-24.

13 Gleason CA, Hamm $\mathrm{C}_{4}$ Jones MD, Ir. Cerebral blood flow, oxygenation, and carbohydrate metabolism in immature fetal sheep in utero. Am I Physio 1989; $25616 \mathrm{Pt} 2$ ): R1 264-8.

14 Sylwia AL, Seidler F., Slotkin TA. Effect of transient hypoxia on oxygenation of the developing rat brain: relationships among haemoglobin saturation, autoregulation of blood flow and mitochondral redox state. I Den physol $1.989 ;$ $1215: 287-292$

15 Parer JT. Effects of fetal asphyxia on brain cell stucture and futction: limis of tolerance. Comp Bhochen physto A Mol integr Phystol 1098; 119131:711.710.

16 Bennet L, Peebles DM, Edwards AD, Ros A, Hanson MA. The cerebral hemodynamic response to asphyxia and hypoxia in the near term fetal sheep as measured by near infrared spectroscopy. Pealat Res $1098 ; 44101051.057$

17 Shelley HJ. Givcogen reserves and their changes at birll and in anoxia. Br Med Bull 196 1; 17:137.143.

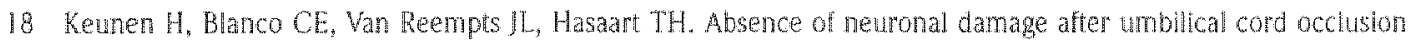
of 10, 15, and 20 minutes in midgestation fetal sheep. Am/ Obster Gyecol 1997; $170131515-520$.

19 Bennet $L$, Rossentode $S_{\mathrm{p}}$ Gunning MI, Gluckman PD, Gunn Al. The cardiowascular and cerebrovascular responses of the innature fetal sheep to acute umbilical cond occlusion. I Physiol Lond 1090; 517 ; P 11:247.257.

20 Barkowich Al, Sargent SK. Profound asphyxia in the premature infant: Imaging findings. Am N Nourordio 1995; $1601: 1837 \cdot 1840$.

21 Riwkin MJ, Flax J, Mozell R, Osathanondh R, Volpe J), Villa-Komaroff L. Oligodendroglial development in human fetal cerebrum. Ann Neural 1995; 381 1):92-101. 


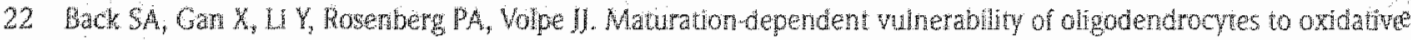

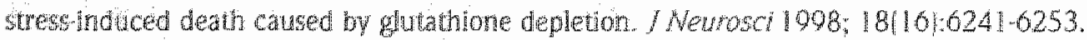

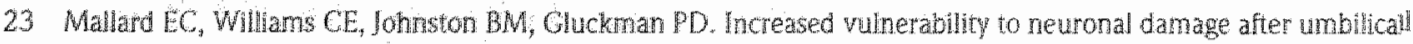
cord occiusion in fetal sheep with advancing gestation. Am/ Obster Gynecol1904; 1701 1 Pt 1/206214.

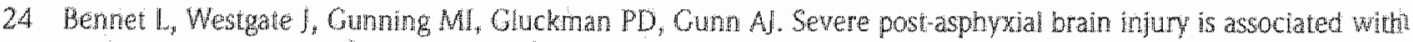
loss of beat wo beat variabilly in the preterm lamb. The Internatonal Fetal Physiology Symoosum 1909; 37. [Abstract).

25 Wilhans $\mathrm{CE}$, cunn $\mathrm{A}$, Mallard $\mathrm{C}$, Gluckman $\mathrm{PD}$. Oucome after ischemia in the dexeloping sheep brain: an electroencephalographic and histological sudy. Ann Newo 1992; 31 (1):1421.

26 Reddy K. Mallatu C, Guan J, Marks K, Bernet L, Gunning M et al. Maturational change in the cortical response to hppoperfusion injury in the fetal sheep. Pediatr Res 1998; 43151:074.082.

27 Hansen A. Extracelular potassitm concentration in juvenile and adult rat brain contex during anoxia. Acta Physiol Scand $197 \%, 09: 412 \cdot 420$

28 Gressens P, Marret 5 , Evrard P. Developmental spectrum of the excitotoxic cascade induced by ibotenate: a model ${ }^{\mathrm{t}}$ of hypoxic insults in fetuses and neonates. Neuropathol Appl Neurobiol 1996; 22(6):498.502.

29 Rees S, Breen S, Loeliger M, McCrabb G, Harding R. Hypoxemia near mid-gestation has long-term effecis on fetal brain development. / Newropathot Exp Neurol 1999; 58191932-945. 


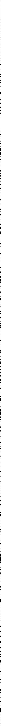




\section{INTRODUCTION}

Intestinal injury following ischemia and reperfusion $[\mathrm{L} / \mathrm{R})$ of the gut is a common clinical complication that is most often assessed by histologic evaluation of standard hematoxylin and eosin (H\&E) stained tissue sections. For this purpose, many different grading systems for bowel injury have been described in the literature. Unfortunately, there is no consensus on how this injury should be graded. Instead, most studies have used their own systems, which often amount to qualitative or semiquantitative descriptions. Thus, it is difficult to compare the results of studies that were evaluated using different grading systems. However, quantitative comparison of results is essential for the development of an understanding of the mechanisms of $I / R$ injury and the development of treatment strategies.

The overall goal of this preliminary study was to determine whether it is possible to recommend a standard histologic grading system that would be broadly suitable for use in typical experimental studies of $I / R$ of the gut. The specific aims of this study were first to identify the histologic grading systems available for assessment of intestinal I/R injury; and second, to examine the validity, reliability, and ease of use of the most commonly used or representative grading systems using tissue sections from a study of $L / R$ of the rat small bowel.

\section{MATERIALS AND METHODS}

\section{Literature Study}

Using MEDLINE (Ovid Technologies, NY) from 1966 to the present, we searched the literature for articles reporting on histologic intestinal $\mathrm{I} / \mathrm{R}$ injury. $\mathrm{A}$ large number and variety of grading systems were identified. In many of these studies, however, histologic damage was either just described, with or without semiquantitative grades attached to this description, or the authors developed entirely new grading systems to suit their needs. From this literature we selected three systems that were most representative of the different types of grading systems. These were the systems developed by Parks !, Sonnino ${ }^{2}$, $\mathrm{Chiu}^{3}$ and Park. ${ }^{4}$ These systems are described briefly below and in Table 1 .

Parks' system scores mucosal injury in intestinal villi and in crypts separately from grade 0 to 4 , according to the number of villi and crypts affected by epithelial necrosis. 'Sonnino's system also grades only mucosal injury using a large number of different, cumulative criteria, each of which are scored 0 for a normal or 1 for an abnormal finding. ${ }^{2}$ The system developed by Park encompasses a system that was earlier developed by Chiu and scores by progression of intestinal injury from the tips of the villi into the deeper layers of the gut wall in 8 grades. 3,4 The present study refers to this system as the Park/Chiu system to avoid any confusion due to the names of the authors.

\section{Experimental Procedures}

Using the three selected grading systems, we reevaluated histologic damage in tissue sections from a previous study of $1 / R$ of the rat small intestine. ${ }^{5}$ This study compared two groups of adult male Lewis rats. The first group of rats $(n=10)$ was subjected to 30 minutes of total warm ischemia of the small bowel by occlusion of the superion and inferior mesenteric arteries, followed by 60 minutes of reperfusion, as previously described. ${ }^{\circ}$ The second group $(n=11)$ received sham occlusion. At the end of the reperfusion period the rats were sacrificed and the terminal ileum was removed and processed for histological analysis. The tissues were processed using standard histologic techniques including formalin fixation, dehydration and paraffin embedding, then cut in $4-\mu \mathrm{m}$ sections and stained with H\&E. ${ }^{6}$ The sections of both groups were coded, and evaluation was carried out by two independent, 
Table 1. Description of Scoring Systems

\begin{tabular}{|c|c|c|}
\hline Parks & & \\
\hline 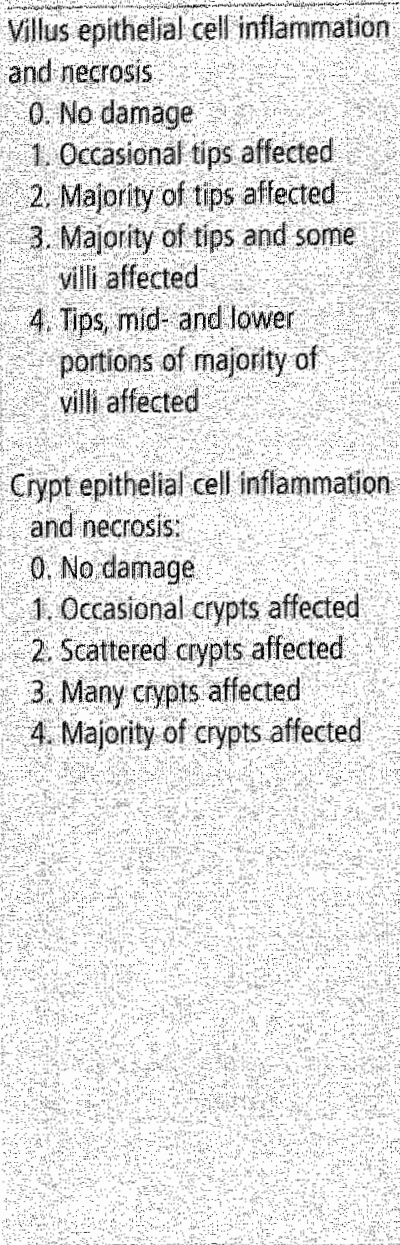 & 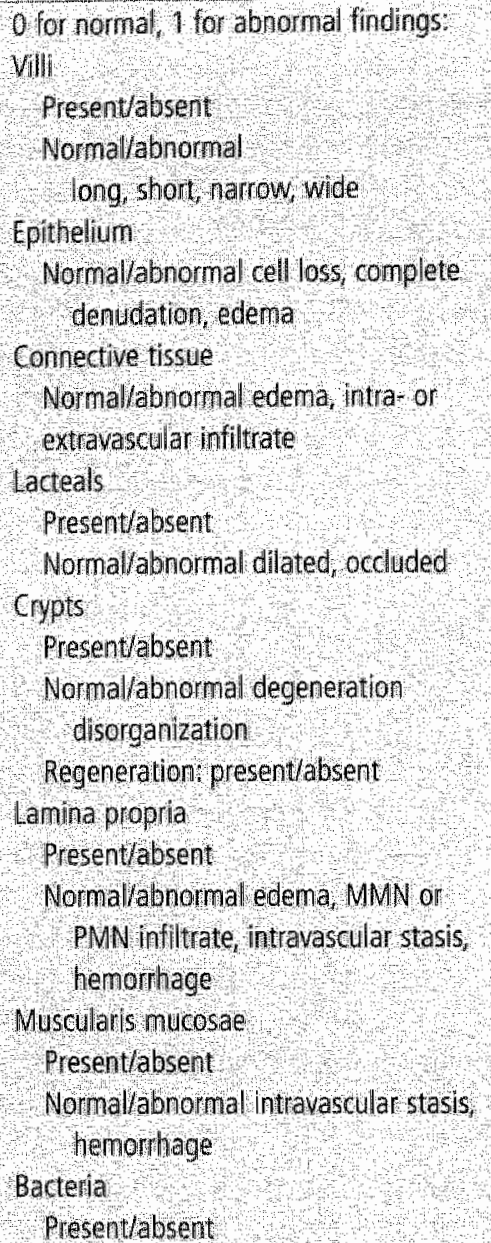 & 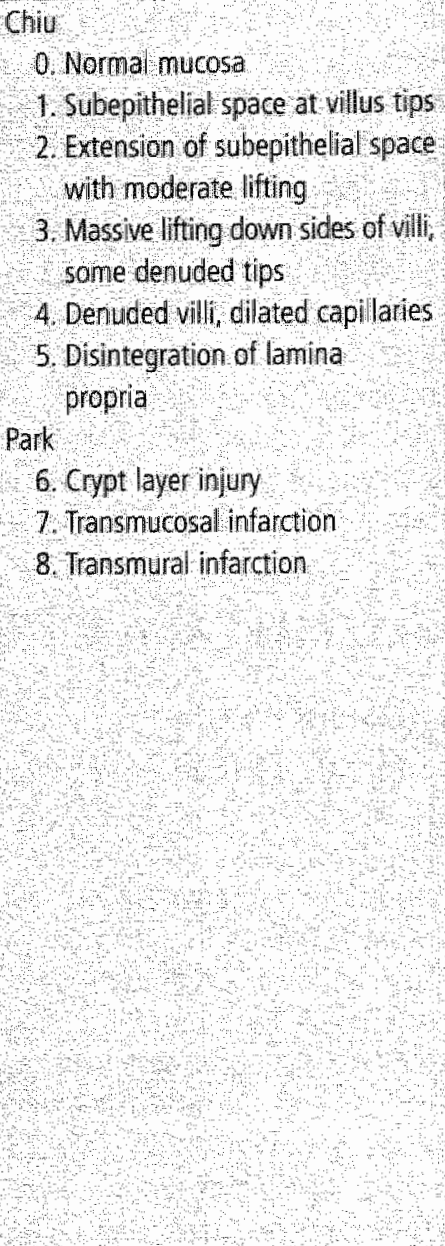 \\
\hline
\end{tabular}

experienced observers blinded to the treatment groups. The correlation coefficients between the scores of the independent observers were calculated separately for each of the three grading systems. The mean of the scores for each section obtained by the two observers were used to compare the three systems together.

\section{RESULTS}

The literature search identified 60 papers in which intestinal damage caused by $I / R$ of the gut was assessed using histologic evaluation. A full listing of these references is available on request. In 18 

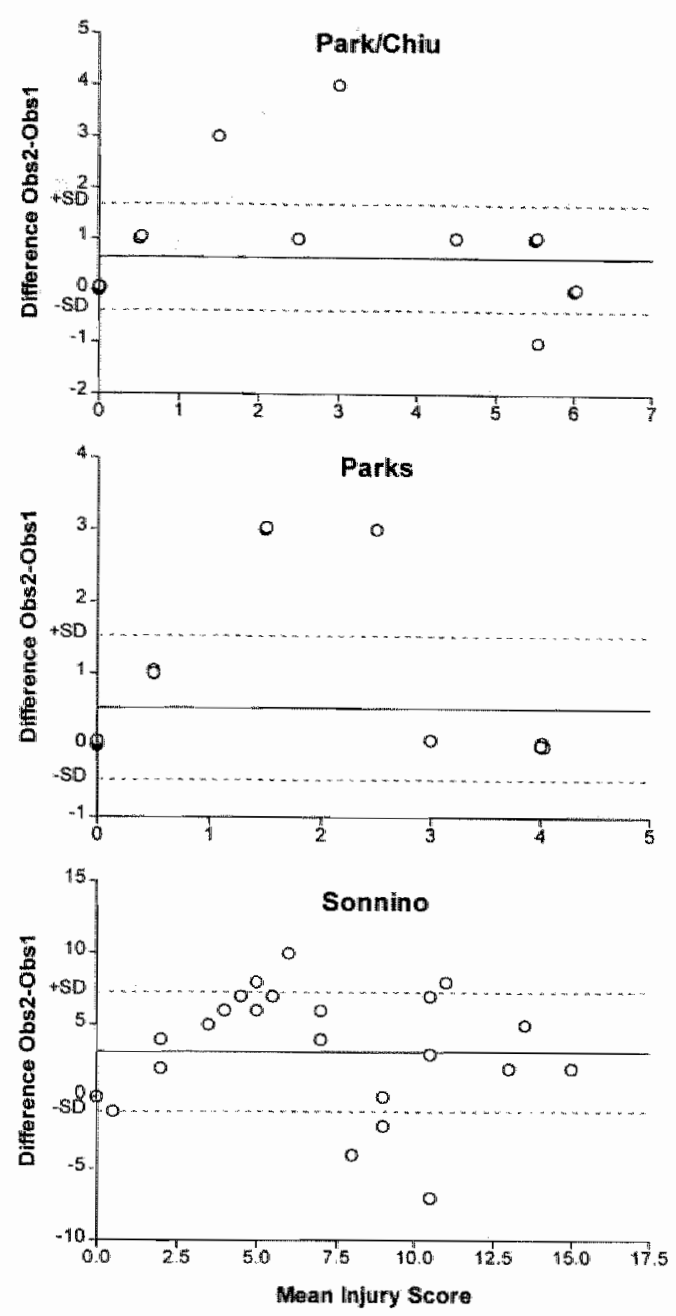

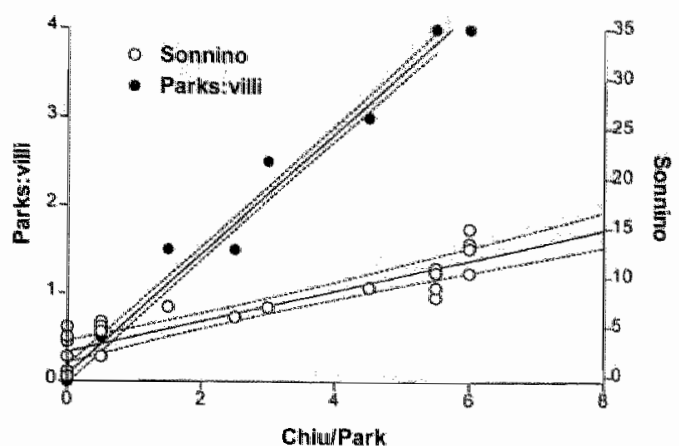

Figure 2. The correlation belween the Park/ Chlu system with both the Parks and Sonnino systems for the mean scores of the two blinded observers. The Parks score for will correlated very well with the Park/Chu system $\left(r^{2}=.99\right)$. However, the Sonnino system showed a less good correlation with the Park/Chiu system $\left(r^{2}=83\right)$, but also a significant baseline shif, with some apparent damage in sham control sections which was not seen with the other two systems. The solid and dotted lines represent the linear correlation and contidence intervals, respectively.

Figure 1. Retationship between the differences between the scones by the two masked observers, and the mean scores for the Park/Chiu, Parks, and Somnino systems of grading injury, 21 sections of the small imestine of rats sublected to either sham ischemia or 30 mimutes of warm ischemia, followed by 60 minutes of reperfuslon. The mean differences. are shown by solid lines and the 1 SD ranges by doted unes.

$(30 \%)$ of these papers intestinal injury was described without grading. Park's system was used in 5 paper's (8\% of all papers); Sonnino's system in $2(3 \%)$; Chiu's system in $13(22 \%)$, and the system of Park/Chiu was used in $7(12 \%)$. The remaining 15 papers used other grading systems, usually reported only by one research group.

The evaluation of intestinal injury in the two experimental rat groups by the two independent observers using the three selected systems demonstrated that the Park/Chiu system had the best correlation between the two observers $\left[r^{2}=.86\right]$. Parks's system produced a relatively good correlation 
for the grading of villus damage $\left(r^{2}=.74\right)$; however, the crypt scores showed much greater discrepancies $\left(r^{2}=26\right)$. Finally, Sonnino's system showed the least overall correlation between the observers $\left(r^{2}=.41\right)$. To better examine the pattern of differences in sconing, we related the differences between scores to the mean scores as shown in Fig 1. The systems by Park/Chiu and Parks showed relatively greater variation between the observers at moderate levels of damage than in the sections with little damage or those with severe damage; however, the overall differences between the observers were linear. The mean \pm SD differences were $0.64 \pm 1.03$ for the Park/Chiu and $0.52 \pm 1.0$ for the Parks system for villi. The Sonnino system showed much greater discrepancies, particularly in the sham control sections, with a mean difference of $4.14 \pm 3.1$.

When the results of the Park/Chiu system were correlated with the other two systems, it was apparent that Soninno's system, as used by the two experienced observers, suggested that there were significant levels of damage in sham control sections. These were scored as zero with either of the other systems (Fig 2). The correlation between the Park/Chiu and Parks (villi) systems was excellent $\left(r^{2}=.99\right)$, whereas the correlation with the Sonnino system was weaker $\left(r^{2}=.83\right)$.

\section{DISCUSSION}

I/R of the small intestine is a common clinical problem, seen for example in neonatal necrotizing enterocolitis and small bowel transplantation, and is thus the subject of considerable ongoing research. The degree of injury caused by intestinal $I / R$ is routinely assessed by histologic evaluation. A commonly used and readily available process for tissue preparation is formalin fixation, dehydration and paraffin embedding, after which sections of $4 \mu \mathrm{m}$ thickness are cut and stained with H\&E. Intestinal damage may be assessed either by choosing the most affected area for grading or by averaging the scores from sections at standard areas.

Ideally, to allow comparisons between different studies of $\mathrm{L} R$ of the bowel, the tissue damage would be quantified using a single standard system, applied to sections that are prepared using this standard method. Our literature search has demonstrated that currently there is no consensus on such a standard grading system making comparisons between studies difficult. Yet comparison between studies that is quantitative as well as qualitative is essential for the determination of potential mechanisms underlying injury and for the development of treatment strategies.

An ideal standard grading system should include the following features. The grades should parallel the morphologic appearance of injury with increasing severity of the insult, and be reliable, producing consistent results within and between observers. Biological validity in this context implies that this hypothetical system should assess both the extent of overail damage to the architectural elements of the bowel wall, including the villi and crypts, as well as more detailed evidence of mucosal and submucosal damage, such as epithelial lifting and mucosal cell debris in the lumen. Typically, ischemic injury leads to progression of damage from the villus tips after the briefest or mildest periods of ischemia, extending to the crypts only after much longer periods of ischemia. ${ }^{3}$ Of equal importance is that an ideal grading system should be logically presented, easy to learn, and use and have a low interobserver variability.

From our literature search we concluded that the Park/Chiu system is the closest to meeting these criteria. This combined system grades the progression of morphologic injury from mild to severe. The grades encompass both architectural and more detailed damage and are well defined, which leads to a low inter-observer variability. The Parks system was equally reliable in the present study; however, it does not include injury beyond the mucosa and its structure, which separates villus and crypt 
damage, made it more cumbersome to use and interpret. In the present study of $L / R$-induced intestinal injury in the rat, damage was primarily seen in the vill, and thus there was excellent agreement between the Parks (villi) scores and those of the Park/Chiu system. With a significantly more severe insult, we would have anticipated increasing damage to the crypts which would be linearly reflected in the Park/Chiu system, but would require assessment of two scores with the Parks system.

In many grading systems only one aspect of $l / R$ damage is singled out and graded according to severity. An example of this is the system by Parks, which only assesses the extent of the epithelial cell necrosis. Other systems, like Sonnino's, are very extensive, scoring a wide range of features; however, this system does not directly assess the progression of injury along the villi and crypts. This is demonstrated in Fig 2; although the Sonnino damage scores increased linearly, the most severe damage scored was still only half of the maximum possible, while the Park/Chiu system had reached a very severe score of 6 out of 8 . Further, the sham control sections were rated as having significant damage in Sonnino's system, which was not a feature of the other two scales.

All of the grading systems would have benefited from more clear and precise descriptions of the grades. This is likely to have contributed to some of the differences between the observers (see Fig 1). For example, the system used by Parks grades epithelial cell necrosis, but does not describe which characteristics of necrosis should be assessed. It is not clear whether the system purely grades cytologic evidence of necrosis, such as rounding of the normally cuboid epithelial cells, or whether epithelial lifting is also considered to be evidence of epithelial necrosis. Sonnino's system was the most difficult to implement for both observers. A large number of different criteria are used to assess intestinal damage. However, again these criteria are only summarized, and not explained in detail, which leaves the reader to decide what is actually meant by factors such as intravascular stasis, regeneration, and disorganization.

In addition to basic morphologic $I / R$ damage, more detailed features of intestinal $L / R$ injury including leukocyte infiltration, apoptosis, and proliferation are a component of many grading systems such as Sonnino's. However, proper evaluation of such detailed objectives is difficult and time consuming. We propose that it would be more appropriate to assess these objectives separately to the basic morphologic assessment and that these criteria should not be incorporated in a standard grading system. Apoptosis and proliferation are better assessed using specialized techniques, such as immunohistochemical staining and TUNEL.

In conclusion a standard quantitative and qualitative histologic scoring system would make it much easier to compare of studies of $I / R$. However, to date no one system has been consistently supported in the literature. An ideal system should be comprehensive in scope, assessing the evolution of injury from mild to severe damage. It should also be well described and easy to use to ensure low inter observer variability. From our assessment of the literature and the present evaluation of representative systems, we propose that the combined grading system of Chiu and Park is the most suitable to be recommended as a standard scoring scale for histological evaluation of intestinal $\mathrm{L} / \mathrm{R}$ damage. However, better description of the last grades of this system would further strengthen its suitability. 
chapter 3 


\section{REFERENCES}

1. Parks DA, Bukley GB, Granger DN, el al: Gastroenterology 82,1982

2. Sonnino RE, Riddle M, Pritchatd T]: Transplant Proc 241201, 1992

3. Chiu CI, McArdle AH, Brown R, et al: Arch Surg 101:478, 1970

4. Park PO, Haglund U, Bukley GB, et al: Surgery $107.574,1090$

5. Beuk R. Heineman E, Tangelder GJ, et al: Ann Surg 1099

6. Beuk R, Heineman E, Tangelder Gl, et al: 7 Surg Res 73:14, 1997

7. Bland JW, Alruan DG: Stat Mehods Med Res 8:135, 1909 


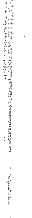

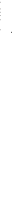

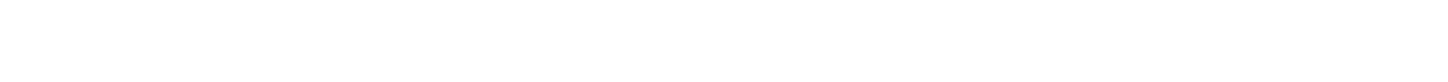
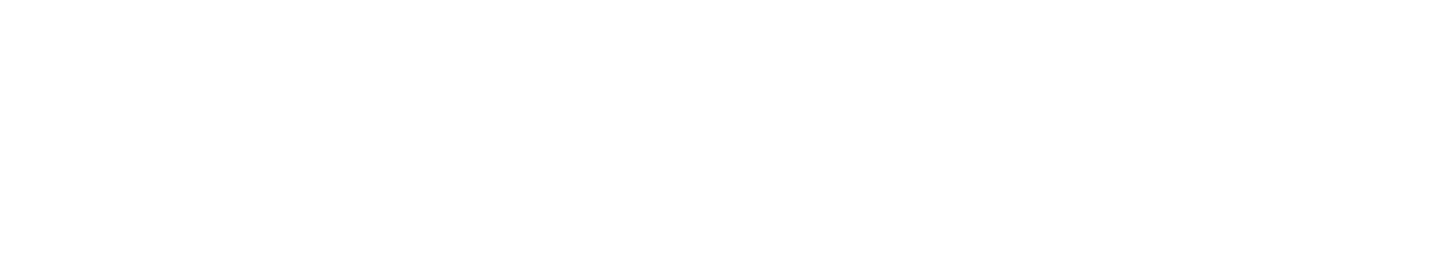

. 


\section{ABSTRACT}

Background/Purpose: The aim of this study was to determine superior mesenteric artery blood flow changes during and after an asphyxial insult in utero in chronically instrumented unanaesthetised premature fetal sheep.

Methods: Fetal sheep at 0.7 gestation (103 to 104 days) underwent 25 minutes of complete umbilical cord occlusion ( $n=6)$ or sham occlusion ( $n=6$ ). Fetal heart rate, blood pressure, superior mesenteric artery (SMA) blood flow and vascular resistance, electroencephalographic activity, and nuchal electromyographic activity were measured from 6 hours before occlusion until 3 days after occlusion.

Fetal gastrointestinal tissue was taken for histological assessment.

Results: During acclusion, cardiovascular response was characterised by 3 phases: initial redistribution of blood flow away from the gut to maintain vital organ function, subsequently partial failure of this redistribution, and finally near terminal cardiovascular collapse with profound hypotension and gastrointestinal hypoperfusion. Postasphyxia there was a secondary period of hypoperfusion that was mediated by increased vascular resistance, not hypotension. There was no evidence of injury on standard histological assessment after 3 days of recovery.

Conclusions: SMA blood low is not only significantly reduced during asphyxia, but also for several hours atter an asphyxial insult. The authors speculate that these penturbations of gastrointestinal blood flow could compromise gut wall integrity potentially leading to increased vulnerability to necrotising P. enterocolitis:

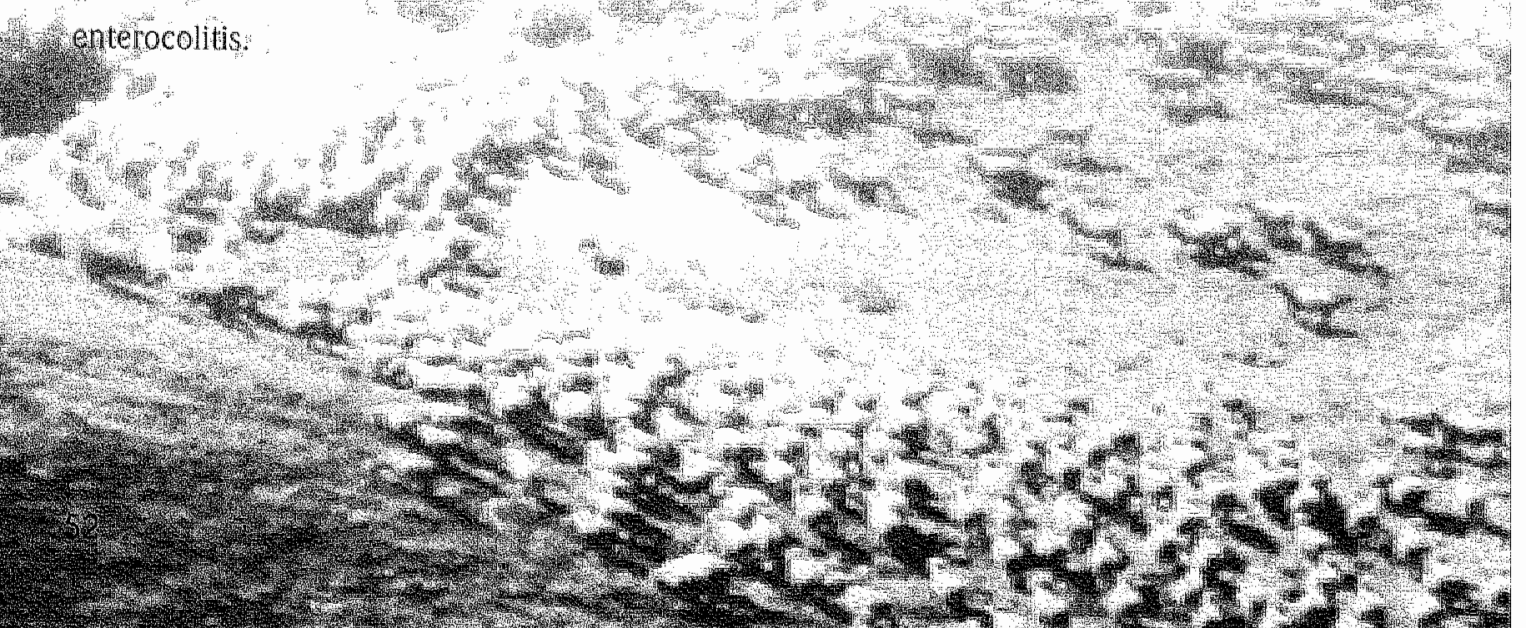




\section{INTRODUCTION}

The Cardiovascular Responses of the nearterm fetus to episodes of reduced oxygen supply have been well described. ${ }^{1,2}$ Gastrointestinal blood flow is maintained during moderate hypoxia and asphyxia, but there is a marked fall in gastrointestinal blood flow during a severe asphyxial insult. ${ }^{3-6}$ The changes in gastrointestinal blood flow during the hours after an asphyxial insult are unknown. Further, little is known about the blood flow responses of the immature fetal gut to asphyxia. Iwamoto $\mathrm{et}^{\mathrm{a}} \mathrm{l}^{7}$ reported that there was no significant change in gastrointestinal blood flow during graded umbilical cord occlusion in the 0.6 to 0.7 gestation fetus. This apparent failure to redistribute combined ventricular output (CVO) at this age traditionally has been attributed to immature cardiovascular development. 1,7 In contrast, however, we recently have shown that the 0.6 gestation fetus is capable of redistributing blood flow away from the periphery during asphyxia and that this severe asphyxial insult leads to a secondary period of significant peripheral hypoperfusion during the first 12 hours after the insult: ${ }^{8}$

It was the purpose of this study, therefore, to examine in the premature fetal sheep the hypotheses that gastrointestinal blood flow is reduced actively during asphyxia and that after this severe asphyxial insult gastrointestinal blood flow would be significantly perturbed.

\section{MATERIALS AND METHODS}

\section{Subjects and Experimental Preparation}

All procedures were approved by the Animal Ethics Committee of The University of Auckland. Twelve singleton Romney/Suffolk fetal sheep were instrumented at 98 to 99 days of gestation (term, 147 days) under general anaesthesia $\left(2 \%\right.$ halothane in $\left.\mathrm{O}_{2}\right)$ using sterile techniques. ${ }^{8,9}$ Catheters were placed in the left femorall artery and vein, right axillary artery, and the amniotic sac. A $2 S$ ultrasound blood flow probe (Transonic Systems Inc, Ithaca, NY) was placed around the superior mesenteric artery to record gastrointestinal blood flow. Two pairs of electroencephalographic (EEG) electrodes (AS633-5SSF, Cooner wire $\mathrm{Co}$, Chatsworth, CA) were placed on the dura over the parasagittal parietal cortex $(5 \mathrm{~mm}$ and 10 $\mathrm{mm}$ anterior to bregma and $5 \mathrm{~mm}$ lateral] and secured with cyanoacrylate glue. A reference electrode was sewn over the occiput. Electromyographic (EMG) electrodes were placed in the nuchal muscle and electrocardiogram (ECG) electrodes were sewn across the chest to record the fetal ECG. An inflatable silicone occluder was placed around the umbilical cord of all fetuses (In Vivo Metric, Healdsburg, CA). All fetal leads were exteriorised through the maternal flank, and a maternal long saphenous vein was catheterised. Antibiotics ( $80 \mathrm{mg}$ gentamicin) were administered into the amniotic sac before closure of the uterus and to the ewes ( $5 \mathrm{~mL}$ of streptopen) intramuscularly before the start of surgery.

After surgery, sheep were housed together in separate metabolic cages with access to water and food ad libitum. They were kept in a temperature-controlled room $\left(16 \pm 1^{\circ} \mathrm{C}\right.$; humicity, $\left.50 \pm 10 \%\right)$, in a 12 -hour light-dark cycle. A period of 4 to 6 days postoperative recovery was allowed, during which time antibiotics were administered daily to the ewe $1600 \mathrm{mg}$ crystapen intravenously for 4 days and $80 \mathrm{mg}$ gentamicin, intravenously daily for the first 2 days). Fetal arterial blood was taken daily from the brachial artery for blood gas analysis for the assessment of fetal health. Catheters were maintained patent by continuous infusion of heparinised saline $\left(20 \mathrm{U} \mathrm{mL}^{-1}\right.$ at $\left.0.15 \mathrm{~mL} \mathrm{~h}^{-1}\right)$.

\section{Experimental Design}

Experiments were conducted at 103 to 104 days gestation. Fetal mean arterial pressure (MAP], corrected for maternal movement by subtraction of amniotic fluid pressure, fetall heart rate (FHR), 
Table 1. Fetal Arterial Data for Control 101 and Oclusion 10 Groups

\begin{tabular}{|c|c|c|c|c|}
\hline & & Control & 5 Minutes & 20 Minutes \\
\hline $\mathrm{pH}$ & c & $7388+0.0$ & $7,385+0.0$ & $7380 \pm 0.0$ \\
\hline 4 & 0 & $7384 \geq 00$ & $7042+006$ & $6.818+0.05$ \\
\hline $\mathrm{PaCO}_{2}(\mathrm{~min} \mathrm{Hg})$ & c & $48.1+18$ & $469+1.4$ & $486 \pm 17$ \\
\hline & व & $470 \pm 13$ & $95.8+423$ & $1412+6.19$ \\
\hline $\mathrm{PaO}_{2}(\mathrm{~nm} \mathrm{Hg})$ & c & $23.5+18$ & $237+0.8$ & $236 \pm 08$ \\
\hline & 0 & $24.9+10$ & $60 \pm 0.48$ & $88+1.05$ \\
\hline Giucose (nimoll) & C & $102 \pm 0.1$ & $1,02 \pm 0.2$ & $1.02 \pm 01$ \\
\hline & a & $103 \pm 0.1$ & $0.36 \pm 0.17$ & $0.61 \pm 0.11$ \\
\hline Lactate (mmollu) & 6 & $0,81 \pm 01$ & $07 \pm 01$ & $0.83+0.1$ \\
\hline & 0 & $0,68 \pm 01$ & $3.95 \pm 0.38$ & $6.32=0.23$ \\
\hline
\end{tabular}

NonE Dala are mean 4 SEM.

sद. 05

$1 \mathrm{P}<01$

$A P<005$

$\$ \mathrm{P}<001$ (between group comparisons, data compared by ANCOVA)

superior mesenteric artery blood flow (SMABF), fetal EEG and nuchal. EMG activity were recorded continuously from 6 hours before occlusion to 72 hours postocclusion. Data were stored to disk by custom software for off-line analysis (Labview for Windows, National Instruments Ltd, Austin, Texas).

Fetuses were assigned randomly to either the sham occlusion group $(\mathrm{n}=6)$ or the occlusion group $(n=6)$. Fetal asphyxia was induced in the occlusion group by rapid inflation of the umbilical cord occluder for 25 minutes with sterile saline of a defined volume known to completely inflate the occluder. Successful occlusion was confirmed by observation of a rapid flattening of the EEG..$^{10}$ The sham group underwent sham occlusion for 25 minutes. In both groups, fetal arterial blood was taken 15 minutes before asphyxia; 5 and 20 minutes during asphyxia; and 2, 4, 6, 10,24, 48, and 72 hours postasphyxia for pH and blood gas determination 1845 blood gas analyzer and co-oximeter; Ciba-Corning Diagnostics, MA) and for glucose and lactate measurements (YSI model 2300, Yellow Springs, Ohio).

On completion of the experiment at 72 hours the ewe and fetus were killed by an overdose of pentobarbitone sodium. Samples of the fetal duodenum, jejunum, ileum, and colon were taken for histological examination. All tissue specimens were fixed in $10 \%$ neutral buffered formalin, embedded in paraffin, sectioned $(4 \mu \mathrm{m})$ and stained with $\mathrm{H \& E}$. The degree of intestinal injury was evaluated by an observer masked to the experimental groups (Ja) using a grading system that describes development. of necrosis on a scale from 0 to 8 in which grade 0 means normal mucosa and grade 8 means transmural infarction. 11

\section{Data Analysis and Statistics}

Off-line analysis was performed using an analysis programme written using Labview for Windows (National Instruments Ltdd). Superior mesenteric artery vascular resistance (SMAVR) was calculated using the formula (mean arterial pressure 2 mean venous pressure)/blood flow ( $\mathrm{mm} \mathrm{Hg}$ min $\mathrm{mL}^{-1}$ ).

Statistical analysis was performed using SPSS for Windows (SPSS, Chicago, IL). Data are presented as mean \pm SEM. Statistical significance was accepted when $P$ was less than .05 . The effect of asphyxia 


\begin{tabular}{|c|c|c|c|c|}
\hline 30 Minutes Post & 2 Hours Post & 4 Hours Post & 6 Houns Post & 10 Hours Post \\
\hline $7387+00$ & $7389+00$ & $7390 \pm 00$ & $7380+00$ & $7382+00$ \\
\hline $1288=0.08$ & $7335+0,0$ & $7,403 \pm 00$ & $7425+00$ & $7395 \pm 00$ \\
\hline $467 \pm 1.4$ & $47.6=18$ & $489+23$ & $488+20$ & $497 \pm 16$ \\
\hline $44.63+13$ & $45,42 \pm 0.8$ & $46.1+0.4$ & $433+10 *$ & $48,3+10$ \\
\hline $231 \pm 0.9$ & $23.2+0.1$ & $231+10$ & $234+07$ & $233+09$ \\
\hline $27.2 \pm 0.86$ & $272 \pm 12^{*}$ & $25,3+111$ & $26,0+12$ & $270+0,8$ \\
\hline $10+0.1$ & $108+101$ & $1.03+0.0$ & $1.07+0.1$ & $119+0.2$ \\
\hline $1.44 \pm 0.2^{*}$ & $121+01$ & $130 \pm 0.1$ & $132+01$ & $152+02$ \\
\hline $079 \pm 0$. & $0.86 \pm 01$ & $0.84 \pm 0.1$ & $0.86 \pm 01$ & $114+0.2$ \\
\hline $4.43+0.49$ & $390 \pm 0.74$ & $263,0,5^{*}$ & $12 \pm 0.4$ & $202 \pm 0.4$ \\
\hline
\end{tabular}

on the biophysical parameters was determined by 2 -way analysis of variance (ANOVA). Time was treated as a repeated measure to allow for repeated sampling. When statistical significance was found between groups or between group and time, analysis of covariance (ANCOVA) was used to compare selected time points, using the baseline period as a covariate. For the analysis of the occlusion and 1 hour postocclusion data, the baseline period was taken as the mean of the hour before occlusion, whereas for the analysis of the long-term recovery data ( 1 to 72 hours postocclusion) the baseline period was taken as the mean of the 6 hours before occlusion.

\section{RESULTS}

\section{Blood Composition Measurements}

All fetuses had normal blood gas, acid base, and glucose and lactate status, according to the standards of our laboratory, before each experiment. Values and statistical comparisons for arterial $\mathrm{pH}$, blood gases, and glucose and lactate levels for the control and occlusion groups up to 10 hours postasphyxia are presented in Table 1 . Between 24 and 72 hours post-asphyxia there were no significant differences between groups for $\mathrm{pH}, \mathrm{PaCO}_{2}$, glucose, and lactate levels. $\mathrm{PaO}_{2}$, however, was significantly elevated in the occlusion group fetuses at each of the 3 days postasphyxia $(P<.05)$ and at 72 hours was $30.0 \pm 1.1 \mathrm{~mm} \mathrm{Hg}$ versus $25.8 \pm 1.6 \mathrm{~mm} \mathrm{Hg}(\mathrm{P}<.05)$.

\section{Changes Observed During Asphyxia}

Fetal MAP, FHR, SMABF, and SMAVR responses during occlusion are shown in Fig 1 (control group data not shown because there were no significant changes after sham occlusion). Umbilical cord occlusion led to a pattern of bradycardia with initial hypertension, followed by profound hypotension. MAP fell to $8.7 \pm 0.7 \mathrm{~mm} \mathrm{Hg}$ by 25 minutes of occlusion ( $w 36 \pm 1.2 \mathrm{~mm} \mathrm{Hg}$ in the control group; 
$P<.001]$, and FHR fell to $54 \pm 3.1$ beats per minute (bpm; $v 195.3 \pm 3.4 \mathrm{bpm}$ in the control group; $P<.001)$. SMABF exhibited a triphasic pattern. Blood flow initially fell to $0.8 \pm 0.1 \mathrm{~mL}$ $\mathrm{min}^{-1}$ by 3 minutes of occlusion compared with $14.7 \pm 3.4 \mathrm{~mL} \mathrm{~min}^{-1}$ in the control group $(P<.005)$. SMABF then rose, transiently returning to levels not significantly different from the control group between 8 and 16 minutes, before falling again in parallel with the fall in MAP. By 25 minutes, SMABF was $3.4 \pm$ $0.9 \mathrm{~mL} \mathrm{~min}^{-1}$ versus $13.1 \pm 2.7 \mathrm{~mL} \mathrm{~min}^{-1}$ in the control group $(P<.05)$. SMAVR increased between 1 and 5 minutes peaking at 4 minutes $(P<.05)$. SMAVR then returned to control values during the rest of the occlusion period. Both EEG and nuchal EMG activity were rapidly and profoundly depressed during the entire period of occlusion $(P<.001$ for each variable; data not shown).

Fig 1. The effect of 25 ninutes of asphyxia induced by complete umbilicall cord acclusion on fetal MAP, FHR, SMABF, and SMAVR. Data from the asphyxia group only shown. The shaded region denotes the period of asphyxia. Values are 1 . minute averages, mean \pm SEM. $(*) P<.05$, $(* * *) P<.005,(* * * *) P<.001$ asphyyia group versus control group $(A N C O N A ; n=6$ in each groupl. The hotizontal bars show the time periods ower which data had the same significance. Data are mean \pm SEM.

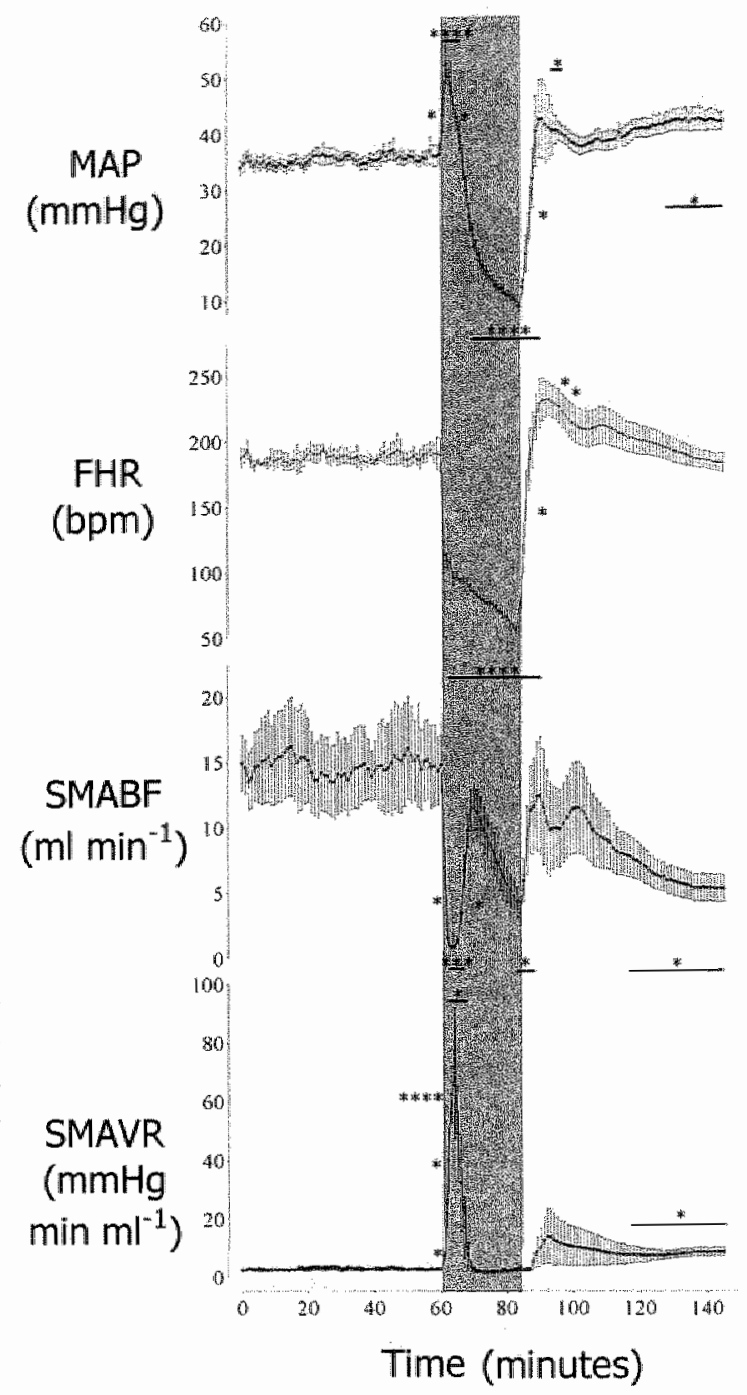

\section{Changes Observed During the 3 Days After Asphyxia}

Figure 2 shows the changes in SMABF after sham asphyxia in the control group and asphyxia in the occlusion group. Postocclusion, SMABF transiently returned to control group values within 3 minutes. Between 35 and 105 minutes there was a spontaneous secondary fall in SMABF in all fetuses $(P<.05)$. The nadir of the fall occurred at 74 minutes postocclusion $\left(4.9 \pm 1.0 \mathrm{~mL} \mathrm{~min}^{-1} \vee 15.5 \pm 3.2 \mathrm{~mL} \mathrm{~min}^{-1}\right.$ in the control group, $P<.05$ ). This period of hypoperfusion was interrupted by a transient rise back to control values, peaking at 206 minutes postocclusion at $14.2 \pm 3.1 \mathrm{~mL} \mathrm{~min}^{-1}\left(v 13.7 \pm 2.8 \mathrm{~mL} \mathrm{~min}^{-1}\right.$ in the control group). This was followed by a further fall in SMABF in all fetuses. In this second phase of delayed hypoperfusion, SMABF was significantly lower than control between 5 hours 40 minutes and 7 hours 20 minutes. The nadir in flow at 6 hours 20 minutes was $7.6 \pm 1.3 \mathrm{~mL}$ min ${ }^{-1}(v 14.7 \pm$ $3.2 \mathrm{~mL} \mathrm{~min}^{-1}$ in the control group, $\left.p<.05\right)$. Thereafter, SMABF returned to control group values 


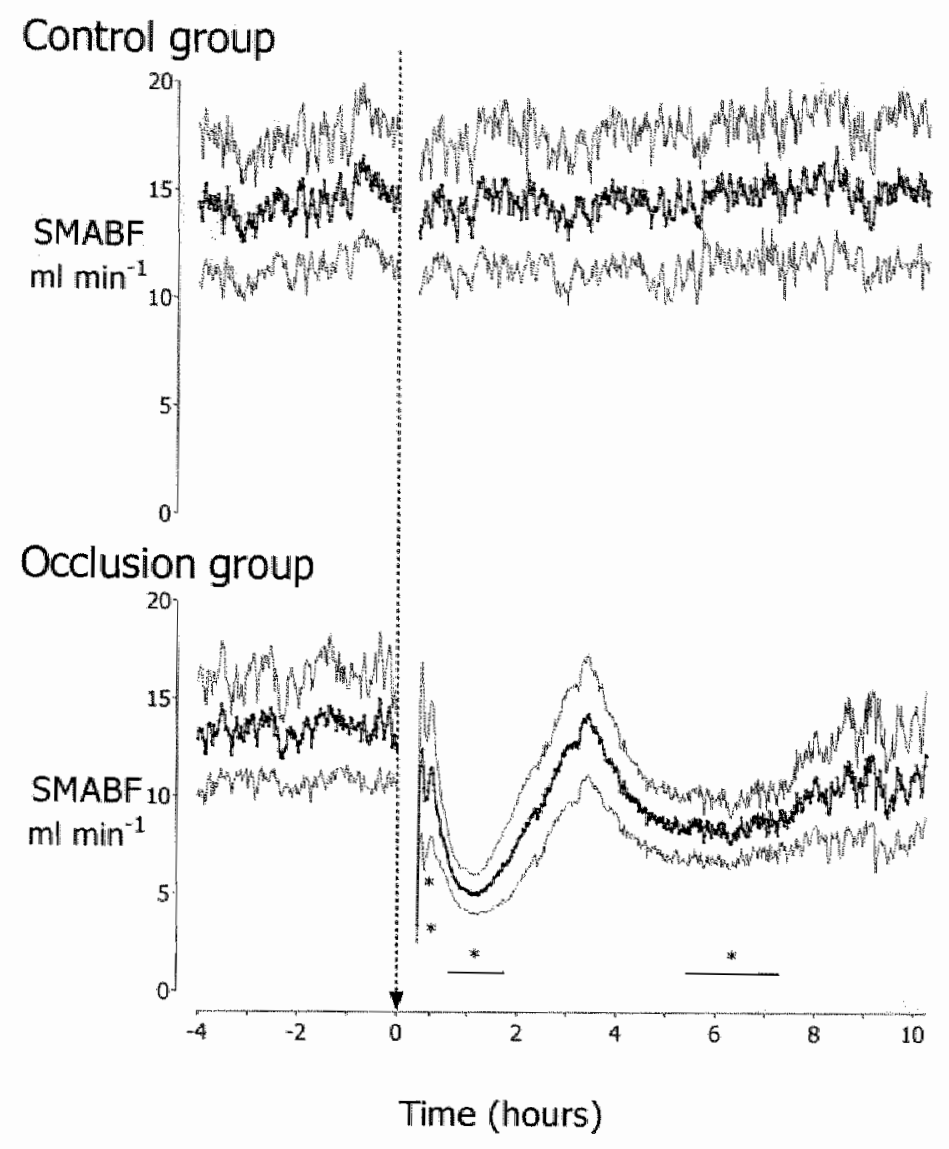

Fig 2. This ilgure shows the time sequence of the changes in superior mesenteric artery blood flow (SMABF) in the control group (top panel), and occlusion group (botiom panel) before ( 4 hours) and for 10 hours after either occlusion or sham occlusion. Data are 1-minute averages, mean \pm SEM. The arrow denotes when occlusion occurred. The postocclusion data start with the last minute of ocdusion. $|x| P<.05$ occlusion group versus control group by ANCONA. For clarity the significant data points are denoted as $P<.05$. The horizontal bars show the tume periods over which data had the same significance.

until the end of recordings at 72 hours. Postocclusion there was a significant increase in SMAVR between 41 minutes and 2 hours, peaking at 66 minutes $(P<.01)$ and again between 5 hours and 40 minutes and 6 hours and 50 minutes $(P<.05$; data not shown). Thereafter, SMAVR returned to control group values.

Figure 3 shows the postocclusion changes in nuchal EMG activity, MAP, and FHR in the occlusion group and control group. MAP returned to control group values by 3 minutes and was significantly elevated between 35 minutes and 2 hours, peaking at 54 minutes $(42.2 \pm 2.2 \mathrm{~mm} \mathrm{Hg} \vee 36.7 \pm 1.7$ $\mathrm{mm} \mathrm{Hg}$ in the control group, $P<.05)$. Thereafter, MAP was not significantly different from the control group. There was a rebound tachycardia between 8 and 14 minutes with FHR peaking at 9 minutes $(231.7 \pm 12.7 \mathrm{bpm} v 190.0 \pm 5.5 \mathrm{bpm} ; P<.05)$. FHR also was significantly elevated between 2 hours 

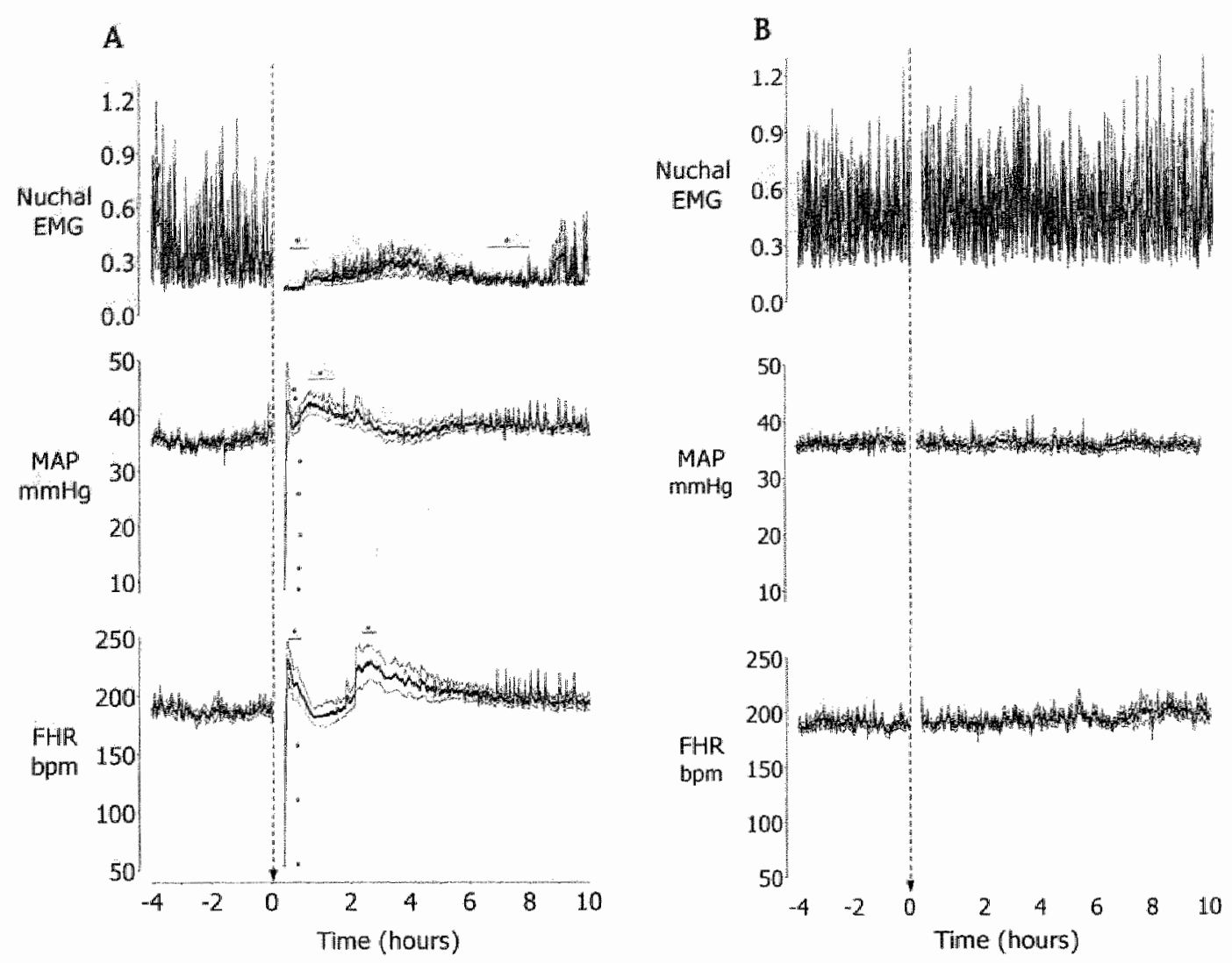

Fig 3. This figure shows time sequence of the changes in nuchal EMG activity, MAP and FHR in the occlusion group $\left(A_{k}\right)$ and control group (B) before ( 4 hours) and for 10 hours after either occlusion or sham acclusion. Data are 1 -minute averages, mean \pm SEM. The arrow denotes when occlusion occurred. The postocclusion data start with the last minute of occlusion. (w) $P<.05$ acclusion group wersus control group by ANCOVA. For clarity the significant data points are denoted as $P<.05$. The horizontal bars show the time periods over which data had the same significance. Dala are mean \pm SEM.

30 minutes and 3 hours with FHR peaking at $229.8 \pm 14.4$ bpm $/ v 190.75 .2$ bpm in the control group; $P<.05)$. Thereafter, FHR was not significantly different from the control group.

EEG activity remained significantly depressed until a mean of 7 hours 45 minutes $(P<.005$; data not shown), corresponding with the onset of epileptiform activity in 4 of the 6 occlusion group fetuses. These epileptiform events were correlated with episodic nuchal EMG activity, and resolved at a mean of 21 hours 30 minutes. EEG activity subsequently remained significantly depressed for the remainder of the study $(P<.01)$. No seizures were observed in the control group. Nuchal $E M G$ activity remained depressed until 40 minutes after occlusion $(P<.05)$. Nuchal EMG activity was transiently depressed again between a mean of 6 hours 35 minutes and 7 hours 50 minutes $(P<.05)$. Nuchal activity then returned to control group values. 


\section{Histology}

Histological evaluation by light microscopy of the H\&E-stained sections did not show intestinal damage in the asphyxiated or control animals after 3 days of recovery.

\section{DISCUSSION}

Results of both animal and clinical studies suggest that the pathogenesis of necrotising enterocolitis (NEC) involves, in part, exposure of the gastrointestinal tract to hypoperfusion during an hypoxic or asphyxial insult. ${ }^{12} \cdot 15$ Such an asphyxial insult may occur either during labour or perhaps more likely, before labour during fetal life. In addition, periods of hypotension or bradycardia duning the early postnatal care of premature newborns also may have potential to cause gastrointestinal hypoperfusion. The current study has described the changes in gastrointestinal blood flow during and after severe asphyxia in utero in the premature fetus. We report for the first time that the premature fetal gut is involved in the acute redistribution of blood flow during asphyxia, and that subsequent to reperfusion, there is a secondary prolonged phase of perturbation of gastrointestinal blood flow. We speculate that this represents a phase of endothelial dysfunction and vulnerability.

Twenty-five minutes of umbilical cond occlusion did not result in gastrointestinal injury on standard histological assessment after 3 days of recovery. This finding is complementary with observations made in the developing chicken embryo subjected to repetitive episodes of asphyxia. ${ }^{16}$ These data and those of the current study are consistent with the hypothesis that such an insult may represent an early predisposing factor in the chain of events leading to NEC.

We previously have shown that the premature fetus at 0.6 gestation is able to mount an acute cardiovascular defense to asphyxia similar to that observed at full term, 8,17,1: The responses include redistribution of CVO, hypertension, and bradycardia. 18.20 The current data confirm this finding. The key maturational difference compared with the full-term fetus is that the premature fetus is able to survive a much longer duration of asphyxia. This capacity of the preterm fetus to survive long periods of reduced oxygen supply is caused by such factors as greater glycogen stores, greater anaerobic capacity in many tissues, and lower basal metabolic activity. 21,22 Paradoxically, this capacity to survive allows the fetus to be exposed to extended periods of profound hypotension and hypoperfusion.

In the current study, the 0.7 gestation fetus was able to survive 25 minutes of asphyxin. During asphyxia the fetal cardiovascular response was characterised by 3 phases: initial redistribution of blood llow away from the gut to maintain vital organ function, subsequent fallure of this redistribution, and finally near-terminal cardiovascular collapse. The initial fall in SMA biood flow to almost zero was mediated by a significant increase in vascular resistance at a time when blood pressure was rising and is likely to be regulated by the same neural mechanisms that mediate redistribution of $C V O$ in the fullterm fetus. ${ }^{23}$ This redistribution of blood flow away from the gut was, however, only sustained for a few minutes. During most of the insult gastrointestinal blood flow was essentially pressure passive, paralleling changes in artenial blood pressure, with low levels of SMA wascular resistance. The mechanisms mediating this failure of redistribution of blood flow are unknown, but we observed a similar pattem in femoral blood flow in the 0.6 gestation fetus. ${ }^{8}$ We speculate that the intense initial peripheral vasoconstriction may have resulted in exacerbated local tissue hypoxia and acidosis, which, in turn, led to rebound wasodilatabion at this time. The fall in blood pressure was steepest during this phase, and it is likely that the failure of the redistribution of blood flow hastened the onset of hypotension. Thus, one consequence of the falure of SMA vasoconstriction was greater perfusion of the gut during asphyxia, at the expense of central organs. The final phase marked the onset of 
circulatory collapse as demonstrated by sustained, profound hypotension with a corresponding progressive significant fall in SMA blood flow.

After the end of occlusion, blood pressure, heart rate, and SMA blood flow all rapidly recovered, and there was a brief period of hypertension and tachycardia. This is consistent with other fetal, neonatal, and aduit data on immediate haenodynamic changes after asphyxia. $8,9,17,18,24: 26$ There was, however, no rebound hyperperfusion of the gut, although SMA blood flow initially did return to control values. An overall increase in vascular resistance appeared to inhibit rebound hyperperfusion. After initial reperfusion, within 20 minutes there was a secondary fail in SMA blood flow. This hypoperfusion was not related to hypotension because blood pressure was still significantly elevated. Rather, the fall in SMA, blood flow was associated with a significant rise in vascular resistance suggesting an actively mediated process.

It has been suggested that the perturbation of ischemia-reperfusion may lead to dysfunction of organ vasculature caused by either a reduced capacity to produce vasodilators such as nitric oxide and a rise in vasoconstrictors such as endothelin or a reduced ability to respond to vascdilators (endothelial dysfunctionj. ${ }^{12,27,28}$ In the adult, local ischaemia reperfusion typically is accompanied in the affected organs by significant changes in basal and reactive vascular function during the first 24 to 48 hours. ${ }^{29}$ We also have observed changes in blood flow after asphyxia in the premature fetus at 0.6 gestation. ${ }^{8}$ The pattern in SMA blood flow in the 0.7 gestation fetus was, however, very different to that observed in femoral blood flow at 0.6 gestation because femoral blood flow took much longer to fall postasphyxia (the nadir occurring at 8 hours). This may be related to maturational changes in the mechanisms controlling blood flow at 0.6 versus 0.7 gestation or, more likely, that asphyxia has a profound and differential effect on the mechanisms controlling SMA blood flow.

The immature intestine has been suggested to be more vulnerable to endothelial dysfunction. Nowicki ${ }^{30}$ showed that mesenteric artery endothelial production of nitric oxide (NO) after ischaemia was reduced in the 3-day-old piglet, whereas production was increased in the 35-day old pig. These data are supported by the recent observation that NO synthase inhibition causes a significantly greater fall in SMA blood flow in the premature fetus compared with later in development. ${ }^{3 !}$ From this study it was suggested that NO plays a greater role in the regulation of fetal gastrointestinal blood flow in the premature fetus than later in gestation.

The pattern of SMA blood flow we observed during the first 9 hours postocclusion is umique and highly consistent. The fall in SMA blood flow was reversed transiently between 2 and 5 hours suggesting that the endothelial dysfunction can be overridden. This rise in SMA blood flow between the periods of postasphyxial hypoperfusion was not related to a rise in blood pressure, but was associated with a significant fall in SMA vascular resistance. It is of interest that this increase in SMA blood flow was associated with a delayed period of sustained tonic nuchal EMG activity. When this muscle activity subsided, SMA blood flow once again fell. The etiology of this increased nuchal EMG activity is not known, but it was not associated with EEG changes; the EEG remained depressed at this time. It also was not associated with an evident increase in general metabolic activity as determined from blood gases, glucose and lactate values, although local gastrointestinal metabolism may have increased. It was associated with a rise in FHR and thus an increase in CVO. ${ }^{32}$ Whether the neural mechanisms mediating this increased nuchal muscle activity are also related to the control of heart rate and gastrointestinal blood flow or whether SMA blood flow increases as a function of almost constant fetal body movements cannot be determined from the current study. The return of SMA blood flow to control values at 9 hours was associated with the onset of episodic nuchal EMG activity and EEG epileptiform activity. 


\section{REFERENCES}

1. Jensen A, Berger R: Fetal circulatory responses to oxygen lack. J Dev Physiol $16: 181.207,1991$

2. Hanson MA: Do we now understand the control of the fetal citculation? Eur / Obset Gylecol Reptod $75.5561,1997$

3. Conn HE, Sacks El, Heymann MA, et al: Cardiovascular responses to hypoxemia and acldenia in letal lambs. Am J Obstet Ghecol 15:817.824, 1974.

4. Iskoviz I, LaGamma EF, Rudalph AM: Effects of cord compression on feral blood fow distribution and 02 delivery. Am I Physial 252:H100-H109, 1987

5. Valfe $H$, Parer IT, Block BS, et al: Cardiorespiratory responses to graded reductions of utentine blood flow in the sheep fetus. J Dey Piysiol $9: 325-336,1987$

6. Jensen A, Hohmann M, Kunzel W: Dynamic changes in organ blood flow and oxygen consumption durng acute asphyxia in letal sheep. J Dev Physio $10: 543-559,1987$

7. [wamoio HS, Stucky E, Roman CM: Effect of graded umbilical cord compression in fetal sheep at 0.60 .7 gestation. Am Physiol 201:H1208-H1274, 1991

8. Bernet L. Rossenrode $S$, Cunning ML, et al: The cardiovascular and cerebrowascular responses of the inmature fetal sheep to acute umbilical cord occlusion. J Physiol 517:247-257, 1999

9. de Haan $\mathrm{HH}$, Gunn $\mathrm{A}$, Willaras $\mathrm{CE}$, et al.: Magnesium sulfate therapy durng asphyxa in neartem letal lambs does not compromise the fetus but does not reduce cerebrai injury. Am J Obstet Cynecol 176:18.27, 1997

10. Mallard EC, Gun AJ, Williams CE, et al: Transient umbilical cord occlusion causes hippocampal damage in the fetal sheep. An J Obstet Gyecol 167:14231430, 1992.

11. Park $\mathrm{PO}$. Haglund U, Bulkley $\mathrm{GB}$, et al: The sequence of development of intesthal tissue injury after strangulaton ischemia and reperfusion. Surgery 107.574-580, 1990

12. Nowicki PT, Nankervis CA: The role of the circulation in the pathogenesis of necrotizing enterocolitis. Chn Perinatol $21: 219-234,1994$

13. Capian MS, Hedind E, Adler $L_{y}$ et al; Role of asphyxia and feeding in a neonatal rat model of necrotizing enterocalitis. Pediatr Pathol 14:1017/1028, 1994

14. Akinbi H, Abbasi $\mathrm{S}$, Hilpert PL, et al: Gastrointescinal and renal blood flow welocity profile in neonates with birth asphyxia. J Pechath 125:625-627, 1994

15. Coombs RC, Morgan ME, Durbin GM, et al: Abnomal gut blood flow velocities in neonates at risk of necrolising enterocolins. A Pediat Castroenterol Wut 1 5:13-19, 1902

16. Rouwet $\mathbb{E}$, Benk RI, Heineman E, et al: Effect of repettive asplyxia on leukocyte vessel wall interactions in the developing intestine, J Pedatr surg /in press/

17. Bennet 1 , Peebles DM, Edwards AD, et al The cerebrai hemodynatuc response to asphyxia and hypoxia in the near tem feal sheep as measured by mearmfrared spectroscopy. Pedat Res 44:951057, 1008

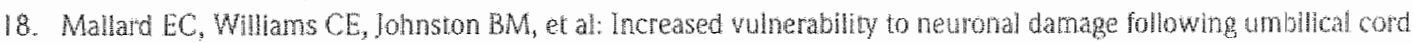
occlusion in the fetal sheep with advancing gestation. Am / obster Ophecol 170.200214, 1904

19. Ball RH, Paree IT, Caldwell LE, et al: Regional blood How and metabolism in ovine fetuses during severe cord occlusion. Am J Obster Ghecol 171:1540-1555, 1904

20. Jenser $A$, Hanson MA: Circuhtory responses to acute asphyxia in intact and chemodenervated felal sheep neat term, Reprod Feril Dev $7: 1351 \cdot 1359,1095$

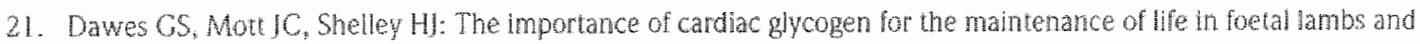
new born animals during anoxia. / Physol $146: 516-538,1059$

22. Duffy TE, Kohle S), Vannuco RC: Carbohwdrate and energy metabolism ir perinatal rat brain: Relation to survival in anoxia. / Netrochem 24:27!276,1975

23. Giussan DA, Spencer IA, Moore PJ, et al: Afferent and efferent components of the cardiovascular reflex responses to acute trypoxia in term fetal sheep. I Physiol 46 1:431-44\%, 1993 


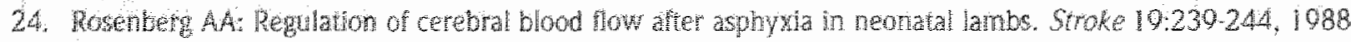

25. Hossman KA: Reperfusion of the brain after gobai ischemia: Hemodwatnic disturbances. Shock 8:95-101, 1097

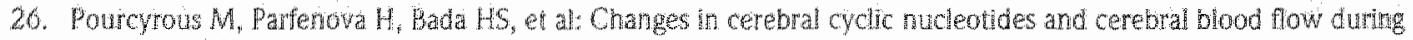
probonged asphyxa and recowery in newborn pigs. Fedatr Res 41:017-623, 1997

27. Wanoute PW, Momboul IV, Vascular endothellurn: vasoactive mediators. Prog Cardovasc Dis $39.229238,1996$

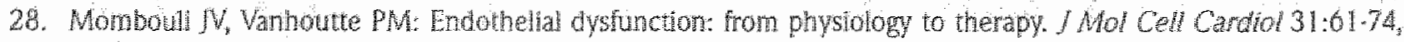
1909

29. Conger ID, Weil IV Abnormal vascular funcion following ischemia-repertusion injury. J invest Med 43.431-442, 1905.

30. Nowick PT: "The effects of ischeniareperfusion on endothelial cell functon in postnatal intesine. Pediatr Res $39.267 .274,1996$

31. Fan Wa, Smolich I), Wild, et al: Major wasodilator role for nitric oxide in the gastrointestinal circulation of the mid-gestation fetal lamb. Pediatr Res 44:344.350, 1998

32. Reller MD, Morton M, Reid DL, er al: Fetal lamb ventrides respond differenty to filling and arterial pressures and to in uhero ventilation. Pedat Res 22:621.626, 1987 


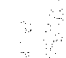

. 


\section{ABSTRACT}

Asphyzia in utero in preterm fetuses is associated with evolving hypoperfusion of the gut after the insult. We examined the role of the sympathetic nervous system (SNS) in mediating this secondary hypoperfusion. Gut blood flow changes were also assessed during post-asphyxial seizures. Preterm fetal sheep at 0.7 gestation (103-104 days, term is 147 days) underwent sham asphyxia or asphyxia induced by 25 min of complete cord occlusion and fetuses were studied for three days afterwards. Phentolamine (10 mg bolus plus $10 \mathrm{mg} \mathrm{h}^{-1}$ ) or saline was infused for $8 \mathrm{~h}$ starting $15 \mathrm{~min}$ after the end of asphyxia or sham asphyxia. Phentolamine blocked the fall in superior mesenteric artery blood flow (SMABF) after asphyxia and there was a significant decrease in MAP for the first $3 \mathrm{~h}$ of infusion $(33 \pm 1.6$ vs. vehicle $36.7 \pm 0.8 \mathrm{mmHg}, P<0.005)$. During seizures SMABF fell significantly $(8.3 \pm 2.3$ vs. $11.4 \pm 2.7 \mathrm{ml} \mathrm{min}^{-1} \quad P<0.005$ ), and SMABF was more than $10 \%$ below baseline for $₫ 3.0 \pm 1.7 \mathrm{~min}$ per seizure ( $v$ s. seizure duration of $78.1 \pm 7.2 \mathrm{sec}$ ). Phentolamine was associated with earlier onset of seizures (5.0 00.4 ws. $7.1 \pm 0.7 \mathrm{~h}, P<0.05)$, but no change in amplitude or duration, and prevented the fall in SMABE. In conclusion, the present study confims the hypothesis that post-asphyxial hypoperfusion of the gut is strongly mediated by the SNS. The data highlight the importance of sympathetic activity th the initial elevation of blood pressure after asphyxia and are consistent with a role for the mesenteric system as a key resistance bed that helps to maintain perfusion in other, more vulnerable systems.

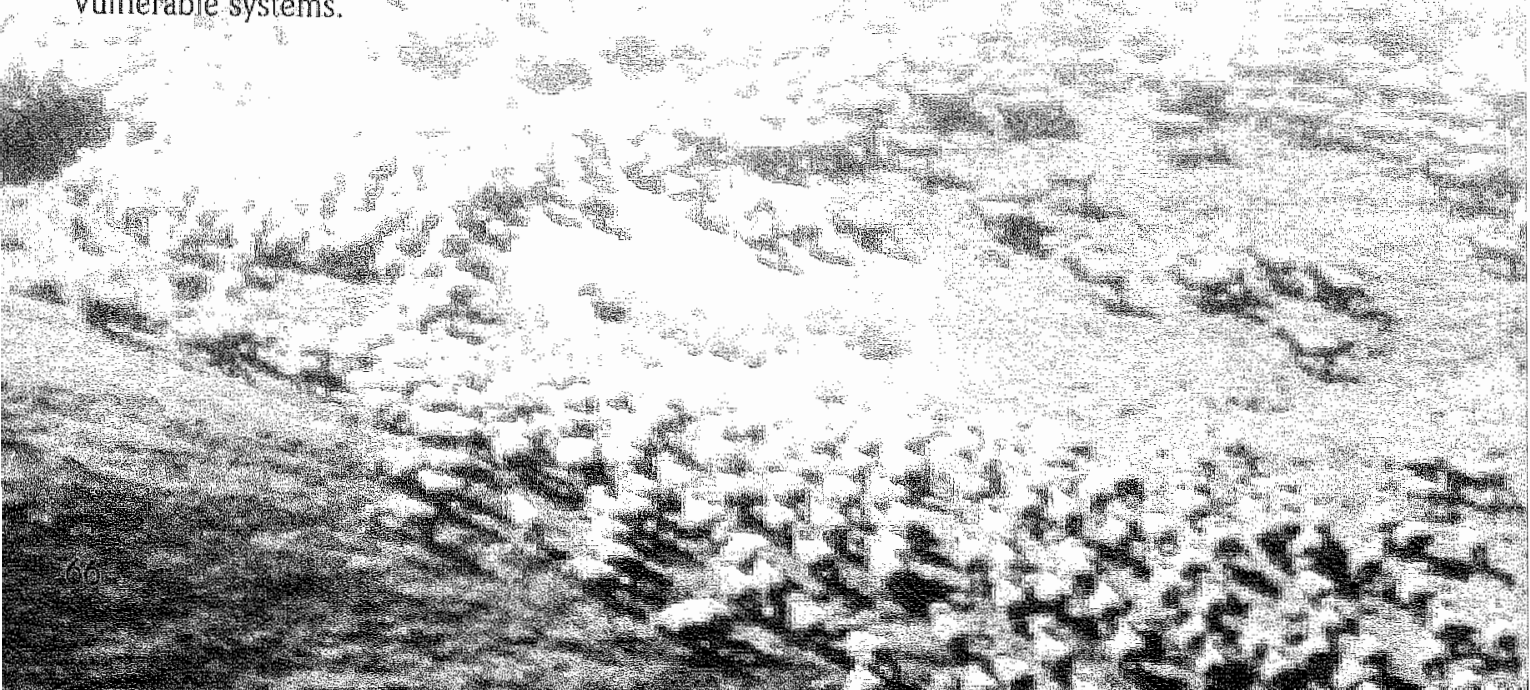




\section{INTRODUCTION}

In the preterm infant, pre-and postnatal haemodynamic disturbances are associated with a high rate of impaired postnatal intestinal adaptation during the first days of life; for example, delayed meconium passage, abdominal distension, bilious vomiting and a delay in tolerating enteral feeding (Robel-Tillig et al, 2002). Establishing early enteral feeding is important, promoting the normal development of the gut as a physical, mechanical, physiologic, and immunologic barrier (Strodtbeck, 2003). The key link between the variety of disparate clinical problems and early gastrointestinal dysfunction, as well as increased risk of severe complications such as necrotising enterocolitis (NEC), appears to be impaired perfusion of the mesenteric bed (Coombs et al., 1990; Malcolm et all, 1991; Coombs et al., 1992; Akinbi et al, 1994). Currently, however, there is little information on the specific mechanisms that control gut perfusion in the perinatal period.

We have recently reported that exposure of the premature fetus to asphyxia in utero is associated with development of delayed hypoperfusion of the gut during the early phase of recovery (Bennet et al., 2000 ). This phenomenon is not specific to fetal life or the gut (Conger \& Weil, 1995), but its mechanisms and significance remain controversial. Some data in the adult suggest that both central and peripheral secondary hypoperfusion is related to impaired endothelial control of blood flow (Hossmann, 1997; Karimova \& Pinsky, 2001; Reber et al., 2002; Ten \& Pinsky, 2002), while others suggest that it is actively mediated, reflecting reduced metabolic requirement (Michenfelder \& Milde, 1990; Gold \& Lauritzen, 2002). Although there is no specific information in the fetus, several lines of evidence suggest the hypothesis that alpha-adrenergic sympathetic nervous system (SNS) activity may play a key role in regulating gut perfusion during recovery after an asphyxial insult. The fetal gut is innervated by the autonomic nervous system from very early in development (Read \& Burnstock, 1970), and the autonomic nervous system is an important regulator of intestinal blood flow under a variety of physiological and pathological conditions (Nuwayhid et al., 1975; Jensen et al., 1987b; Paulick et al., 1991 ; Jensen \& Lang, 1992; Rouwet et al., 2000; Mulder et al., 2002). Redistribution of blood flow away from the peripheral organs such as the gut during hypoxia and asphyxia in utero is, for example, largely mediated by alpha-adrenergic receptors (Iwamoto et al., 1983; Jensen \& Lang, 1992; Giussani et al., 1993), and sympathectomy in the sheep fetus results in increased meconium passage (Westgate et al., 2002).

A potential further complication of exposure to asphyxia is the development of seizures which may occur both pre- and postnatally (Osiowich \& Barrington, 1996; Ingemarsson \& Spencer, 1998; Westgate et al, 1999; Keogh et al, 2000; Patane \& Ghidini, 2001). Seizures may cause further circulatory instability, although most studies of seizures have largely focussed on their impact on cerebral circulation, with little attention given to other vascular beds. In the adult, however, data shows that the marked increase in blood pressure typically observed during seizures is facilitated primarily by increased peripheral vascular resistance, in particular in the mesenteric bed, rather than by changes in cardiac output (Doba et al, 1975; Kreisman et al., 1993). In the adult, there is marked activation of the SNS during seizures which is likely to mediate this wasoconstriction (Baumgartner et al., 200 l). It is known that seizures in preterm infants also cause marked increases in blood pressure (Perlman \& Volpe, 1983), but the effects on peripheral blood flow have not been evaluated.

Thus it was the aim of the current study to test the hypothesis that the post-asphyxial secondary hypoperfusion of the preterm fetal sheep gut is mediated by alpha-adrenergic receptor activation. Further, we characterised the impact of post-asphyxial seizures on gut blood flow and examined the role of alpha-adrenergic receptors in mediating changes in gut blood flow during seizures. 


\section{METHODS}

\section{Surgical procedures}

All procedures were approved by the Animal Ethics Committee of The University of Auckiand. Twenty eight time mated singleton Romney-Suffolk cross sheep were operated on at $98-99$ days of gestation (term $=147$ days). Food, but not water was withdrawn $18 \mathrm{~h}$ before surgery. Ewes were given $5 \mathrm{mll}$ of Streptocin (Procaine Penicilin $(250,000 \mathrm{IU})$ and Dihydrostreptomycin $\left(250 \mathrm{mg} \mathrm{m}^{-1}\right.$, Stockguard Labs Ltd, Hamilton, New Zealand) intramuscularly for prophylaxis $30 \mathrm{~min}$ prior to the start of surgery. Anaesthesia was induced by i:v. injection of Alfaxan (Alphaxalone, $3 \mathrm{mg} \mathrm{kg}^{1}$, Jurox, Rutherford, NSW, Australia), and general anaesthesia maintained using $2.3 \%$ halothane in $\mathrm{O}_{2}$. Ewes were not ventilated and the depth of anaesthesia, maternal heart rate and respiration were constantly monitored by trained anaesthetic staff. Under anaesthesia a 20 gauge i.v. catheter was placed in a maternal front leg vein, and the ewes were placed on a constant infusion isotonic saline drip lat an infusion rate of approximately $250 \mathrm{ml} \mathrm{h}$ ) to maintain maternal fluid balance.

All surgical procedures were performed using sterile techniques (Bennet et al., 1999; Bennet et al., 2000 ). Catheters were placed in the left fetal femoral artery and vein, right brachial artery and vein, and the amniotic sac. A $2 S$ ultrasound blood flow probe (Transonic Systems Inc., Ithaca, NY, USA) was placed around the superior mesenteric artery (SMA) to measure gastrointestinal blood flow. Two pairs of electrodes (AS633-5SSF, Cooner Wire Co, Chatsworth, CA, USA) were placed on the dura over the parasagittal parietal cortex ( $5 \mathrm{~mm}$ and $10 \mathrm{~mm}$ anterior to bregma and $5 \mathrm{~mm}$ lateral) and secured with cyanoacrylate glue to measure electrocortical activity (EEG). A reference electrode was sewn over the occiput. Electromyographic electrodes were placed in the nuchal muscle to measure electromyogram (EMG) activity, and electrocardiogram [ECG) electrodes were sewn across the chest to record fetal heart rate (FHR). An inflatable silicone occluder was placed around the umbilical cord of all fetuses (In Vivo Metric, Healdsburg, CA, USA). All fetal leads were exteriorised through the maternal flank and a maternal long saphenous vein was catheterised to provide access for post operative care and euthanasia. Antibiotics (80 mg Gentamicin, Pharmacia and Upjohn, Rydalmere, NSW, Australia) were administered into the amniotic sac prior to closure of the uterus.

Post-operatively, all sheep were housed together in separate metabolic cages with access to water and food ad libitum. They were kept in a temperature-controlled room $\left(16 \pm 1^{\circ} \mathrm{C}\right.$, humidity $\left.50 \pm 10 \%\right)$, in a $12 \mathrm{hlight} /$ dark cycle. A period of 4.5 days post-operative recovery was allowed before experiments commenced, during which time antibiotics were administered daily for four days i.v. to the ewe $1600 \mathrm{mg}$ Benzylpencillin Sodium, Novartis Ltd, Auckland, New Zealand, and $80 \mathrm{mg}$ Gentamicin.). Fetal catheters were maintained patent by continuous infusion of heparinised saline (20 $\mathrm{U} \mathrm{ml}^{-1}$ at $0.15 \mathrm{ml} \mathrm{h}^{-1}$ ) and the maternal catheter maintained by dally flushing.

\section{Experimental design}

Experiments were conducted at 103-104 days gestation. Mean arterial pressure (MAP) measured from the femoral artery, mean venous pressure measured from the femoral vein (both corrected for materna! movement by subtraction of amniotic fluid pressure), FHR, SMABF, EEG and nuchal EMG activity were recorded continuously from $12 \mathrm{~h}$ before occlusion wntil $72 \mathrm{~h}$ after occlusion. Data were stored to disk by custom software for off-line analysis (Labview for Windows, National Instruments Ltd, Austin, Texas, USA).

Fetuses were randomly assigned to one of four groups: sham occlusion plus vehicle infusion (sham vehicle group, $n=7$ ), sham occlusion plus infusion of the alpha-adrenergic antagonist phentolamine (sham phentolamine, $n=5$ ), occlusion plus vehicle infusion (asphyxia vehicle, $n=8$ ), occlusion plus 
infusion of phentolamine (asphyxia phentolamine, $n=8$ ). Phentolamine (Regitine, Novartís Pharma AG, Basel, Switzerland》 was administered i.v., wia the brachial vein, to the fetus as a $10 \mathrm{mg}$ in $1 \mathrm{ml}$ bolus given over $5 \mathrm{~min}$, followed by a continuous infusion at $10 \mathrm{mg} \mathrm{h}^{-1}$ at $1 \mathrm{ml} \mathrm{h}^{4}$, starting $15 \mathrm{~min}$ after the end of occlusion or sham occlusion and continued for $8 \mathrm{~h}$. In the vehicle groups, isotonic saline was infused at the same volume and rate over the same time period. The period of $8 \mathrm{~h}$ was chosen because this was the mean duration of gastrointestinal hypoperfusion post asphyxia observed in previous studies (Bennet et al, 2000).

In the occiusion groups, asphyxia was induced by rapid inflation of the umbilical cord occluder, for $25 \mathrm{~min}$, with sterile saline of a defined volume known to completely inflate the occluder as determined by previous pilot experiments using flow probes placed on an umbilical vein. Successful occlusion was confirmed by a rapid rise in MAP and bradycardia (Bennet et al., 2000). Arterial blood was taken from the brachial artery at $15 \mathrm{~min}$ prior to asphyxia, at 20 min during asphyxia, and $2,4,6,10,24,48$ and $72 \mathrm{~h}$ post-asphyxia for pre-ductal pH and blood gas determination (Ciba-Corning Diagnostics 845 blood gas analyser and co-oximeter, MA., USA) and for glucose and lactate measurements (YSI model 2300, Yellow Springs, Ohio, USA).

On completion of the experiment at $72 \mathrm{~h}$ ewes and fetuses were killed by an overdose of pentobarbitone sodium ( $9 \mathrm{~g}$ i.v. to the ewe; Pentobarb 300, Chemstock International, Christchurch, New Zealand).

\section{Data analysis and statistics}

The nuchal EMG signal was bandpass filtered between $100 \mathrm{~Hz}$ and $1 \mathrm{kHz}$, the signal was then integrated using a time constant of one sec. The EEG signal was low-pass filtered with a 6th order lowpass Butterworth filter, with a cut-off frequency of $50 \mathrm{~Hz}$. A power spectrum was then calculated from this $256 \mathrm{~Hz}$ sampled signal. Data from left and right EEG electrodes were averaged to give mean total EEG activity. For clarity of data display the EEG intensity was $\log$ transformed (dB, $20 \mathrm{x} \log ($ intensity) (Williams et al, 1992). Additionally the raw EEG signal was processed through a digital FIR low pass filter with a cut-off frequency of $30 \mathrm{~Hz}$ and stored at a sampling rate of $64 \mathrm{~Hz}$ for analysis of seizures. Seizures were identified visually and defined as the concurrent appearance of sudden, repetitive, evolving stereotyped waveforms in the EEG signal lasting more than 10 sec and of an amplitude greater than $20 \mu \mathrm{V}$ (Scher et al., 1993). Superior mesenteric artery vascular resistance was calculated using the formula (mean arterial pressure - mean venous pressure)/blood flow ( $\left.\mathrm{mmHg}\left(\mathrm{min} \mathrm{ml}^{-1}\right)^{-1}\right)$.

Statistical analysis was performed using SPSS for Windows (SPSS, Chicago, USA). For the analysis of the long-term recovery data (1.72 h post-occlusion) the control pre-occlusion baseline period was taken as the mean of the $12 \mathrm{~h}$ before occlusion. For between group comparisons two way analysis of variance for repeated measures was performed. When statistical significance was found between groups, or between group and time, analysis of covariance (ANCOVA) was used to compare selected time points, using the baseline control periods prior to occlusion as a covariate. For seizure analysis, the pre-seizure baseline period was taken as the two min prior to the onset of a seizure. Maximum changes observed during seizures were compared to the pre-seizure baseline using Students-t test. Percentage changes in nuchal. EMG are presented as median (25th, 75th percentile). Data are presented as mean \pm SEM. Significance was accepted when $P<0.05$. 


\section{RESULTS}

\section{Blood Composition Measurements}

Values and statistical comparisons for arterial $\mathrm{pH}$, blood gases, glucose and lactate for the control and treatment groups, before occlusion, at 20 min of sham occlusion or occlusion, and $2,4,6,8,24,48$ and $72 \mathrm{~h}$ after sham occlusion or occlusion, are presented in Table 1.

\section{Superior mesenteric artery blood flow and vascular resistance}

There were no significant differences in SMA blood flow or resistance between groups before occlusion and between the asphyxia groups during occlusion. SMABF rapidly returned to sham vehicle values immediately post-occlusion in both occlusion groups (Fig. $1 \mathrm{~A}$ ). In the asphyxia vehicle group SMABF then changed in a biphasic hypoperfusion pattern similar to that previously described (Bennet et $a L_{\text {, }}$ 2000 , with an initial hypoperfusion between $35 \mathrm{~min}$ and $2 \mathrm{~h}$ after the start of infusion (nadir at 73 min post-occlusion of $4.5 \pm 0.9$ vs. $11.5 \pm 0.8 \mathrm{ml} \mathrm{min}^{-1}$ in the sham vehicle group, $P<0.01$ ).

Table 1 Fetal anterlal ph, blood gases, glucose and lactate values for all groups 15 min before (control), during (20 minutes), and after $(2,4,6,8,24,48$ and 72 houss $)$, either sham umbilical occlusion or occlusion.

\begin{tabular}{|c|c|c|c|c|}
\hline 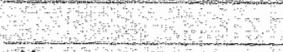 & Control & $20 \mathrm{~min}$ & 2 hours & 4 hours \\
\hline $\mathrm{pH}$ & 3 & & & 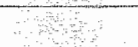 \\
\hline Sham vehicle & $739 \pm 0.0$ & $738 \pm 0.0$ & $7.39 \pm 0.0$ & $7.39 \pm 0.0$ \\
\hline Sham phentolamine & $7.38 \pm 00$ & $739 \pm 0.0$ & $7.40 \pm 0.0$ & $7,39 \pm 0.0$ \\
\hline Asplyxia vehicle & $7.37 \pm 0.0$ & $6.83 \pm 0.05$ & $7.34 \pm 0.0^{*}$ & $7.40 \pm 0.0$ \\
\hline Asphyxia phentolamine & $7.36 \pm 0.0$ & $6.88 \pm 0.09$ & $7.36 \pm 0.0$ & $7.41 \pm 0.0$ \\
\hline \multicolumn{5}{|l|}{$\mathrm{Pa}, \mathrm{CO}_{2}(\mathrm{mmHg})$} \\
\hline Sham vehicle & $48.0 \pm 1.8$ & $48.6 \pm 1.7$ & $47.6 \pm 1.8$ & $48.9+23$ \\
\hline Sham phentolamine & $45.2 \pm 3.1$ & $45.0 \pm 3.0$ & $47.2 \pm 1.2$ & $46.2 \pm 3.4$ \\
\hline Asphyxia vehicle & $47.2 \pm 0.9$ & $1377 \pm 7.78$ & $44.1 \pm 1.4$ & $45.3 \pm 0.8$ \\
\hline Asphyxia phentolamine & $48.9 \pm 3.6$ & $132.0 \pm 3.4 \xi$ & $46.1 \pm 3.6$ & $46.4 \pm 2.0$ \\
\hline \multicolumn{5}{|l|}{$\mathrm{Pa}_{1} \mathrm{O}_{2}$ (mnHg) } \\
\hline Sham vehicte & $23.5 \pm 0.8$ & $23.2 \pm 0.7$ & $23.1 \pm 0.9$ & $23.2 \pm 1.0$ \\
\hline Sham phentolamine & $25.6 \pm 1.2$ & $256 \pm 13$ & $26.9 \pm 1.3$ & $24.9 \pm 0.5$ \\
\hline Asphyyxia vehicle & $24.4 \pm 0.7$ & $8.2 \pm 1.15$ & $26.8 \pm 1.2^{*}$ & $24.2 \pm 1.4$ \\
\hline Asphyxia phentolanine & $23.6 \pm 1.6$ & $90 \pm 1.25$ & $23.8 \pm 1.9$ & $245 \pm 1.2$ \\
\hline \multicolumn{5}{|l|}{ Lactate (mnol) } \\
\hline Sham vehicle & $0.82 \pm 0.1$ & $0.81 \pm 0.1$ & $0.87 \pm 0.2$ & $0.85 \pm 0.1$ \\
\hline Sham phentolamine & $0.73 \pm 0: 0$ & $0.75 \pm 0.2$ & $0.72 \pm 0.1$ & $0.76+0.1$ \\
\hline Asplnyia vehicle & $0.74 \pm 0.1$ & $6.11 \pm 0.25$ & $3.71 \pm 0.7 \neq$ & $2.56 \pm 0.5 t$ \\
\hline Asphyxia phentolamine & $0.88 \pm 0.1$ & $6.02 \pm 0.28$ & $1.90 \pm 0.4^{*}$ & $1.15 \pm 0.5$ \\
\hline \multicolumn{5}{|l|}{ Glucose (mmol) } \\
\hline Sham vehicle & $1.03 \pm 0.1$ & $1.02 \pm 0.1$ & $1.09 \pm 0.1$ & $1.03 \pm 0.1$ \\
\hline Sham phentolamine & $0.91 \pm 0.1$ & $0.93 \pm 0.1$ & $0.80 \pm 0.1$ & $0.64 \pm 0.1 *$ \\
\hline Asphyxi vehicle & $1.07 \pm 0.1$ & $0.59 \pm 0.1 \dagger$ & $1.25 \pm 0.1$ & $1.28 \pm 0.1$ \\
\hline Asphysia phentolamine & $0.90 \pm 0.1$ & $0.40 \pm 0.1 \pm$ & $1.02 \pm 0.1$ & $0.96 \pm 0.1$ \\
\hline
\end{tabular}

Data ale mean $\pm 5 E M, P<0.05{ }_{8}, p<0.01 \uparrow, P<0.005$ \#, $P<0.0015$, compared to sham vehicle group values 
Hypoperfusion was associated with a significant increase in vascular resistance $(8.6 \pm 2.6 \mathrm{w} .3 .3 \pm 0.4$ $\mathrm{mmHg}\left(\mathrm{min} \mathrm{m}^{1}\right)^{-1}$, compared to sham vehicle, $P<0.005$ ). This first period of hypoperfusion was followed by a transient return to basal values; maximal at $3.5 \mathrm{~h}$, before falling significantly again between 4.5 and $7.5 \mathrm{~h}(P<0.05)$ and then returning again to baseline before seizures started. This. secondary decrease in SMABF was also associated with a small, but significant rise in vascular

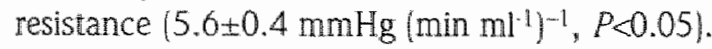

In the asphyxia phentolamine group there was a transient rise in SMABF, maximal at 20 min after

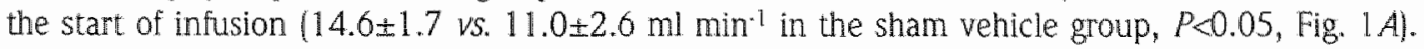
This was associated with a small but significant drop in vascular resistance $(1.9 \pm 0.4 \mathrm{vs} .3 .4 \pm 0.4 \mathrm{mmHg}$ $\left(\text { min } \mathrm{ml}^{-1}\right)^{-1}$, compared to the sham vehicle group, $P<0.05$ ). Thereafter SMABF was not significantly different to sham vehicle group values, despite a tendency to rise between 1.5 and $2.5 \mathrm{~h}$; this rise was similar to that seen in the asphyxia vehicle group, but occurred earlier (maximal at $2 \mathrm{~h} v \mathrm{hs} .3 .5 \mathrm{~h}$ ). In the sham phentolamine group, phentolamine infusion produced a transient but modest rise during the first 15 min of infusion, followed by a slight reduction in flow between $1-3$ hours (coincidental with the transient fall in FHR seen in this group after initial tachycardia, Fig. 4B), but there were no overall significant differences between the sham vehicle and sham phentolamine groups (Fig. 1B).

During seizures SMABF fell in the asphyxia vehicle group from $11.4 \pm 2.7 \mathrm{ml} \mathrm{min}^{-1}$ to a nadir of

\begin{tabular}{|c|c|c|c|c|}
\hline 6 hours & 8 hours & 24 hours & 48 hours & 72 hours \\
\hline $7.39 \pm 0.0$ & $7.38 \pm 0.0$ & $7.38 \pm 0.0$ & $7.37 \pm 0.0$ & $7.37 \pm 0.0$ \\
\hline $7.39 \pm 0.0$ & $7.39+0.0$ & $7.38 \pm 0.0$ & $7.38 \pm 0.0$ & $7.38 \pm 0.0$ \\
\hline $7.4 .2 \pm 0.0^{\star}$ & $739 \pm 0.0$ & $7.38 \pm 0.0$ & $7.38 \pm 0.0$ & $7.37 \pm 0.0$ \\
\hline $7.40 \pm 0.0$ & $7,36 \pm 0.0$ & $7.38 \pm 0.0$ & $7.38 \pm 0.0$ & $7.37 \pm 0.0$ \\
\hline & 3 & & & \\
\hline $48.8 \pm 2.0$ & $49.7 \pm 1.6$ & $47.5 \pm 1.9$ & $48.7 \pm 1.8$ & $48.3+2.8$ \\
\hline $47.1 \pm 3.7$ & $46.2 \pm 2.6$ & $48.0 \pm 2.3$ & $49.0 \pm 3.2$ & $45.7 \pm 2.0$ \\
\hline $43.0 \pm 1.0^{*}$ & $48.3+1.1$ & $44.8 \pm 1.8$ & $45.3 \pm 0.8$ & $44.3 \pm 1.2$ \\
\hline $47.5 \pm 2.0$ & $46.7 \pm 1.8$ & $46.1 \pm 0.7$ & $46.1 \pm 0.7$ & $44.9 \pm 0.7$ \\
\hline $23.4 \pm 0.7$ & $23.3 \pm 0.9$ & $24.9 \pm 0.9$ & $24.9 \pm 1.4$ & $25.0 \pm 1.1$ \\
\hline $25.0 \pm 0.7$ & $25.3 \pm 0.8$ & $26.0 \pm 1.2$ & $27.8 \pm 2.7$ & $25.4 \pm 1.0$ \\
\hline $24.8 \pm 1.0$ & $26.8 \pm 0.9^{*}$ & $28.4 \pm 0.9^{*}$ & $28.7 \pm 0.8^{*}$ & $29.1 \pm 1.2$ \\
\hline $25.8 \pm 2.3$ & $27.4+2.2$ & $28.0 \pm 1.2$ & $28.0 \pm 1.2$ & $28.1 \pm 1.6$ \\
\hline $0.86 \pm 0.1$ & $1.15 \pm 0.2$ & $0.66 \pm 0.2$ & $0.75 \pm 0.1$ & $0.85 \pm 0.1$ \\
\hline $0.75 \pm 0.0$ & $0.82 \pm 0.1$ & $0.65 \pm 0.1$ & $0.74 \pm 0.1$ & $0.78 \pm 0.0$ \\
\hline $1.83 \pm 0.3^{*}$ & $2.03 \pm 0.5$ & $0.95 \pm 0.1$ & $0.73 \pm 0.1$ & $0.83 \pm 0.1$ \\
\hline $1.25 \pm 0.4$ & $0.67 \pm 0$. & $0.64 \pm 0.0$ & $0.64=0.0$ & $0.72 \pm 0.1$ \\
\hline $1.07 \pm 0.1$ & $1.19+0.2$ & $1.15 \pm 0.1$ & $1.16 \pm 0 . \hat{1}$ & $1.16 \pm 0.1$ \\
\hline $0.88 \pm 0.1^{*}$ & $0.90 \pm 0: 1$ & $0.83 \pm 0.1$ & $0.94 \pm 0.1$ & $0.93 \pm 0.1$ \\
\hline $1.36 \pm 0.1$ & $1.52 \pm 0.2$ & $1.43 \pm 0.1$ & $1.24 \pm 0.1$ & $1.18 \pm 0.1$ \\
\hline $0.97 \pm 0.1$ & $109 \pm 0.1$ & $1.07 \pm 0.1$ & $1.07 \pm 0.1$ & $1.09 \pm 0.1$ \\
\hline
\end{tabular}



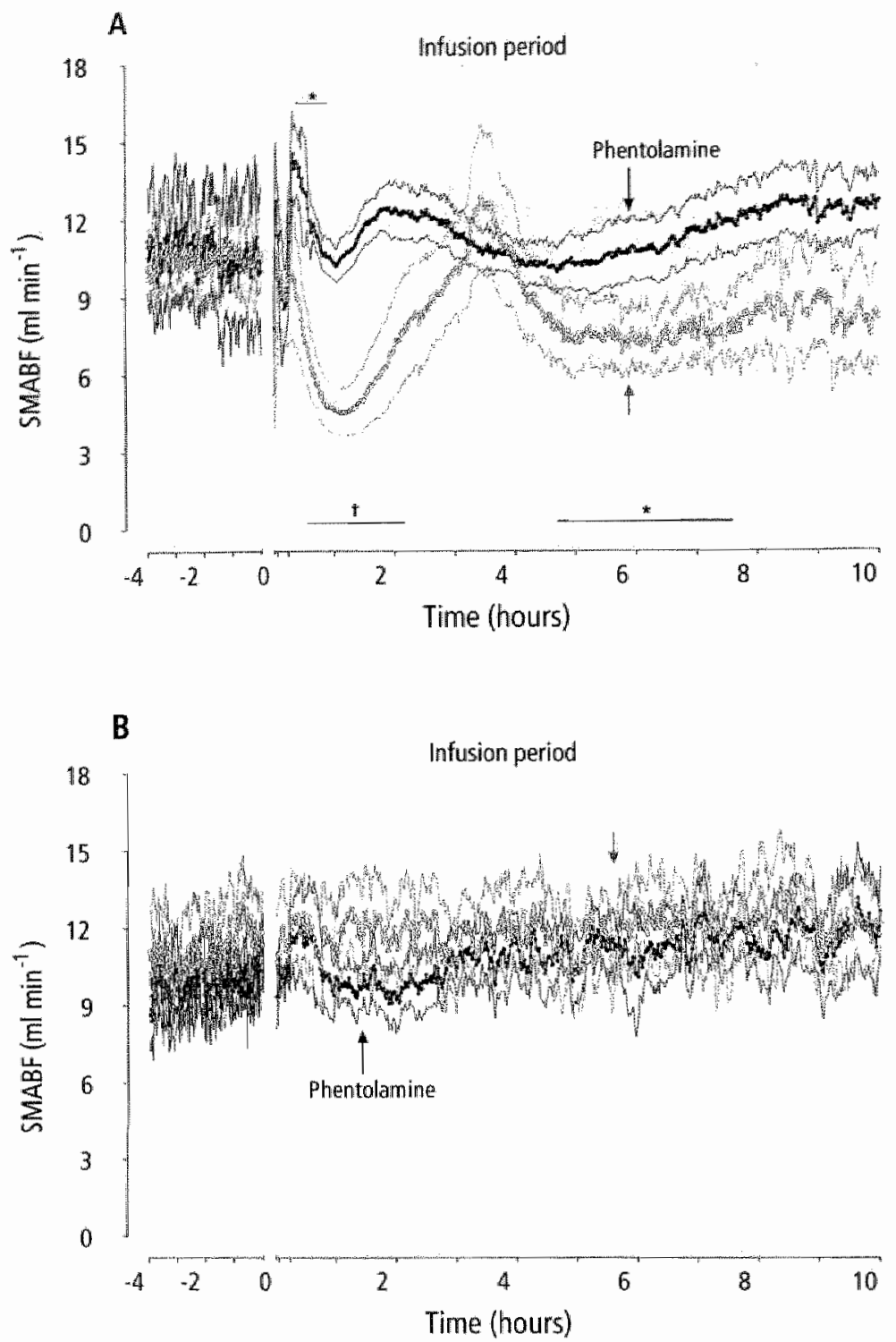

Figure 1. Time sequence of changes in superior mesenteric artery blood flow (SMABF) during the four hours prior to occlusion and for ten hours post acclusion.

Pand A shows the responses of the asphyxia vehicle group lopen circles) and the asphyxia phentoiamine group (closed circies. The groups are further denoted by arrows. Note the biphasic fall in SMABF in the vehicle group, interrupted by a uansient period of vasodilatation. phetitolamine causes an initial vasodilatation, but the secondary hypoperfusion phases are prevented. The same transient vasodiatation seen in the asphyxia vehicle group also accurs in the phentolamine group, but the response occuis earlier. Panel B shows the SMABF responses of the sham vehicle group (open circles) and sham phentolamine group (closed circles) showing no differences between groups. Data are one min averages, mean \pm SEM, ${ }^{*} P<0.05,+P<0.01$ compared to sham vehicie group. The axis break denotes the period of ocelusion, not shown. 
Figure 2. Examples of changes in electroencephalographic (EEG), nuchal electromyographic (EMG), mean arterial blood pressure (MAP) and superior mesenteric artery bload flow (SMABF) during seizures.

Data are one min averages from single fetuses recorded over two hours three hours after seizures had begun. Panel A shows the response of an asphyxia vehicle group felus demonstrating marked vasoconstriction and increased blood pressure during seizures. Panel $B$ shows the response of an asphyxia phentolamine group fetus showing abolition of both the blood flow and blood pressure responses to each seizure.
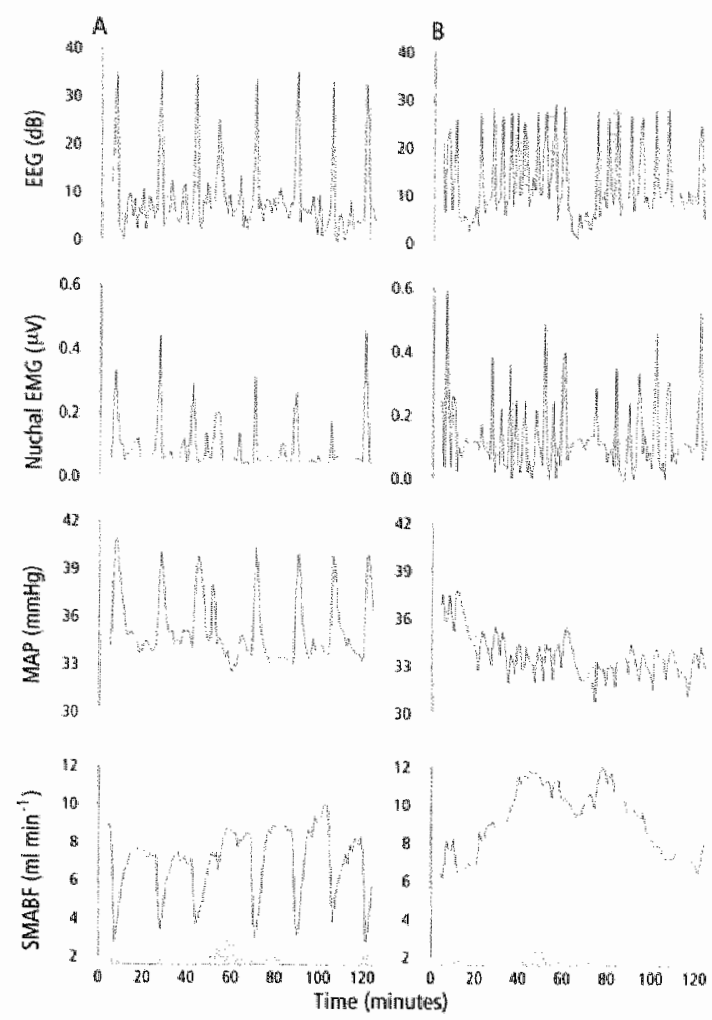

$8.3 \pm 2.3 \mathrm{ml} \mathrm{min} \mathrm{m}^{-1}(P<0.005$, Fig. $2 A)$; regardless of whether electrographic seizures were present. SMABF was more than $10 \%$ below baseline for $13.0 \pm 1.7$ min per seizure ( $v s$. seizure duration of $78.1 \pm 7.2 \mathrm{sec}$ ). The fall in SMABF was associated with a significant increase in SMA vascular resistance

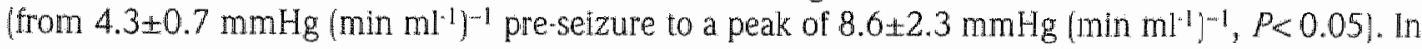
contrast there was no change in SMABF in the asphyxia phentolamine group during any seizures $\left(9.0 \pm 1.4 \mathrm{vs} .8 .6 \pm 1.4 \mathrm{ml} \mathrm{min}^{-1}\right.$, Fig. $\left.2 \mathrm{~B}\right)$ and no significant change in resistance $(5.2 \pm 1.1 \mathrm{vs} .5 .4 \pm 1.3$ $\mathrm{mmHg}\left(\mathrm{min} \mathrm{ml}^{-1}\right)^{-1}$. No seizures occurred in the sham occlusion groups.

\section{Blood pressure}

There was no significant difference in MAP between groups before and between the asphyxia groups during occlusion. In the asphyxia vehicle group an initial transient period of hypertension immediately post-occlusion $(P<0.001$, Fig. $3 A)$ was followed by a period of sustained elevation of pressure between $30 \mathrm{~min}$ and $3 \mathrm{~h}$ after the start of infusion $[41.0 \pm 1.0 \mathrm{vs} .36 .0 \pm 0.8 \mathrm{mmHg}$ in the sham vehicle group, $P<0.05$ ). Thereafter MAP returned to basal values until seizures started. During seizures MAP increased during individual seizure episodes from $36.3 \pm 0.4$ to $42.0 \pm 0.9 \mathrm{mmHg}(P<0.005$, Fig. 2A).

In the asphyxia phentolamine group MAP was also significantly increased immediately postocclusion $(P<0.001$, Fig. $3 A)$ but pressure fell rapidly at the onset of infusion and was reduced for 3 $\mathrm{h}$ after the start of infusion $(33 \pm 1.6 \mathrm{vs} .36 .7 \pm 0.8 \mathrm{mmHg}$ in the sham vehicle group, $P<0.005)$. There was a notable secondary fall in pressure at starting at $1.8 \mathrm{~h}$ post-occlusion for $54 \mathrm{~min}$ (nadir of $30.4 \pm 2.1$ 


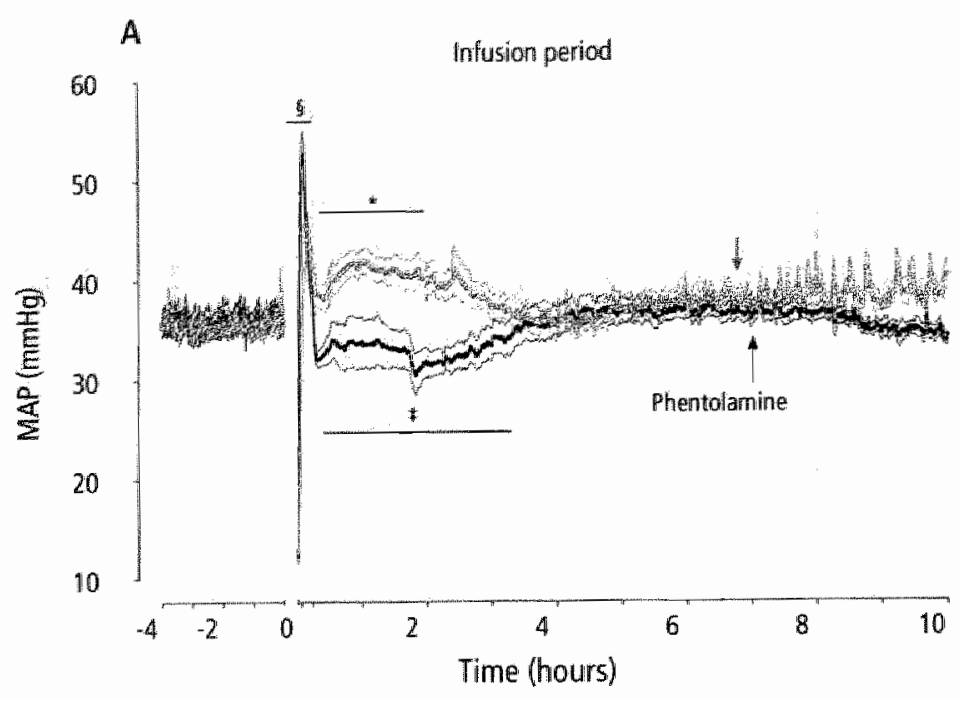

B

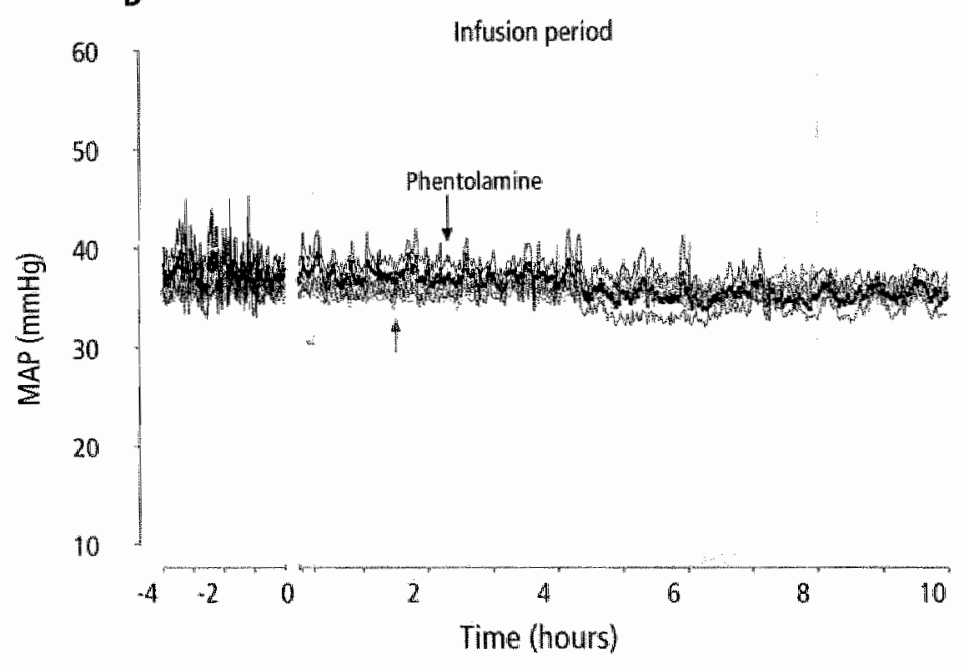

Figure 3. Time sequence of changes in mean arterial bload pressure (MAP) during the four hours prior to occlusion and for ten hours post-occlusion.

Panel $A$ shows the responses of the asphyxia vehite group (open circles) and the asphyyxia pheniolamine group (closed circles]. The groups are further denoted by arrows. Note the lower blood pressure in the phentolamine group compared to vethcte intusion, and the subsequent further fall in blood pressire corresponding with the transient vasodilatation seen in the phentolamine group in figure 1. Similarly MAP falls in the vehicle group during the same period of vasocilatation, but at a slighty later time. Panel $B$ shows the MAP responses of the sham vehicle group (open circles] and sham phentolamine group (closed circles) showing no differences between groups. Data are one min averages, mean $S E M, * P<0.05, * P<0.005, \$ P<0.001$ compared to sham vehicle group. The axis break denotes the period of occlusion, not shown. 

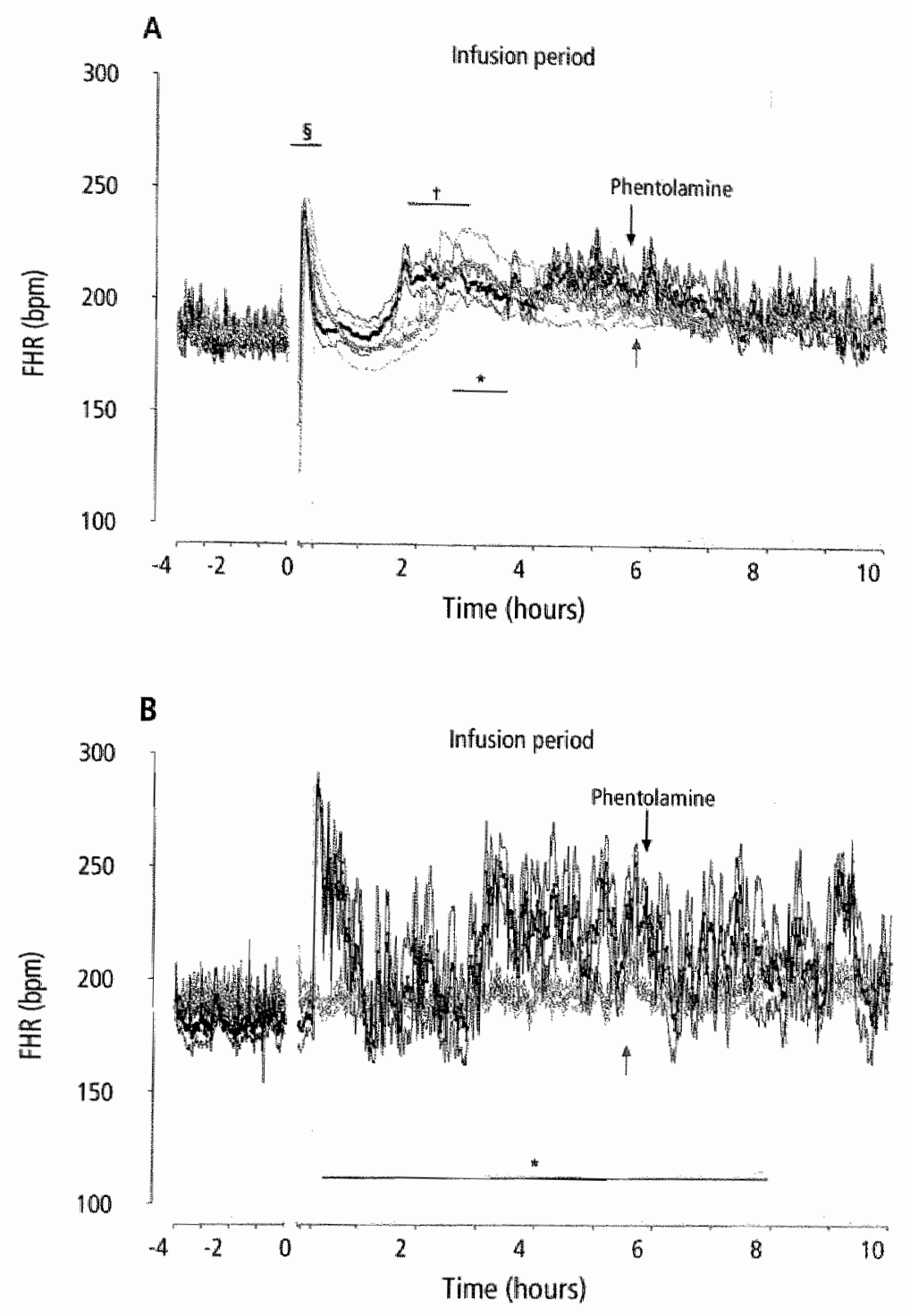

Figure 4. Time sequence of changes in fetal heart rate (FHR) during the four hours prior to occlusion and for ten hours post occlusion.

Panel A shows the responses of the asphyxia wehicle group (open circles) and the asphyxia phemtolamine group (closed circles). The groups are further clenoted by arrow. Both groups had a stmilar inittal response, but note the earlier onset of tacthycardia in the phentolamine group at around 2 hours post-occlusion, corresponding with the transient period of increased SMABF shown in figure 1. Note also the increase in FHR after four hours th this group, cortesponding with the appearance of seizures. Panel $B$ shows the FHR responses of the sham vehicle group (open circles) and sham phentolamine group (closed circles). Note the tachycardia observed with phentolamine infusion alone which is not seen in the asphyxia phentalamine group in panel $A$. Data are mean $S_{S E M} * *<0.05,+p<0.01, \$ P_{<} 0.001$ compared to sham vehicle group. The axis break denotes the period of umbilical cord occlusion, not shown. 
$m m H g ; P<0.0011$, thereafter MAP progressively returned to baseline. During seizures there were no significant changes in MAP during phentolamine infusion (Fig. $2 B$ ). There was no difference in MAP between sham occlusion groups (Fig. 3B).

\section{Fetal heart rate}

In the asphyxia vehicle group, after a transient period of rebound tachycardia during the first $10 \mathrm{~min}$ post-occlusion $(P<0.001$, Fig. $4 A$ ), FHR returned to sham vehicle group values until $1.6 \mathrm{~h}$ when FHR slowly began to rise again, increasing abruptly at $2.2 \mathrm{~h}$ for 54 min $\left(220.0 \pm 15\right.$ beats min ${ }^{-1}$ (bpm) vs. $183.4 \pm 4.4 \mathrm{bpm}$ in the sham vehicle group, $P<0.05$ ). FHR then gradually returned to baseline until seizures started. There were no significant changes in FHR during seizures.

In the asphyxia phentolamine group FHR followed a similar but time shifted pattern to the asphyxia vehicle group. Rebound tachycardia $(P<0.001$, Fig $4 A)$ was followed by a transient return to baseline for $1.45 \mathrm{~h}$ then after a gradual rise FHR rose abruptly for $67 \mathrm{~min}(209.9 \pm 7.0 \mathrm{bpm} v \mathrm{vs} .183 .6 \pm 5.6 \mathrm{bpm}$ in the sham vehicle group, $P<0.005$ ), thereafter FHR was variably increased as a function of seizures rising significantly to $219.7 \pm 8.5 \mathrm{bpm} v$ s. an interseizure baseline of $189.0 \pm 3.2, P<0.05)$. Phentolamine infusion alone significantly increased FHR during the first hour (maximal at $5 \mathrm{~min}$ of infusion; $282.4 \pm 0.6 \mathrm{vs}$. sham vehicle group values of $189.4 \pm 5.5 \mathrm{bpm}, P<0.001$, Fig $4 \mathrm{~B}$ ), thereafter the changes in FHR were variable, but there was a significant effect of treatment over time compared to the sham vehicle group $(P<0.05)$.

\section{EEG, EMG and seizure activity}

EEG amplitude was rapidly suppressed at the onset of occlusion in both groups, and remained significantly suppressed $15.3 \pm 0.9 \mathrm{vs} .45 .6 \pm 5.8 \mu \mathrm{V}$ in the sham vehicle group and $5.4 \pm 0.9$ vs. $43.6 \pm 6.7 \mu \mathrm{V}$ in the sham phentolamine group, $P<0.001$ both groups) except between 9 and $18 \mathrm{~h}$ in the asphyxia wehicle group and 6 and $14 \mathrm{~h}$ in the asphyxia phentolamine group when EEG amplitude increased due to seizures.

The onset of seizures occurred significantly earlier in the asphyxia phentolamine group compared to the asphyxia vehicle group $(5.01 \pm 0.4 \mathrm{~h}$ vs. $7.1 \pm 0.7 \mathrm{~h}$ respectively, $P<0.05)$. There were no significant differences, however, in the total seizure duration $(15.5 \pm 3.5 \mathrm{~h} v \mathrm{vs} .23 .2 \pm 3.7 \mathrm{~h}$, asphyxia vehicle vs. asphyxia phentolamine), total number of seizures ( $56.0 \pm 10.0 \mathrm{vs} .73 .2 \pm .28 .0$ ), number of seizures per hour ( $3.1 \pm 0.7$ vs. $4.2 \pm 1.3)$, intensity of individual seizures $(118.2 \pm 20.8$ vs. $172.0 \pm 25.3$ $\mathrm{HV})$ and duration of individual seizures $[78.1 \pm 7.2 \mathrm{sec} v \mathrm{vs} .76 .8 \pm 12.0 \mathrm{sec})$. All fetuses in the asphyxia groups had electrographic evidence of seizures (Figs. $2 A$ and $B$ ), except one fetuses in the asphyxia vehicle group where there was only cardiovascular and nuchal EMG evidence of seizure activity. There were no seizures in the sham groups. Nuchal EMG activity was present during $75.0 \%(73,81)$ of seizures in the asphyxia vehicle group, and $80.0 \%(79,88)$ of seizures in the asphyxia phentolamine group (Fig. 2A and $B$ ).

\section{DISCUSSION}

This study demonstrates for the first time that the sympathetic nervous system is a key mediator of delayed gastrointestinal hypoperfusion during recovery from an asphyxial insult in preterm fetal sheep. Prevention of this delayed hypoperfusion by alpha-adrenergic blockade significantly impaired fetal blood pressure during the early recovery phase after asphyxia. Further, it confirms that sympathetic activity mediates the fall in gut blood flow during post-asphyxial seizures in the immature fetus. 
Interestingly gut blood flow remained markedly suppressed for several minutes after resolution of each seizure indicating that sympathetic activation was not simply a non-specific effect of the epileptic discharge. Thus while post-asphyxial seizures were brief and infrequent compared to those seen at term, their impact on gut blood flow was marked.

Secondary hypoperfusion is known to develop in many vascular beds after ischaemic insults both pre-and postnatally, typically in the first few days after an insult (Conger \& Weil, 1995). The duration and speed of onset, and to a lesser extent the degree of the hypoperfusion, are reported to be related to the severity of the insult, at least in the brain where the phenomenon has mostly been assessed (Karlsson et al., 1994; Huang et al., 1999). The underiying factors which mediate this phenomenon remain the subject of research. Proposed hypotheses include endothelial dysfunction, disturbed blood/vessel wall interactions and reduced metabolic demand (Hossmann, 1997; Reber et al., 2002; Ten \& Pinsky, 2002). The current study shows that for the preterm fetal sheep gut after asphyxia, hypoperfusion is not related to hypotension, but rather is primarily related to a sympathetically mediated increase in vascular resistance. Both the relative rapidity of the changes in flow and its variable nature, with a transient reduction in vasoconstriction between two and four hours postasphyxia in both groups, argues against the reduction in blood flow being due to passive vascular dysfunction.

The physiological significance of this apparently active, and relatively prolonged period of hypoperfusion of the gut during the latent phase of recovery after asphyxia is unknown, however, we may hypothesise that its purpose is to maintain systemic perfusion pressure. In the aduit under conditions of decreased cardiac output caused by cardiogenic or hypovolaemic shock, selective vasoconstriction of the afferent mesenteric arterioles is reported to be crucial in sustaining total systemic vascular resistance, thereby maintaining systemic arterial pressure (Reilly et at, 2001; Ceppa et al., 2003). Under these conditions, while there is some degree of vasoconstriction in other peripheral systems, it is disproportionately greater within the mesenteric circulation, and thus perfusion of non-mesenteric organs is maintained at the expense of the gut (Reilly et al., 2001; Ceppa et al, 2003). Similarly, in the fetal sheep marked constriction of the mesenteric bed occurs during acute asphyxia to facilitate redistribution of combined ventricular output in favour of central organs (Jensen et al, 1987a; Yaffe et al., 1987; Bennet et al, 2000), but its role during post-asphyxial recovery has not been evaluated.

Although myocardial histology and function were not able to be directly evaluated in the present study there is considerable clinical and experimental evidence to show that reversible myocardial injury and associated cardiac dysfunction are common during recovery from exposure to perinatal asphyxia (Gunn et al., 2000; Lumbers et al., 2001; Hunt \& Osborn, 2002). Consistent with the hypothesis of early myocardial dysfunction, in the current study phentolamine infusion led to a reduction in blood pressure for three to four hours despite normalisation of SMA blood flow for most of this period. This is in contrast with the significant elevation seen in the asphyxia vehicle group, which was associated with an increase in SMA vascular resistance. This hypothesis is further supported by the fall in blood pressure observed in the asphyxia vehicle group during the period of spontaneous gastrointestinal vasodilatation around four hours postasphyxia, which was followed by a modest increase in pressure during the second period of hypoperfusion between five and seven hours. Currently it is unclear what is mediating this transient rise in blood flow. It may be related to a reduction in sympathetic tone, however, other factors are likely to play a role in mediating both the vasoconstriction and vasodilatation. Nitric oxide (NO), for example, is known to be an important modulator of perfusion in the preterm gut (Fan et al, 1998; Reber et al., 2002), and is also known to modulate sympathetic activity (Prast \& Philippu, 2001). Additionally, NO can also alter vascular 
reactivity at the sympathetic neuroeffector junction in the rat mesenteric bed by deactivating noradrenaline (Kolo et aL, 2004). There may also be similar roles for other neurotransmitters and peptides such as NPY (Sanhueza et al., 2003; Kolo et al., 2004).

Finally, it is striking that in the sham phentolamine group, phentolamine infusion was associated with a marked inmediate tachycardia, but no change in blood pressure. Subsequently FHR varied but on average was elevated for the remainder of the infusion period. Since in the fetus stroke volume is relatively fixed and therefore changes in combined ventricular output are primarily dependent on changes in FHR, this finding strongly implies that under normal conditions that the fetus responds to the fall in SMA resistance during alpha-adrenergic blockade with an increase in combined ventriculat output to prevent hypotension. Conversely, the transient return of FHR to baseline between two to three hours in this group was associated with an increase in resistance and a fall in SMA blood flow. In marked contrast, there was no increase in FHR in the asphyxia phentolamine group in response to the start of phentolamine, and when FHR was elevated at around two to three hours, at the same time as SMA vasodilatation, pressure fell abruptly. These data suggest a limited ability to increase combined ventricular output after asphyxia, consistent with myocardial dysfunction, and further highlight the requirement for peripheral vasoconstriction for pressure support.

The other major findings of the present study are that post-asphyxial seizures in the preterm sheep fetus are also associated with mesenteric vasoconstriction, and that the SNS plays a key role in mediating this phenomenon. In the human newborn, post-asphyxial seizures generally occur within a few hours of birth (Scher, 1997), however, under some circumstances seizures may also start in utero (Osiovich \& Barrington, 1996; Ingemarsson \& Spencer, 1998; Westgate et al, 1999; Patane \& Ghidini, 2001 ), and then continue after delivery (Keogh et al, 2000). The present study is the first to report the appearance of stereotypically evolving seizures in the preterm fetal brain. We have previously reported that such seizures do not develop at 0.6 of gestation (Bennet et al., 1999) and it is likely that the appearance of seizures at 0.7 gestation reflects changes in neuranal development such as the onset of cortical myelination (Barlow, 1969).

Neonatal seizures in preterm infants are classically described as being brief and subtle, sometimes composed of unusual behaviours which are difficuit recognise and classify and thus typically EEG analysis is required to confirm their presence (Scher et al., 2003). In part, because such EEG monitoring has not been routine during the early recovery period (Hellstrom-Westas et al., 1995; Caravale et at, 2003; Scher et al., 2003) there have been limited studies of the impact of seizures on cerebral circulation in preterm infants (Perlman \& Volpe, 1983; Boylan et al, 2000), and none which have evaluated peripheral blood flow. The present study demonstrates that seizures were brief and relatively infrequent events which caused marked vasoconstriction of the gut. This vasoconstriction was mediated by sympathetic activity, with complete abolition of the reduction in SMA blood flow during each seizure by alpha-adrenergic blockade. However, while the seizure duration was short it was notable that the impact on the gut was longer lasting, with blood flow to the gut reduced for longer than the seizure duration itself, with a corresponding elevation in MAP. Speculatively this prolonged effect may help support perfusion of critical organs, such as the brain, until cerebral metabolism fully recovers after each seizure. Further, our data support a role for the sympathetic nervous system in modulating seizure activity in the preterm sheep fetus. Postnatally, the SNS is well known to play a role in modulating the threshold for seizures. Endogenous noradrenaline is an anticonvulsant neurotransmitter, and blockade of aipha- and beta-adrenoreceptors potentiates seizures (Weinshenker \& Szot, 2002). Consistent with this, in the current study, the mixed alpha-receptor blocker phentolamine was associated with significantly earlier onset of stereotypic evolving seizures but no change in their amplitude, frequency or total duration. 
In conclusion, the present study confirms the hypothesis that delayed post-asphyxial hypo-perfusion of the gut is mediated by alpha-adrenergic activity. The data highlight the importance of endogenous sympathetic activity in maintaining the initial elevation of blood pressure after asphyxia and are consistent with the hypothesis that the mesenteric system is a key resistance bed that helps to support perfusion in other, more vulnerable systems. Further, this study has shown that seizures develop after asphyxia in the premature fetus at 0.7 gestation and that these seizures are associated with a significant impact on blood flow to the fetal gut. Postnatally, perfusion of the mesenteric circulation is tightly linked with gut function. Thus although the hypoperfusion seems to be responsive rather than a consequence of local injury, we may predict that it will be associated with gastrointestinal disturbances and delayed adaptation to postnatal life (Coombs et al., 1990; Malcolm et al., 1991; Coombs et al., 1992; Akinbi et al., 1994).

\section{ACKNOWLEDGEMENTS}

We acknowledge the support of the Auckland Medical Research Foundation, Lottery Grants Board of New Zealand, The National Institutes of Health, USA (HD32752) and the Health Research Council of New Zealand. JO was supported by the Foundation "De Drie Lichten" in The Netherlands. 


\section{REFERENCES}

Akimbi H, Abbasi S, Mipert PL \& Bhutani VK I 1994). Gastrointestinal and renal blood low welocty profle in neondes with birth asphyxia. / Pediatr $125,625-627$.

Barlow RM 1969). The foetal sheep: morphogenesis of the nervous system and histochemical aspects of myeination. J Comp Nourol $135,249.262$

Batmgarmer C, Lurger S \& Leutmezer F (200 1). Autonomic smptoms during epleptic seizures. Epheptic Bisoro 3 , $103-116$

Bennet L, Ouaedackers IS, Gunn AJ, Rossenrode S\& Heineman E 2000). The eflect of asphyxia on superor mesenteric antery blood fow in the premature sheep letus. J Pediat Surg $35,34.40$.

Bennet L, Rossenrode S, Guning M, Gluckman PD \& Gun A (1999). The cardiovascular and cerebrovascula: responses of the immature fetal sheep to acute umbilical cord occlusion. I Physol (Lond/ $517,247.257$.

Soylan GB, Young K, Panerai RB, Rennie JM \& Evans DH 120001 . Dymamic cerebral autoreguation in sick newbom infants. Pediats Res 48,1217 .

Caravale B, Allemand F \& Libenson MH (2003). Factors predictive of seizures and neurologic ontcome in permatal depression. Pedate Neurol 29, 1825.

Ceppa EP, Fuh KC \& Bulkey GB (2003). Mesenteric hemodynamic response to circulatony shock. Cun Opin Crit Care $9,127-132$.

Conger JD \& Weil JV (1995). Abnomal wascular function following ischemiareperfusion injury. / Mvestig Med 43, 431 442.

Coombs RC, Morgan ME, Durbin GM, Booth IW \& MCNeish AS (1990). Gut blood llow velocites in the newborn: effects of patent ductus arteriosus and parenteral indomethacin. Afch Dis Child 65, 1067-1071.

Coombs RC, Morgan ME, Durbin GM, Booth IW \& McNeish AS (1902). Abnomal gut blood flow velocities in neonates at risk of necrotising enterocolitis. J Pediat Gastroenterol Wut $15,13.19$.

Doba $N$, Beresford HR \& Reis D) (1975). Changes in regional blood flow and cardiodymamics associated with electrically and chemically induced epilepsy in cat. Brain Res $90,115.132$.

Fan WO, Snolich II, Wild J, Yu WX \& Walker AM (1998). Major wasodilator role For nitric oxide in the gastrointestinal circulation of the midgestation fetal lamb. Pediatr Res 44, 344-350.

Giussani DA, Spencer IA, Moore PJ, Bennet L \& Hanson MA (1993). Afferent and efferent components of the cardiowascular reflex responses to acute hypoxia in term fecal sheep. I phystol (Lond) $461: 431 \cdot 49,431 \cdot 449$.

Gold L. \&aurizen M (2002). Neuronal deacivation explains decreased cerebelan blood flow in response to focal cerebral ischemia or suppressed neocortical function. Froc Nat Acad SC U S A 90, 7009-7704.

Cum A. Marwell L, de Haan HH, Bennet L, Whllams CE, Gluckman PD, el al. (2000). Delayed hypotension and subendocardial injury after repeated umbilical cond occlusion in nearerm fotal lambs. Am fobstet Gyecol 183. 1504.1572 .

Hellstrom. Westas $L$, Rosen I \& Swenningsen NW (1095). Predictive value of early continuous amplitude integrated EEC recordings on outcome after severe birth asphyxia in full term. infarts. Arch Dis Chid Fetal Meonatal fat $72,134$. 38.

Hossmann KA 1907 . Reperfusion of the brain atter global ischemia: hemodynamic disturbances. Shock 8,95101 ; discussion $102-103$.

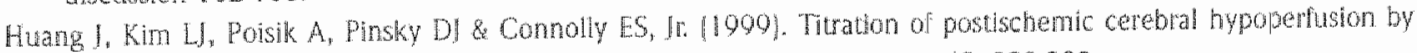
variation of ischemic severity in a murine model of siroke. Neurosurgery 45,328333 .

Hunt $R$ \& Osborn D 2002 . Dopamine for prevention of morbidty and mortalify in term newbom intants with suspected perinatal asphyxia. Cochrarye Database Syst Rev, CDO03484.

Ingenarsson I \& Spencer IA (1908). Fetal seizure activity associated with lethal cerebral damage at birth two cases. Ack Obstet Gyecol Scand 77, 127.129. 
Wwamoto HS, Rudow AM, Mirkn BL Geil LC (1983). Circuhtory and humoral responses of symathectomized tetal

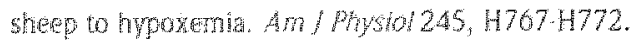

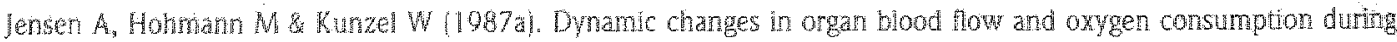
acute asphyia in Feal sheep. I Dev Physor $0,543-550$

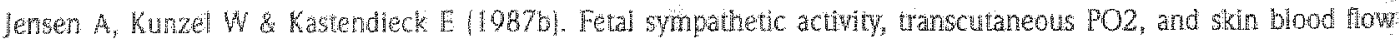
during repeated asphyxia in sheep. / Dev Bhysiol $0,337-346$.

Jensen $A$ \& Lang U (1992). Fetal circulatory responses to arrest of uterine blood low in sheep: effects of chemical

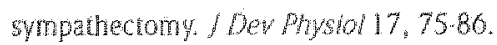

Karinow A P Pnsky D) (200!). The endothellat response to oxygen deprivation: biology and chincal implications Intensive Care Med27, 1931 .

Karlsson BR, Grogaand B, Gerdin B \& Steen PA (1994). The severily of postischemic hypoperfusion increases with duration of cerebral ischemia in mats. Acka Araesthestol $5 \mathrm{cand} 38,248253$.

Keogh IM, Badawi N, Kurinczuk J, Dixon G, Jongeling B \& 5tanley W] 2000]. Maternal awareness of fetal seizures in pregnancles resuiting in newborn encephalopathy. Acla Obstei Gyecol Scand $79,787789$.

Kolo LL, Westal "TC \& Macarthur H 12004 . Nitric oxide decreases the blological activity of norepinephrine resulting in altered vascular fone in the rat nesenteric arterial bed. An J Physol Heart Circ Physiol $280, \mathrm{H} 296-303$.

Kreisman NR, GautherLewis ML, Conkhn SG, Voss NF \& Barbee RW (1993). Cardiac output and regional hemodynanics during recurtent seizures in rats. Brain Res 626, 205-302.

Lumbers ER, Gum Al, thang DY, Wu IJ, Maxwell. L \& Bennet L $2001 \%$. Nonimmune hydrops fetalis and activation of the reninangiotensin system ater asphwia in pretern letal sheep. Am / Phystol Regul hiegr Comp Physiol 280 , R1045.R1051.

Malcolm G, Ellwood D, Devonald K, Beilby R \& Henderson-Smart D (1991). Absent on reversed end diastollc flow velocily in the umbilical artery and necrouling enterocolitis. Arch Dis Child 60, 805.807.

Michenfelder ID Milde IH (1900). Postischemic canine cerebral blood fow appears to be determined by cerebral melabolic needs. J Cereb Brood Flow Metab 10,71-70.

Mulder AL, Miedema A, De Mey JG, Gussant DA \& Blanco CE [2002]. Sympathetic control of the cardiovascular response to acute hypoxemia in the chick embryo. Am / Physiol Regul Integr Comp Prysiol 282, R1 156-R1103.

Nuwayhid B. Brinkman CR, SU C, Bewan JA \& Assali NS 1975 . Development of autonomic control of fetal cinculation. Ant l physiol 228, 337-344.

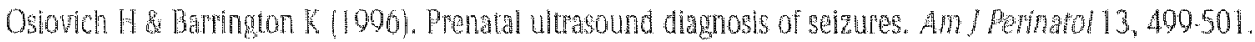

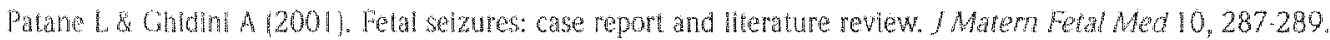

Paulck RP, Meyers RL, Rudolph CD \& Rudolph AM (1901). Hemodynamic responses to alpha adrenergic blockade during hypoxema in the feal tamb. J Dev Phstoh $16,63-69$.

Periman IM \& Wolpe II [1083]. Seizures in the preterm infant: effects an cerebral blood low welocity, intracranial pressurs, and arierial blood pressure./Pedatr 102,288203.

Prast H\& Phitppu A (2001). Nitric oxide as modulator of neuronal function. Prog Neurobiol 64, 51-58.

Reat $I B$ \& Bunstock $6[1070]$. Developement of the adrenergic innerwation and chromaffin celis in the human fetal gut Der Bol $22,513.534$.

Reber KM, Nankevis CA \& Nowicki PT (2002). Newborn intestral circulaton. Physiology and pathophysiology. Chn Perimol 20, 23.39.

Reily PM. Wikins KB, Fun KC. Hagund U \& Bukley GB 2001 . The mesenteric hemodynamic response to circulatory shodk an overview 5 hod $15,320-343$.

RobelTillg E, Vogtmann C \& Bennek J 2002). Prenatal hemodyamic distubances - pathophysiological background of intesinal motlity distubances in small for gestadional age infanis. Eur / pedatr Surg $12,175-179$.

Rouwet EV, De Mey IG, Stat DW, Heneman E, Ramsay $G$ \& Le Noble BA 2000 . Development of vasomotor responses

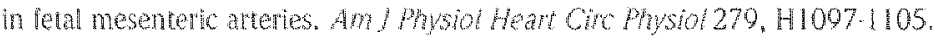




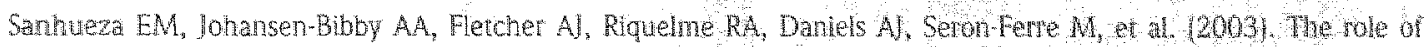

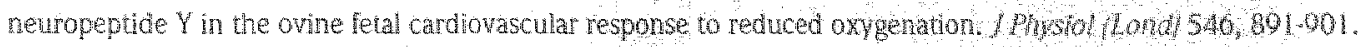

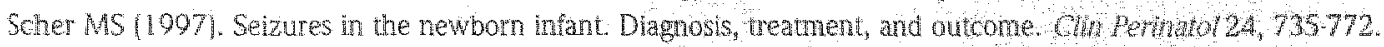

Scher MS, Awin J, Gaus L, Minnigh B \& Painter MU (2003). Unowpling of EEColinical neonatal seizures atter antiepheptic drug use. Peditr Neurol $28,277280$.

Scher MS, Hamid MY, Steppe DA, Beggary ME \& Panter MI (1993). Iotal and interictal electrogratuc selzure duratons in preterm and term neonates. Fplepsia 34,284288 .

Strodubck F (2003). The role of eary enteral mutition in protecting premature infants from sepsis. Crit Cate Murs Cha North Am 15, 79-87.

Ten VS \& Pnsky DI (2002). Endothelial response to hypoxia: physiologic adaptation and pathologic dystuncton. Cur Opin Crit Care $8,242,250$.

Weinshenker D \& Szot P (2002). The role of catecholamines in seizure susceptbility: new resuls using genetically engneered mice. Phamacol Ther $04,213 \cdot 233$

Westgate IA, Bennet L \& Gunn Al (1999). Fetal seizures causing increased heart rate waribiling dung terminal feial hypoxia. Am j Obstet Gnecol $181,765.760$.

Westgate JA, Bennet L. Gunn AJ (2002). Meconimm and fetal hypoxia: some experimental observations and cinical relevance. Br/ Obstet Gyaecol100,1171-1174.

Williams CE, Gumn A1, Mallard C\& Giuckman PD (1992). Outcome after ischemia in the developing sheep brain: an electroencephalographic and histological study. Ainn Neurol 31, 1421.

Yaffe $H$, Parer JT, Block BS \& Llanos A] (1987). Cardiorespiratory responses to graded reductions of uterine blood flow in the sheep fetus. / Dev Physiol $9,325-336$. 


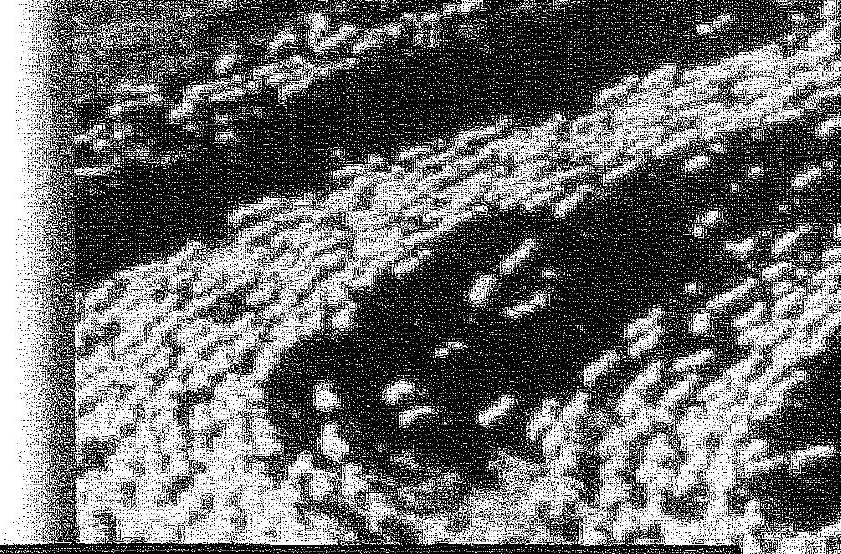

\section{Chapter 6}

\section{POLYURIA AND IMPAIRED RENAL BLOOD FLOW AFTER ASPHYXIA IN PRETERM FETAL SHEEP.}

I.S. Quaedackers, V. Roelfsema, C.J. Hunter, E. Heineman, A.J. Gunn, L. Bennet. American Journal of Physiology.

Regulatory, Integrative and Comparative Physiology. 2004 Mar;286(3):R570.83. 


\section{ABSTRACT}

Renal impairment is common in preterm infants, often after exposure to hypoxia/asphyxia or other circulatory disturbances. We examined the hypothesis that this association is mediated by reduced renal blood flow (RBF), using a model of asphyxia induced by complete umbilical cord occlusion for 25 min ( $n=13$ ) or sham occlusion $(n=6)$ in chronicaily instrumented preterm fetal sheep (104 days, term is 147 days). During asphyxia there was a significant fall in RBF and urine output (UO). After asphyxia, RBF transiently recovered, followed within $30 \mathrm{~min}$ by a secondary period of hypoperfusion $(P<0.05)$. This was mediated by increased renall vascular resistance (RVR, $P<0.05)$; arterial blood pressure was mildly increased in the first $24 \mathrm{~h}(P<0.05)$. RBF relatively normalized between 3 and $24 \mathrm{~h}$, but hypoperfusion developed again from 24 to $60 \mathrm{~h}(P<0.05$, analysis of covariance). UO significantly increased to a peak of $249 \%$ of baseline between 3 and $12 \mathrm{~h}(P<0.05)$, with increased fractional excretion of sodium, peak $10.5 \pm 1.4$ vs. $2.6 \pm 0.6 \%(P<0.001)$. Creatinine clearance returned to normal after $2 \mathrm{~h}$; there was a transient reduction at $48 \mathrm{~h}$ to $0.32 \pm 0.02 \mathrm{ml} \mathrm{min}^{-1} \mathrm{~g}^{\text {! }}$ (vs. $0.45 \pm 0.04, P<0.05$ ) corresponding with the time of maximal depression of RBF. No renal injury was seen on histological examination at $72 \mathrm{~h}$. In conclusion, severe asphyxia in the preterm fetus was associated with evolving renal tubular dysfunction, as shown by transient polyuria and natriuresis. Despite a prolonged increase in RVR, there was only a modest effect on glomerular function. 


\section{INTRODUCTION}

Preterm infants are well known to be at increased risk of acute renal failure as well as transient fluid and electrolyte disturbances particularly in the first few days of life $(9,19,52)$. The etiology of neonatal acute renal failure is most often associated with hemodynamic disturbances such as hypotension, hypowolemia, and exposure to acute asphyxia $(44,48)$. It has been proposed that since preterm infants have a low basal glomerular filtration rate, which is very close to basal renal blood flow (RBF), the pathogenesis of this renal impairment is predominantly prerenal, i.e., secondary to reduced intrarenal blood flow (45). However, there is little direct experimental evidence.

Moderate hypoxia in the near-term fetus is associated with an acute decrease in fetal urine production (41), whereas during prolonged hypoxia urine output (UO) and glomerular filtration rate and urine osmolality rapidly normalize (14). Similarly, in near-term fetal sheep prolonged moderate hypoxia was associated with an increase in RBF, which returned to control values during recovery $(8,22)$. However, in contrast with the effects of moderate hypoxia, exposure to acute asphyxia, with acute hypotension and profound hypoxia (5), commonly results in significant postinsult hemodynamic perturbations. For example, clinical studies in near-term infants have demonstrated that asphyxia is associated with reduced $R B F$ velocity on the first, but not the third, day of life using Doppler ultrasound $(2,34)$.

There are only limited data on the effect of asphyxia on RBF in the preterm fetus, which suggest that $\mathrm{RBF}$ is acutely reduced during asphyxia but normal 2 and $4 \mathrm{~h}$ after asphyxia despite impaired glomerular filtration and a small increase in renal vascular resistance (RVR; 38). This is somewhat surprising since, in contrast, recent evidence using continuous blood flow monitoring suggests that exposure to asphyxia in the premature fetal sheep leads to prolonged secondary hypoperfusion in other peripheral vascular beds, including the femoral and gastrointestinal beds $(4,5)$. These data raise the possibility that similar changes in renal perfusion would lead to significant impairment of renal function.

In the present study we examined the hypothesis that exposure to severe asphyxia in the preterm sheep fetus would lead to secondary renal hypoperfusion and that this would be associated with impaired glomerular and tubular function. Renal histological examination and immunohistochemical staining for disruption of cytoskeletal anchorage of Na,K-ATPase after 3 days recovery were undertaken to assess the presence of renal damage.

\section{METHODS}

\section{Animal preparation.}

All procedures were approved by the Animal Ethics Committee of the University of Auckland. Singleton Romney/ Suffolk fetal sheep were instrumented using sterile techniques at 97-98 days of gestation (term = 147 days) under general anesthesia induced by Alfaxalone $12.5 \mathrm{mg} / \mathrm{kg}$; Schering Plough Animal Health, Wellington, NZ) and maintained with 2-3\% halothane in oxygen (4). Ewes were given $5 \mathrm{ml}$ of Strepcin (Stockguard Laboratories, Hamilton, New Zealand) intramuscularly for prophylaxis before the start of surgery. The uterus was exposed via a midline incision, and the fetal hindlimbs and abdomen were exteriorized. Polyvinyl catheters were placed in the left femoral artery and vein to measure fetal blood pressure. The fetal bladder was exposed via a paramedian incision, and a blunt-ended polyvinyl catheter was inserted to allow continuous gravity drainage of fetal urine. The left fetal kidney was exposed via a paravertebral incision, and a size $2 S B$ ultrasonic flow probe (Transonic Systems, Ithaca, NY) was placed around the left renal artery to continuously record RBF. The uterus was then closed in layers, and the upper body of the fetus was exteriorized via a second 
uterine incision. A polyvinyl catheter was placed in the right brachial artery for blood sampling. Two multiperforated catheters were placed in the amniotic sac for reading of intra-amniotic pressure and the return of collected urine. Electrocardiogram (ECG) electrodes (Cooner Wire, Chatsworth, CA) were sewn across the chest to record the fetal ECG. An inflatable silicone occluder was placed around the umbilical cord of all fetuses for the induction of asphyxia (In Vivo Metric, Healdsburg, CA). All fetal leads were exteriorized through the maternal flank, and a maternal long saphenous vein was catheterized. Antibiotics (80 mg gentamicin, Pharmacia and Upjohn, Perth, Australia) were administered into the amniotic sac before closure of the uterus.

After surgery sheep were housed together in the vivarium in separate metabolic cages with ad libitum access to water and food. They were kept in a temperature-controlled room $\left(16 \pm 1^{\circ} \mathrm{C}\right.$, humidity $50 \pm$ $10 \%$, in a $12: 12 \mathrm{~h}$ light-dark cycle. A period of 6-7 days postoperative recovery was allowed, during which time antibiotics were administered intravenously daily to the ewe $1600 \mathrm{mg}$ Crystapen, Biochemie, Vienna, Austria, for 4 days and $80 \mathrm{mg}$ gentamicin, daily for the first 3 days). Fetal arterial blood was taken daily from the brachial artery for blood gas analysis for the assessment of fetal health. Catheter patency was maintained by continuous infusion of heparinized saline ( $20 \mathrm{U} / \mathrm{ml}$ at $0.2 \mathrm{ml} / \mathrm{h})$.

\section{Experimental design.}

Fetal mean arterial pressure (MAP) and venous pressure (MVP) corrected for maternal movement by subtraction of intraramniotic fluid pressure, fetal heart rate (FHR) derived from the ECG, and RBF were recorded continuously from $24 \mathrm{~h}$ before umbilical cord occlusion until $72 \mathrm{~h}$ afterward. Data were stored to disk by custom software for off-line analysis (Labview for Windows, National Instruments, Austin, TX]. Urine was collected continuously using a fraction collector, hourly volume was measured, and urine was returned to the amniotic sac after sterilization using a $0.2 \mu \mathrm{m}$ syringe filter (Acrodisc, Gelman Laboratory, Ann Arbor, MI).

Experiments were conducted at 103-104 days gestation. Fetuses received either sham occlusion ( $n=6)$ or asphyxia induced by rapid inflation of the umbilical cord occluder for $25 \mathrm{~min}(n=13$ ) with sterile saline of a defined volume known to completely inflate the occluder. Successful acclusion was confirmed by observation of an immediate sharp rise in MAP and a rapid fall in FHR $(4,5)$. Blood samples were taken at 15 min before occlusion, 5 and 17 min during occlusion, and $30 \mathrm{~min}, 2,4,8,24,48$, and 72 $\mathrm{h}$ postocclusion for $\mathrm{pH}$ and blood gas determination (Ciba-Corning Diagnostics 845 blood gas analyzer and co-oximeter], glucose, and lactate measurements (YSI model 2300, Yellow Springs, OH). Blood samples were taken for measurement of creatinine, sodium, potassium, osmolality, atrial natriuretic peptide (ANP), and plasma renin activity (PRA) at $15 \mathrm{~min}$ before occlusion, and $30 \mathrm{~min}, 2,4,8,24$, 48, and 72 h postocclusion (Auckland Healthcare Laboratory Services, Auckland, NZ). ANP and PRA were also measured at 17 min during asphyxia. Plasma ANP levels were measured by ovine specific radioimmunoassay as previously reported (10). PRA was calculated as the amount of angiotensin I produced per liter of plasma per hour (18). Paired urine samples were taken for measurement of urine composition in 8 of the 13 asphyxia group fetuses; insufficient urine samples were available for analysis in the sham control group. On collection, blood was transferred into chilled test tubes and spun at $4^{\circ} \mathrm{C}$ $(3,000 \mathrm{tpm})$ for $15 \mathrm{~min}$. Plasma and urine were stored at $-80^{\circ} \mathrm{C}$ for subsequent analysis.

On completion of the experiment at $72 \mathrm{~h}$ the ewe and fetus were killed with an intravenous overdose of pentobarbital sodium. Fetuses were removed, weighed, and examined for the presence of hydrops fetalis, and samples of the fetal kidney were taken for histological examination. Tissue specimens were fixed in $10 \%$ neutral buffered formalin, embedded in paraffin, sectioned ( $4 \mu \mathrm{m})$, and stained with hematoxylin and eosin (H\&E). Immunohistochemical staining of $\mathrm{Na}$, K-ATPase was performed after blocking nonspecific binding sites. The primary antibody (MA3-929, mouse anti-sheep 
a1-subunit of Na,K-ATPase, Affinity Bioreagents, Golden, CO) was incubated for $48 \mathrm{~h}$ at $4^{\circ} \mathrm{C}$ at a concentration of 1:100. After repeated washes the slides were exposed to secondary horse anti-mouse antibody for $24 \mathrm{~h}$ at $4^{\circ} \mathrm{C}$ and $\mathrm{ABC}$ reagent for $1 \mathrm{~h}$ at room temperature (Vector Laboratories, Burlingame, CA). Slides were developed with diaminobenzidine (DAB).

\section{Data analysis and statistics.}

Renal artery vascular resistance (RVR) was calculated using the formula (MAP-MVP)/absolute RBF (mmHgmin/ml). Creatinine clearance (ClCr) and fractional excretion of sodium and potassium $\left[\mathrm{FE}_{\mathrm{Na}}, \mathrm{FE}_{\mathrm{K}}\right]$ were calculated as follows

$$
\begin{aligned}
& \mathrm{ClCr}=\left(\text { urine }_{\text {Creat }} \mathrm{X} \text { volume }\right) /\left(\text { plasma }_{\text {Creat }} \mathrm{X} \text { kidney } \mathrm{wt}\right) \\
& \mathrm{FE}_{\mathrm{Na}}=\text { (urine } \mathrm{Na} / \text { plasma }_{\mathrm{Na}} \text { )/ (urine } \mathrm{Crea} / \text { plasma }_{\mathrm{Creat}} \text { ) }
\end{aligned}
$$

Statistical analysis was performed using SPSS (SPSS, Chicago, IL). The effect of asphyxia on continuous variables was tested by ANOVA, with time treated as a repeated measure to allow for repeated sampling. For comparisons over time, baseline levels were used as a covariate. For the analysis of the occlusion and $1 \mathrm{~h}$ postocclusion periods, data were compared with the mean of the hour before acclusion (baseline). For the analysis of the long-term recovery data (1-72 $\mathrm{h}$ postocclusion), the baseline period was taken as the mean of the $12 \mathrm{~h}$ before occlusion. These data were analyzed in $12 \mathrm{~h}$ blocks by repeated measurement ANOVA. If a significant effect of group was found for the first $12 \mathrm{~h}$, since rapid changes occurred for many parameters within this interval, individual time points were compared by ANOVA, adjusted using the baseline levels as the cowariate. The within-subjects relationship of RBF and $\mathrm{ClCr}$ was determined by regression analysis using the method of Bland and Aitman (7). Proportions were compared using the Fisher exact test. Statistical significance was accepted when $P<0.05$. Data are presented as means $\pm S E$.

\section{RESULTS}

\section{Blood composition measurements during asphyxia.}

Before each experiment, all fetuses had normal blood gas, acid-base, and glucose and lactate status according to the standards of our laboratory and were not statistically different between groups. Umbilical cord occlusion was associated with the development of profound hypoxia and mixed respiratory and metabolic acidosis. Fetal arterial pH fell to $6.888 \pm 0.013$ at 17 min of cord occlusion ( $v s .7 .367 \pm 0.004$ in sham controls, $P<0.05$ ) and normalized by $8 \mathrm{~h}$ postocciusion; at $72 \mathrm{~h}$, fetal $\mathrm{pH}$ was $7.381 \pm 0.008$. Fetal arterial $\mathrm{PO}_{2}\left(\mathrm{PaO}_{2}\right)$ fell to $8.8 \pm 0.6$ at $17 \mathrm{~min}$ of asphyxia $(v s .23 .2 \pm 1.0 \mathrm{mmHg}$ in sham controls, $P<0.05)$, rapidly normalized after occlusion, and subsequently increased moderately $(27.2 \pm 1.0 \mathrm{vs}$. $22.9 \pm 0.7 \mathrm{mmHg}$ in sham controls at $72 \mathrm{~h}, P<0.05)$. Fetal arterial $\mathrm{PCO}_{2}\left(\mathrm{PaCO}_{2}\right)$ increased during occlusion to $134.9 \pm 3.3 \mathrm{mmHg}$ at $17 \mathrm{~min}(v \mathrm{~s} .51 .2 \pm 2.1 \mathrm{mmHg}$ in sham controls, $P<0.05)$ and recumed to control values by $30 \mathrm{~min}$ postocclusion. Fetal arterial glucose decreased to $0.51 \pm 0.1$ at 17 min of occlusion (vs. $0.93 \pm 0.0 \mathrm{mmol} / 1$ in sham controls, $P<0.05$ ). Postocclusion fetal glucose increased rapidly and remained mildly elevated to the end of the study $(1.12 \pm 0.1 \mathrm{vs} .0 .92 \pm 0.1 \mathrm{mmol} / 1$ in sham controls, $P<0.05$ ). Fetal arterial lactate increased during occlusion to $6.22 \pm 0.2$ at $17 \mathrm{~min}$ ( vs. $0.58 \pm$ $0.1 \mathrm{mmol} / \mathrm{l}$ in sham controls, $P<0.05$ ) and postocclusion gradually normalized by $48 \mathrm{~h}$; at $72 \mathrm{~h}$ lactate was $0.79 \pm 0.0$ w. $0.66 \pm 0.1 \mathrm{mmol} / \mathrm{l}$ in sham controls (not significant). 


\section{Cardiovascular measurements during asphyxia.}

Asphyxia led to progressive bradycardia with initial hypertension followed by the development of profound hypotension at the end of occlusion (Fig. 1). The nadir of MAP was $9.4 \pm$ $0.5 \mathrm{mmHg}$ (v/s. $35.8 \pm 0.6 \mathrm{mmHg}$ in sham controls, $P<0.05$ ), and FHR fell to $59 \pm 4$ beats/ $\min$ at the end of occlusion ( $v s .172 \pm 3$ beats $/$ min in sham controls, $P<0.05)$. RBF was markedly reduced by asphyxia, in a triphasic pattern. At the onset of occlusion RBF fell rapidly to $0.8 \pm 0.3 \mathrm{ml} / \mathrm{min}$ at $4 \mathrm{~min}$ of occlusion ( $v s .13 .8 \pm 1.1 \mathrm{ml} / \mathrm{min}$ in sham controls, $P<0.05$ ).

RBF then showed a transient, partial rise to $6.6 \pm 1.0 \mathrm{ml} / \mathrm{min}$ at $9 \mathrm{~min}$ and then fell again to a nadir of $1.1 \pm 0.3 \mathrm{ml} / \mathrm{min}$ at the end of occlusion. RVR was markedly increased between 1 and $7 \mathrm{~min}$ after asphyxia, peaking at 4 min $(P<0.05)$ and then falling toward control values. Although RVR tended to be slightly greater than sham controls for the remainder of the occlusion period, this was significant only in the last 4 min of umbilical cord occlusion (Fig. 1).

Floure 1. Time sequence of charges in feral mean arterla blood phessure (MAP), heart rate (FHR), remal blood flow IRBF, and renal vascular resistance [RVR] in sham controls lopen circtes, $n=6$ ) and in fetuses exposed to umbilloal cold occhion lor 25 mith itilled circles, $n=13$ ) from $60 \mathrm{~min}$ before occlusion 1060 min after release of occhusion or sham occlusion. The shaded area shows the period of occlusion or sham occlusion. Data are 1.min averages, shown as means $15 E$ * $P<0.05$, asphyxia group $v$ s. gham controls, analysis of covariance (ANCOVA].

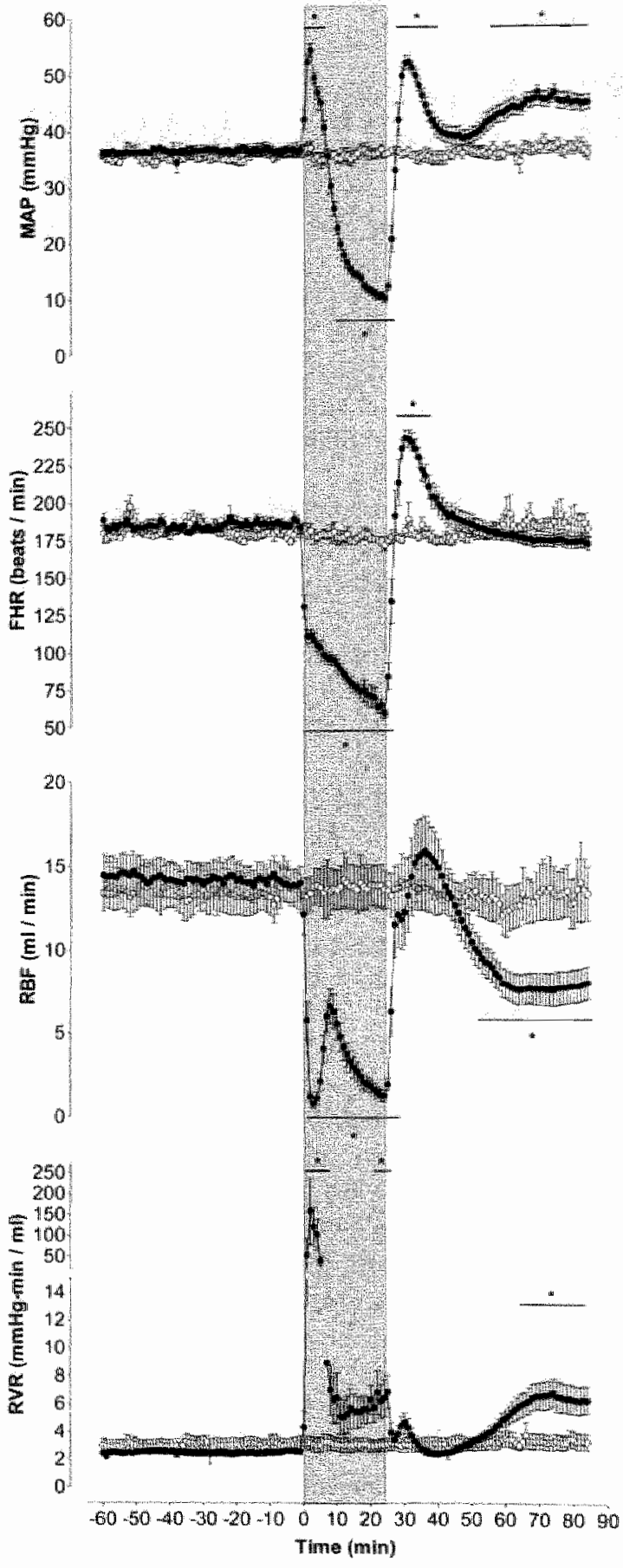



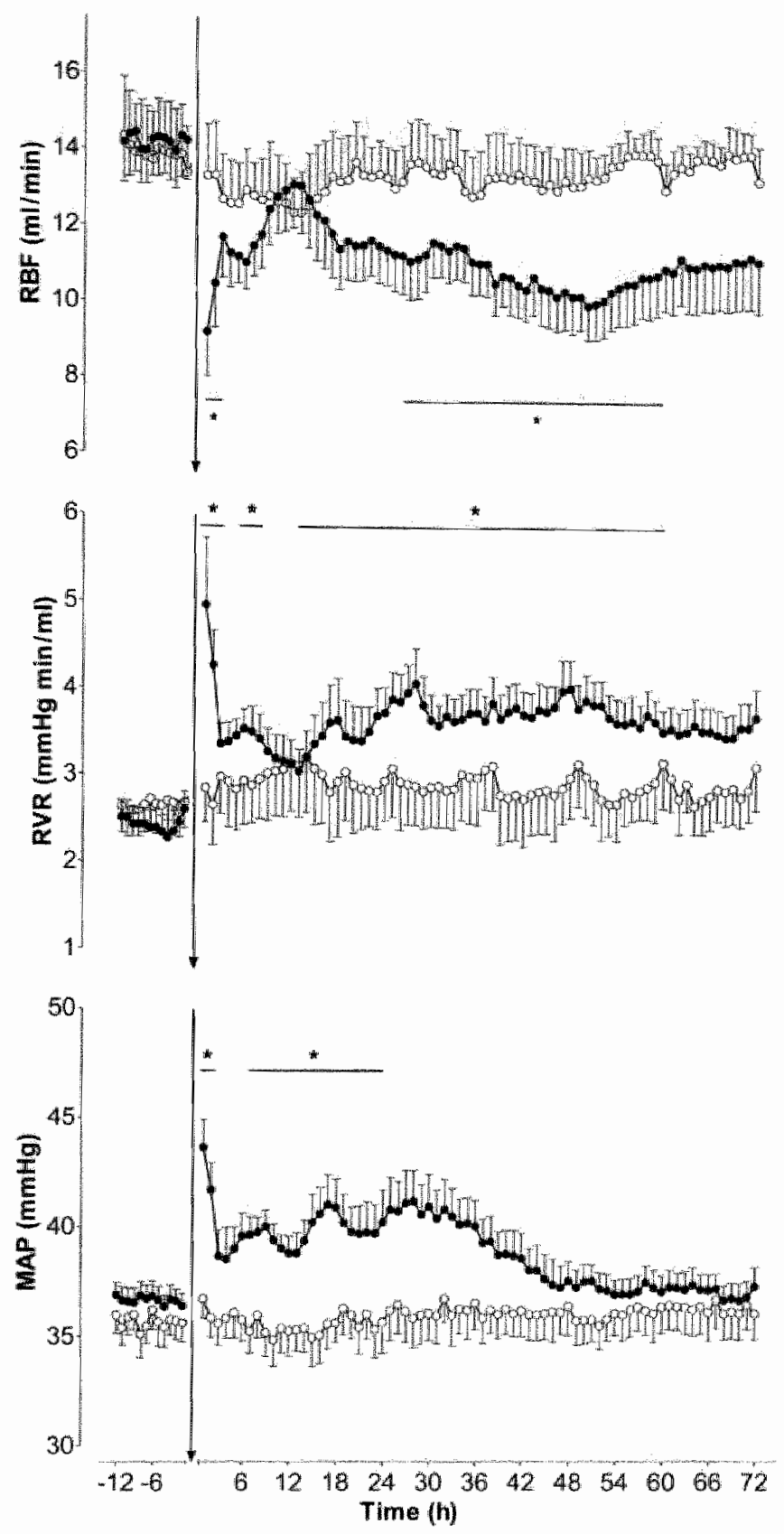

Figure 2. Time sequence of changes in fetal RBF; RVR, and MAP in shaim controis lopen circles, $n=0$ ) and in fetuses exposed to umbilical cord occlusion for 25 min (filled circles, $n=13$ from $12 \mathrm{~h}$ before acclusion to $72 \mathrm{~h}$ after release of occlusion or sham occlusion. The arrows show the period of occlusion or sham occlusion. Data are 1 th averages, shown as means \pm SE * $p<0.05$, asphyxia group ws. sham controls, ANCOVA. 

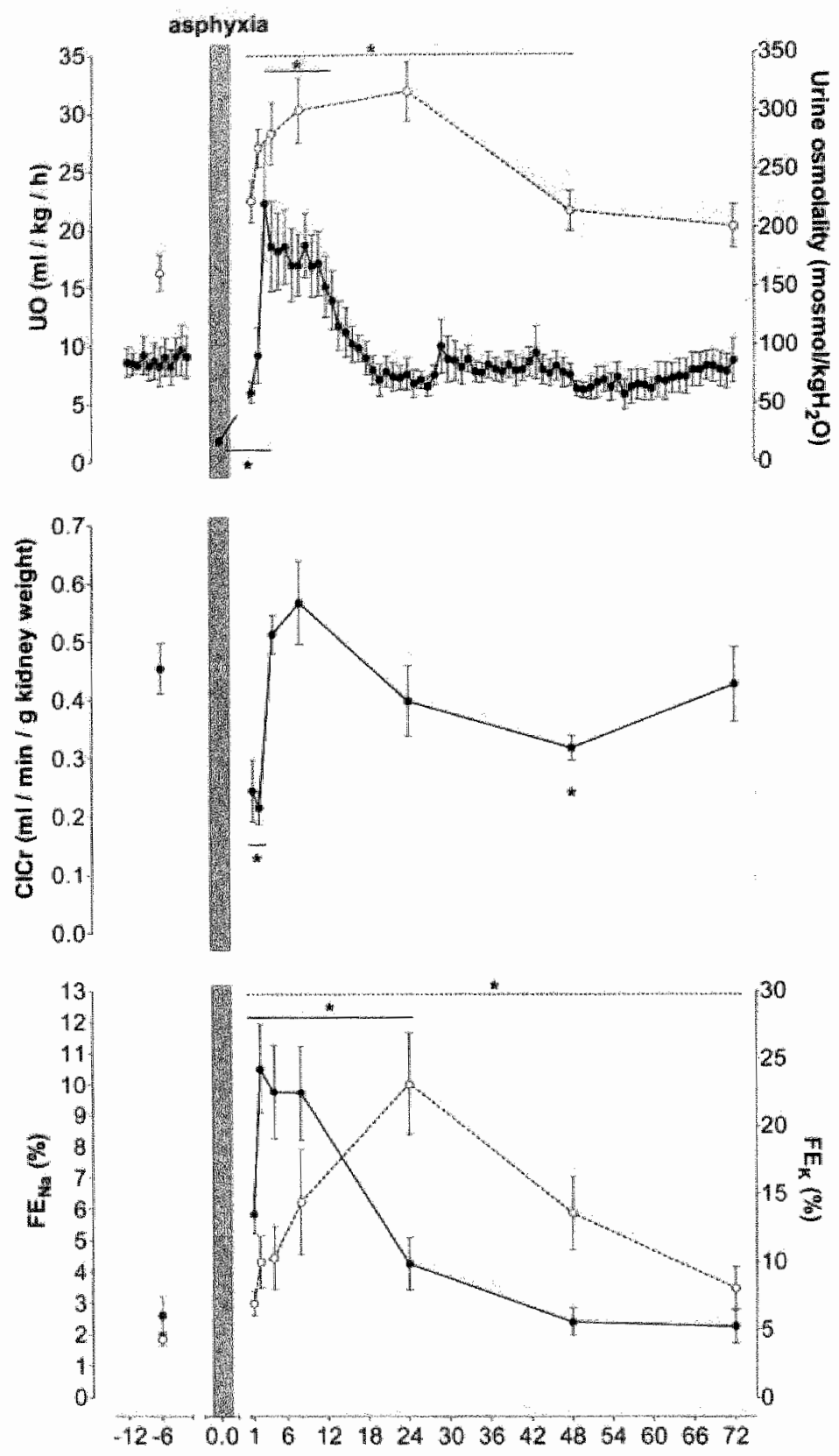

Figure 3. Time sequence of changes in letal urine output [uO, illted circles\}, unine osmolality fopen circles, dashed line, top panel), creatinine clearance (CIC, midde panel), and fractional excretion of sodiun (FE ${ }_{\text {Na }}$ filled circles) and potassium (FE $E_{K}$, open circles, dasthed line, bottom panel in fetuses exposed to umbilical cord occlusion for $25 \mathrm{~min}$ $(n=8)$. The shaded area shows the period of occlusion. Data are neans $\pm S E * P<0.05$ ws. baseline measurements, ANOVA 
Figure 4. Relationship between changes in glomerular function as shown by fetal ClCr and RBF for fetuses exposed to occlusion of the umbilical cord. Lines represent individual regression analysis; the different symbols represent individual animals. All but one fetus showed a positive within-subjects relationship between $\mathrm{CICr}$ and RBF over the course of the study, $r^{2}$ $=0.16, P=0.002$. Overall, a marked reduction in $\mathrm{ClCr}$ is seen at low values of $\mathrm{RBF}$

Figure 5. Time sequence of changes in fetal atrial natriuretic peptide (ANP) and plasma renin activity (PRA) in sham controls (open bars, $n=$ 61 and in fetuses exposed to umbilical cord occlusion for 25 min (filled bars, $n=13$. Con, baseline control values; 17 occ, sample taken at 17 min of cord occlusion. Subsequent time points represent time from release of cord occlusion. * $P<0.05$ ws, sham controls, ANCOVA.
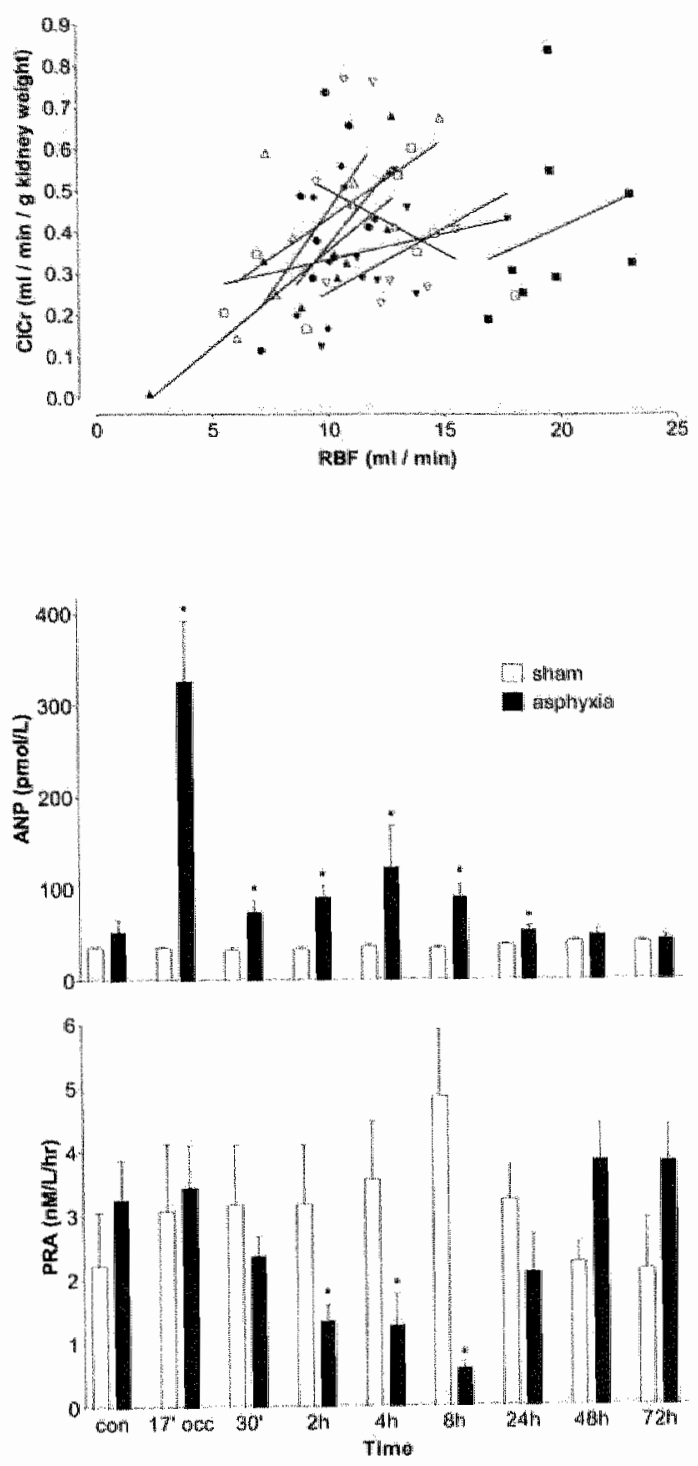

\section{Cardiovascular measurements during recovery.}

Postocclusion RBF transiently returned to sham control values (Fig. 1). This was followed by a secondary fall in RBF from $\sim 25 \mathrm{~min}$, with a marked elevation of RVR, such that RBF was significantly reduced compared with sham controls for the first $2 \mathrm{~h}$ (Fig. 2). Although the initial marked postocclusion increase in RVR became attenuated from $3 \mathrm{~h}$ onward, RVR was significantly elevated for most of the remaining recovery period, with an associated reduction in RBF (Fig. 2]. RVR was transiently normalized between 8 and $18 \mathrm{~h}$ and appeared to be resolving toward the end of recowery, such that values of RVR and RBF were not significantly different from sham controls. There was significant rebound hypertension for the first 2 h postocclusion, and MAP remained significantly elevated during 
much of the first $24 \mathrm{~h}$ postocclusion $(P<0.05)$, progressively returning to baseline thereafter (Fig. 2$)$.

Fetal heart rate (Fig. 1 ) showed a brief rebound tachycardia at the end of occlusion, peaking at 6 mir at $243 \pm 5$ (vs. $182 \pm 2$ beats/min in sham controls, $P<0.05$ ); however, subsequently FHR was not significantly different from sham controls (data not shown).

\section{Renal function.}

UO was rnarkedly decreased during occlusion to a mean of $1.7 \pm 0.3 \mathrm{ml} \mathrm{kg} \mathrm{h}^{-1}\left[\mathrm{vs} .9 .1 \pm 0.5 \mathrm{ml} \mathrm{kg}^{-1} \mathrm{~h}^{-1}\right.$ at baseline (Fig. $3, P<0.05)$ ). Postocclusion, UO remained sĭgnificantly decreased for $1 \mathrm{~h}$ followed by a marked increase in UO between 3 and $12 \mathrm{~h}$, maximal at $3 \mathrm{~h}\left(22.2 \pm 5 \mathrm{mi} \mathrm{kg}^{-1} \mathrm{~h}^{-1}, P<0.05\right)$. UO then returned to control values for the remainder of the study (Fig. 3 ).

$\mathrm{CICr}$ (Fig. 3) was reduced during the first $2 \mathrm{~h}$ postocclusion $\left(0.22 \pm 0.03 \mathrm{vs} .0 .45 \pm 0.04 \mathrm{ml} \mathrm{min}^{-1} \mathrm{~g}^{-1}\right.$ at baseline, $P<0.05)$ and again at $48 \mathrm{~h}$ to $0.32 \pm 0.02 \mathrm{ml} \mathrm{min}^{-1} \mathrm{~g}^{-1}(P<0.05)$. The reduction at 48 $\mathrm{h}$ corresponded in time with the lowest level of RBF in the final $48 \mathrm{~h}$. There was a positive withinsubjects correlation between RBF and $\mathrm{ClCr}, r^{2} \pm 0.16$ (Fig. $4, P<0.002$ ).

$\mathrm{FE}_{\mathrm{Na}}$ (Fig. 3) was increased during the first $24 \mathrm{~h}$ postocclusion, reaching a maximum of $10.5 \pm$ $1.4 \%$ at $2 \mathrm{~h}$ (vs. $2.6 \pm 0.6 \%$ at baseline, $P<0.05)$. $\mathrm{FE}_{\mathrm{K}}$ gradually increased, later than the increased $\mathrm{FE}_{\mathrm{Na}}$, to a maximum of $23.1 \pm 3.8 \%$ at $24 \mathrm{~h}$ (v.s. $4.3 \pm 0.5 \%$ at baseline, $P<0.05$ ) (Fig. 3). Urine osmolality was increased immediately postocclusion, maximal at $24 \mathrm{~h}(317 \pm 26$ vs. $149 \pm 12$ mosmol $/ \mathrm{kg} \mathrm{H} \mathrm{H}_{2} \mathrm{O}$ at baseline, $P<0.05$ ), returning to control values by $72 \mathrm{~h}$ (Fig. 3).

\section{Plasma ANP and PRA.}

ANP was markedly increased during occlusion to $327 \pm 65 \mathrm{pmol} / 1$ (vs. $35 \pm 2 \mathrm{pmol} / \mathrm{l}$ in sham controls, $P<0.05$, Fig. 5). After asphyxia ANP remained mildly increased during the first $8 \mathrm{~h}$, with a maximum of $123 \pm 45 \mathrm{pmol} / 1$ at $4 \mathrm{~h}$, after which plasma ANP returned to control levels. PRA (Fig. 5) was decreased postocclusion and returned to baseline values by $24 \mathrm{~h}$.

\section{Postmortem examination, renal histology, and immunohistochemistry.}

Mild subcutaneous edema was observed in 5 of 13 asphyxia group animals $v s$. no edema in 6 sham control group animals (not significant, Fisher exact test). Frank ascites and pleural effusions were not seen in any fetus in either group. Average fetal body weight was $1,770 \pm 66 \mathrm{~g}$ in the asphyxia group vs. 1,645 $\pm 61 \mathrm{~g}$ in the sham group (not significant). Immunohistochemical staining of Na,K-ATPase demonstrated no disruption of the predominantly basolateral cytoskeletal anchorage of Na,K-ATPase. Histological examination of H\&E-stained sections by light microscopy confirmed that there was no tubular or glomerular injury after 3 days recovery in either the asphyxia or sham control groups.

\section{DISCUSSION}

Despite exposure to a near-terminal episode of asphyxia, associated with a severe reduction in RBF, preterm fetal sheep showed transient renal dysfunction during recovery, with no histological injury observed 3 days later. Recovery of renal function was characterized by a marked increase in UO and $\mathrm{FE}_{\mathrm{Na}}$ during the first $24 \mathrm{~h}$, which was associated with a moderate secondary rise in plasma ANP levels and a fall in PRA. We repont for the first time that there was a prolonged secondary increase in RVR during recovery, which was just beginning to resolve after 3 days. Renal perfusion was maintained in part in the first $24 \mathrm{~h}$ by a mild increase in fetal blood pressure and in part by the transient period of relative normalization of RVR around $12 \mathrm{~h}$ postinsult. When blood pressure returned to control levels 
the increased RVR led to a prolonged reduction in RBF. Despite this continuing renal hypoperfusion in the 2 nd and 3 rd days of recovery, during this interval $\mathrm{ClCr}$ was only significantly but mildly impaired when RBF was most markedly reduced.

In contrast with the effects of moderate hypoxia, the acute responses to severe asphyxia included a profound fall in $\mathrm{RBF}$ and oliguria. The oliguria is likely primarily mediated by reduced perfusion, although release of stress hormones such as arginine vasopressin may also be important $(20,21)$. The initial fall in RBF was actively mediated as shown by the very rapid increase in RVR in the first 3 min after the start of umbilical cord occlusion, at a time when blood pressure was elevated. This response is similar to that measured using the microsphere technique in the more mature, near-term fetus (29) and is believed to be an important adaptive mechanism acting to redistribute combined ventricular output from nonessential or peripheral organs to essential organs such as the heart, brain, and adrenals (25). The current data refute previous suggestions that this initial cardiovascular defense response is immature in the premature fetus (28).

However, consistent with studies in the near-term fetus, this initial adaptation was rapidly lost, with a change in the mechanism of renal hypoperfusion from active vasoconstriction, with arterial hypertension, to a near pressure-passive fall secondary to worsening hypotension $(29,30)$. From $\sim 4$ min after the start of occlusion renal resistance fell progressively, with a reciprocal increase in RBF, although flow never reached control levels. Once overt hypotension developed, from 9 min of occlusion, RBF fell in parallel with the fall in blood pressure. The mechanism of this loss of renal vascular tone is unknown, but it is not unique to the renal vascular bed. In the near-term fetus the initial vasoconstriction during asphyxia is mediated by sympathetic neural activity (30). Potentially, loss of vasoconstriction could reflect loss of sympathetic activity; however, this seems relatively improbable given that circulating catecholamines increase markedly during prolonged asphyxia (24). Levels of circulating ANP were markedly increased toward the end of cord occlusion in the present study by nearly 10 -fold, consistent with the effect of inhalational hypoxia (11). ANP has direct renal vasodilatory effects in the fetal and postnatal sheep (49), and its effects are enhanced after ischemia in the adult dog (1). Interestingly, administration of ANP is reported to reduce renal damage in experimental models of ischemic acute renal failure (15); thus the present results raise the possibility that the increase in endogenous ANP may help limit renal injury during fetal asphyxia by reducing the duration of intense vasoconstriction.

After release of occlusion there was an initial rapid but transient recovery of RBF, followed by a secondary fall, such that mean RBF was significantly depressed for the first $2 \mathrm{~h}$. This hypoperfusion occurred despite significant rebound hypertension as shown in Fig. 2 and was actively mediated, as demonstrated by the increase in RVR. This was accompanied by initial oliguria, reduced $\mathrm{ClCr}$, and developing natriuresis (Fig. 3). Following this, polyuria developed with continuing natriuresis resolving between 13 and $24 \mathrm{~h}$ after reperfusion. The dewelopment of polyuria was broadly paralleled by relative normalization of RBF. The significance of this relationship is unknown but speculatively might reflect changes in renal metabolism during reversible injury.

Urine osmolality remained increased until $48 \mathrm{~h}$ postocclusion, refiecting the overlapping time courses of the secondary increases in $\mathrm{FE}_{\mathrm{Na}}$ and $\mathrm{FE}_{\mathrm{K}}$ (Fig. 3). The later increase in potassium excretion, at the time that the natriuresis was resolving, is consistent with improving renal function allowing increased tubular sodium/potassium exchange. Glomerular function, as indicated by $\mathrm{ClCr}$, was only briefly impaired during the initial recovery phase, indicating a rapid recovery of glomerular function after severe asphyxia in the preterm fetus. This overall pattern suggests primary, reversible tubular dysfunction. Clinically, this pattern is well described and may be more common than the classic pattern of oliguric renal failure in newborns $(23,31)$, although currently there are few data in preterm infants. The finding of normal renal architecture in the present study after 3 days recovery is consistent with the generaily good clinical prognosis of polyuric 
renal fallure (31). This and the finding of a normal distribution of Na,K.ATPase in the present study are consistent with the reported greater renal tolerance to ischemic injury in the immature rat, as shown by reduced Na,K-ATPase disiocation, compared with adult rats (50).

There was a mild reduction in ClCr at $48 \mathrm{~h}$ of recovery, corresponding in time with the most pronounced decrease in RBF in the chronic recovery phase. Within-subjects regression analysis demonstrated a positive relationship between $\mathrm{RBF}$ and $\mathrm{ClCr}$ in all but one subject. However, since this relationship accounted for $20 \%$ of variance in $\mathrm{ClC}$, and the effect of impaired $\mathrm{RBF}$ on $\mathrm{ClCr}$ appears to be predominant only with substantial reductions in blood flow, additional factors are likely to be important particularly within the normal range. There are limited data on the determinants of changes in RBF after premature birth; however, Doppler flow measurements suggest that RVR is initially elevated shortly after birth and progressively falls with time $(13,47)$. These studies found only a weak relationship between RBF velocity and $U O(32)$ and that oliguria is typically seen only with marked reductions in renal velocity. These data are consistent with the present study and do not support the hypothesis that the glomerular filtration rate in the preterm kidney is more dramatically affected by small reductions in renal perfusion than is the case at later ages (45).

Plasma ANP has an important physiological role in regulating fluid balance by inhibiting tubular sodium reabsorption and increasing UO $(37,51)$. In the present study, plasma ANP levels were modestly but significantly elevated for the first $24 \mathrm{~h}$ after asphyxia. Although this broadly corresponds with the period of polyuria, ANP levels were still mildly elevated at $24 \mathrm{~h}$, when polyuria had resolved. This suggests that ANP may have contributed to the development of polyuria and natriuresis but is unlikely to be the primary mechanism. Limited data from studies of hypoxia at this gestation suggest that circulating cortisol levels may also be elevated after asphyxia and thus also contribute to increased MAP, polyuria, and natriuresis (46). Although as noted above ANP is overall a vasodilator, its effects on RBF can be complex, with afferent arteriolar vasodilatation and efferent vasoconstriction (43). Thus the combination of elevated RVR with elevated ANP in the first $24 \mathrm{~h}$ may reflect alterations in this balance or simply that the levels of circulating ANP were insufficient to overcome the background vasoconstrictor tone. This late rise in ANP was not due to fetal hypoxia, which resolved rapidly after reperfusion, or to hypotension, because blood pressure was modestly elevated at this time, or to fetal tachycardia. In the aduit, release of hypoxia-inducible factor during hypoxia induces atrial ANP gene expression (12), and thus a brief insult can lead to prolonged effects on ANP.

The renin angiotensin system is also a significant potential contributor to changes in $\mathrm{ClCr}$ and renal perfusion. In the nearterm fetus reduced perfusion pressure is a potent stimulator of renin release (42), which is mediated through activation of the sinoaortic receptors (33). However, there is conflicting evidence on the effect of hypoxia on PRA. Whereas postnatally, hypoxia is associated with increased PRA (3), no changes in PRA were observed during hypoxemia in the immature fetus (40, 41), and inhibition of the renin-angiotensin system during hypoxia has little effect on renal perfusion or function (36). These data are consistent with the present study, in which there was no significant change in PRA during cord occlusion.

There are few data on PRA during recovery from hypoxia (35). In the present study there was a consistent transient fall in PRA after asphyxia. The mechanism of this fall is unknown. The postasphyxial increase in ANP that parallels this fall may contribute, since infusions of ANP are reported to inhibit renin release in the isolated kidney (37) and in the adult dog (26), at least partly due to the increase in the filtered sodium load (51). An additional factor may be the increased renal perfusion pressure at this time, which is known to inhibit renin release (42). Finally, renal maturation is likely to be important. For example, in contrast with the present data, Lumbers et al. (35) found a sustained increase in PRA after severe asphyxia undertaken in fetal sheep at an even earlier stage of maturation, 
near-midgestation. It is striking that Lumbers et al. (35) found severe nonimmune hydrops fetalis after asphyxia (35), whereas in the slightly less immature $10.7 \mathrm{vs.} 0.6$ gestation) fetuses in the current study, despite a very similar insult, with a comparably severe degree of acidosis and hypotension, frank fetal hydrops was never seen, and mild skin subcutaneous edema only occurred in a minority of the fetuses. A subsequent study in the same model has shown that the pattern of recovery of renal function at 0.6 gestation was also very different from the present study (38). There was a more prolonged suppression of glomerular function at least to $4 \mathrm{~h}$ of recovery and no increase in UO or sodium loss, and without prolonged impairment of RBE, measured at 2 and $4 \mathrm{~h}$ of recovery (38).

These contrasting findings are consistent with the hypothesis that sustained activation of the reninangiotensin system is an important mechanism in the development of fetal hydrops, through an increase in transplacentall fluid uptake, as previously reviewed (17). Further, polyuria as seen in the current study may facilitate the excretion of such a fluid load and thus help alleviate the development of hydrops. The effect of maturation on the appearance of hydrops is intriguing and may relate to the greater anaerobic capacity of the younger fetuses, which permitted a greater tolerance to prolonged asphyxia (typically 30-40 min at 0.6 gestation vs. $25 \mathrm{~min}$ at 0.7 gestation) and thus exposed these younger fetuses to a more profound and prolonged period of hypotension and hypoperfusion (38). Alternatively, it may reflect a relatively greater maturity of intrarenal control mechanisms at the older age. Further research is clearly required to determine the specific factors controlling the appearance of hydrops in the immature fetus.

\section{Perspectives}

Premature infants frequently develop an early phase of intense polyuria with salt wasting after birth, which resolves over the first week 16, 19]. The etiology is very poorly understood. The present study highlights two relevant aspects of preterm renal injury: first, that at least experimentally the immature kidney is relatively resistant to injury even after severe ischemia or asphyxia $(38,50)$; and second, that postasphyxial renal dysfunction may be commonly manifested by polyuria and natriuresis (31). There is now increasing evidence from early electrophysiological and hemodynamic recordings that many preterm infants are exposed to significant events either in the immediate perinatal period or shortly after birth $(27,39)$; as illustrated by the present study adaptation to such events can lead to significant changes in systemic or regional perfusion $(2,16,34)$. These intriguing observations raise the possibility that the common early, transient phase of polyuria in preterm infants may also be a consequence of early hypoxicischemic events and thus reflect reversible renal compromise rather than a purely maturational phenomenon.

\section{ACKNOWLEDGMENTS}

We are grateful to Dr. Karen Gibson and Prof. Eugenie Lumbers at the University of New South Wales, Australia for advice and Prof. Jelte de Haan at the University of Maastricht for critically reviewing the manuscript. This study was supported by the Health Research Council of New Zealand, National Institutes of Health Grant RO-1 HD-32752, Lottery Health Board of New Zealand, and the Auckland Medical Research Foundation. J. S. Quaedackers was supported by the Ter Meulen Fund, Royal Netherlands Academy of Arts and Sciences. 
chapter 0 


\section{REFERENCES}

1. Akabane S, Imanishi M, Matsushima Y. Kawamura M, Kuramochi M, lto K, and Omae T. Renal actions of atilat natriuretic peptide on the postischemic kidney. Can / Phystol Phamacol 60: 001-607, 1988.

2. Akinbi $\mathrm{H}$, Abbasi S, Hipert PL, and Bhutani VR. Gastrointestinal and renal blood fow velocity profle in neonates with birth asphyxia. I Fediatr 125: 625-627, 1904.

3. Alward CT, Hook. JB, Helmbrath TA, and Bailie MD. Effects of asplyxia on renal function in the newbon piglet. Pediatr Res 12:225-228, 1978 .

4. Bennet L, Quadackers IS, Gurn AJ, Rossenrode S, and Heineman E. The effect of asphyxia on supento mesenteric artery blood flow in the premature sheep letus. I Pediat Surg 35: 34-40, 2000.

5. Bennet $L$, Rossenrode S, Gunning MI, Guckman PD, and Gunn A. The caviovascular and cerebrovasoula: responses of the immature fetal sheep to acute umbilical cord occhusion. A Physiot $517: 247-257_{\text {in }} 1909$.

6. Bidwala KS, Lorenz JM, and Kleinman LI. Renal function correlates of posthatal diuresis in preterim infants. Pediatrics 82: 50-58, 1088.

7. Bland JM and Altman DG. Calculating correlation coefficients with repeated observations. I. Correlation within subjects. BMI 310: 446, 1095 .

8. Braaksma MA, Dassel $\mathrm{AC}$, and Aarnoudse $J \mathrm{G}$. Renal responses to prolonged $(48$ h) hypoxemia withoul acidenia In the late-gestation ovine fetus. Am I Physiol Regul htegr Comp Physiol 277, R395-R402, 1909).

9. Bueva $A$ and Guignard JP. Renal function in preterm neonates. Pedatr Res 36: $572-577,1094$.

10. Chartes CJ, Espiner EA, and Richards AM. Cardiovascular actions of ANF: contributions of renal, neurohumoral, and hemodynamic factors in sheep. Am I Phusiol Regul hregr Comp Physiol 204: R533-R538, 1903.

11. Cheung CY. Autonomic and arginine vasopressin modulation of the hypoxia-induced atrial natriuretic factor release in immature and mature ovine fetuses. Am f Obster Cynecol 167: 1443-1453, 1992.

12. Chun YS, Hyun JY, Kwak YG, Kim IS, Kim CH, Choi E, Kim MS, and Park JW. Hypoxic activalon of the atual natriunetic peptide gene promoter through direct and indirect actions of hypoxia-inducible factor- 1 . Bochend $370: 149 \cdots 157,2003$

13. Cleary GM, Higgins ST, Merton DA, Cullen $J$, Gottlieb RP, and Baumgari S. Developmental changes in renal artery blood flow velocity during the first three weeks of life in preterm neonates. J Pediat 129: $251-257,1990$.

14. Cock ML, McGrabb GJ, Wlodek ME, and Harding R. Effects of prolonged hypoxemia on fetal renal function and amniotic flud volume in sheep. Am / Obsre Gynecol $176: 320-320,1907$.

15. Conger JD, Falk SA, and Hammond WS. Atrial natruretic peptide and dopamine in established acute renal failute in the rat. kidney/nit $40: 21-28,1901$.

16. Coombs RC, Morgan ME, Durbin GM, Booth IW, and McMeish AS. Abnormal gut blood fiow velocilles in neonates at risk of mecrotising enterocolitw. / Pedatr Gastroenterof Nut 15: 13-19, 1902.

17. Faber JI and Anderson DF. Angotensin medited inferaction of fatal kidney and phacenta in the control of fetal arterial pressure and tis tole in hydrops fetalis. Placenta $18: 313-320,1007$.

10. Fitzatrick MA, Rademaker MT, Frampton CM, Charles Cl, Yendle TG, Espiner EA, and kram H. Hemodymamic and hormonal effects of renin inhibition in owne heari falure. Am / Physiol teat Ciro phystof 258 : H1625-H1631, 1900.

19. Gallini F, Maggio L, Romagnoli C, Marocco $\mathrm{G}$, and Tontorolo G. Prognession of renal function in pretem neonates with gestational age or 32 weeks. Pedtat Nephrol 15:119-124, 2000 .

20. Gibson Ku and Lumbers ER. Ovine fetal cardiovascular, renal, and |uid balance responses to 3 days of high anginine vasopressin levelis. Am I Physol Regul Integ Comp Fhysiol 272: R1069 R1076, 1907.

21. Giussani DA, McGarrigle HH, Spencer IA, Moore PI, Bennet L, and Harson MA. Effect of carotid demervallon on plasma wasopressin levels during acute hypoxia in the lategestation sheep ferus. / Physlol 477: 81-87, 1994. 


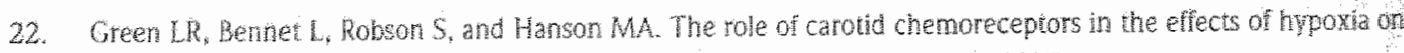

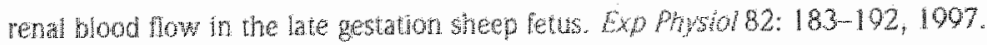

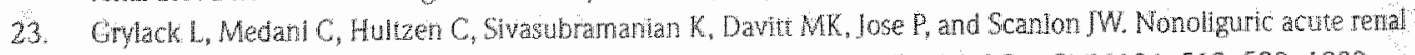

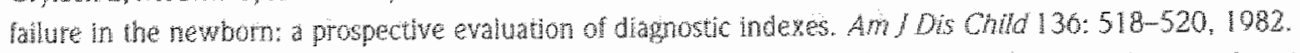

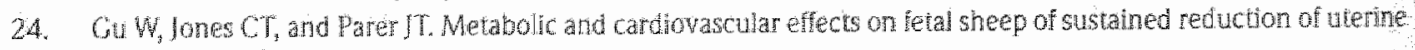
blood low. J physiol 368: 109-129, 1985.

25. Hanon MA. The impontunce of baro and chemoreflexes in the control of the hetal cardiovascuar system. J Dev. Prosol $10: 491-511,1988$

26. Hisa $\mathrm{H}$, Tomura $\mathrm{Y}_{\text {, and }}$ Satoh $\mathrm{S}$. Arial natruretic factor suppresses neural stimulation of renin release in dogs

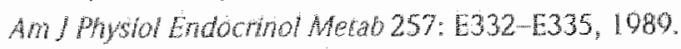

27. Itakura A, Kurauch O, Hayakawa F, Matsuzawa $\mathrm{K}$, Mizutan $S$, and Tomoda $\mathrm{Y}$. Thring of perventricular leukomatacia using neonatal electroencephalography. Int/Gyaecol Obstet $55: 111-115,1900$.

28. Wamow 115 , Kauman T, Kell LC, and Rudolph AM. Responses to acute hypoxemia in fetal sheep at $0.5-0.7$ gestation. Am / Physol Hean Che Phystol 250: Ho13-Ho20, 1989.

29. Jensen $A$, Hobmann $M$, and Kunzel $W$. Dynamic changes in organ bood flow and oxygen consumption dung acute asphyxu in fetal sheep. / Dov Physio $9: 543-559,1987$.

30. Jensen A and lang U. Foetal circulatory responses to arest of uterife blood flow in sheep: effects of chemical sympathectony. / Dev Physiol 17: 75-80, 1902 .

3. Kartowicz MG and Adelman RD. Nonoligutic and oliguric acute renal failure in asphyxiated term neonates. Fodiar Nephol o: $718-722,1905$.

32. Kusuda S, Kim T, Miyag N, Shishida N, hitani H, Tanaka Y, and Yamairi T. Postnatal change of renal artery blood flow velocily and its relationship with wine volume in very low birth weight infants duting the first month of lle. JPrinat Med 27: 107-111, 1099.

33. Laklhdir $\mathrm{BR}$, Tong $\mathrm{H}$, and Wood $\mathrm{CE}$. Baroreceptor and prostanoid control of fetal renal cordical blood flow and plasma renin activity. Reprod Ferin Dey 13: 119-124, 2001.

34. Luciano R, Galin F, Romagnoli $\mathrm{C}$. Papacc $P$, and Tortorolo G. Doppler evaluation of renal blood low welociry ass a predictive index of acute renal falure in perinatal asphyxia. Eur f Pedar 157: 656-060, 1908.

35. Lumbers ER, Gunn AJ, Zhang DY, Wu IJ, Maxwell L, and Bennet L. Nonimmune hydrops fetalls and activation of the reninangiotensin system atter asphyxia in preterm fetal sheep. Am I Physiol Regul Integr Comp Physol 280: R1045-R1051, 2001 .

36. Nakamura KT, Ayes NA, Gomez, RA, and Robillard JE. Renal pesponses to bypoxemia during renin angiotensin

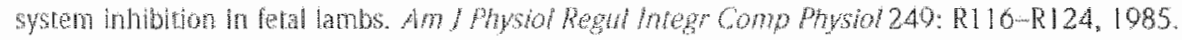

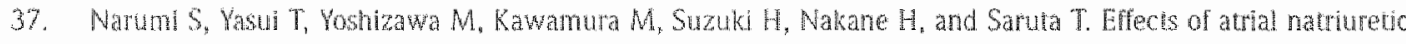
peptide on renal function and lentin release in the isolated perfused rat kidnew Jph Hedr/28, 221-227, $198 \%$.

38. OConnell AE, Boyce AC, Lumbers ER, and Gibson K. The effects of asphyxia on teral function in fetal sheep at midgestation. Fysol $552: 033-043,2003$.

30. Okumuma A, Toyota N, Hayakawa F, Kato T, Maruyama K, Kubota T, Kidokoro H, Kuno K, and Watanabe K. Cerebral hemodynamics duning early neonatal period in preterm infans with periventricular leukonalacia. Brain Dev24: $003-607,2002$.

40. Raff $\mathrm{H}$ and Wood CE. Effect of age and blood pressure on the heart rate, vasopressin, and renin response to hypoxia in fetal sheep. Am / Whystol Regul Integr Comp Physio 263: R880-R884, 1902.

41. Robilard JE, Weitman RE, Burmetster $\mathrm{L}$, and Smih FG Jr. Developmental aspects of the renal response ro Inpokema in the tamb fetus. Cirmes $48: 128-138,1981$.

42. Rosnes IS, VatrgoN, Wang 1, Zehnder T, and Rose $\mathrm{C}$. Actire renin, prorenin, and reningene expression after reduced renal perfusion pressure in term ovine fetuses. Am / physol Regul htegr Comp physiol275: R141-R147, 1998.

43. Star RA. Theatment of acute renal dailute. Kidney ho 54: 1817-1831, 1908. 


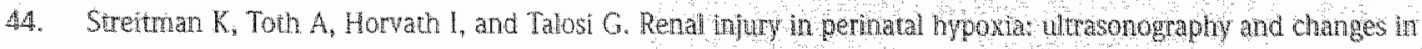
renal function. Ev J Pediat 160:473-47?, 2001

45. Toth-Heyn P, Drukker A, and Gugnard IP. The sthessed neonatal kidney trom pathophysology to onncal management of neonatal wasomotor nephropathy Pedatm Nephol $14: 227-239,2000$.

46. Towsioless MK, McDougall IG, and Wintour EM. Cestational chathge in renal responsiveness to cortisol in the ovine leus. Pediatr Res $20: 6-10,1989$.

47. Wan de Bor $M$. Renal blood flow velocity in nondistressed pretem infants during the first 72 hours of life. Bol Neonate 67: 346-351, 1995.

48. Wanpee M, Ergander U, Herin P, and Aperia A. Renal function in sick, very low bith-weight infants. Acta Padat" 82: $714-718,1993$.

49. Waville VA, Nakamura KT, McWeeny OI, Matheme GP, Smith FG, and Robillard JE. Renai hemodynamic response to atrial natriuretic factor in fetal and newbom sheep. Pediatr Res 25: 291-294, 1989.

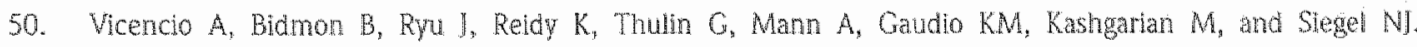
Developmental expression of HSP-72 and ischemic tolerance of the immature kidney. Pediatr Nephrol $18.85-91$, 2003.

51. Villarreal D, Freman RH, Davis JO, Verburg KM, and Var RC. Renal mechanisms for suppression of tenim secretion by atrial natriuretic factos. Hypertension 8 : $1128-1135.1986$.

52. Wikins BH. Renal function in sick very low birthweight infants. 3. Sodium, potassium, and water excretion. Arch Dis Child 67: 1154-1161, 1992. 



\title{
Chapter 7
}

\author{
CARDIOVASCULAR AND \\ ENDOCRINE EFFECTS \\ OF A SINGLE COURSE \\ OF MATERNAL
}

DEXAMETHASONE TREATMENT

IN PRETERM FETAL SHEEP.

J.S. Quaedackers, V. Roelfsema, M. Fraser, A.J. Gunn, L. Bennet.

British Journal of Obstetrics and Gynaecology $2005 \mathrm{Feb} ; 112(2): 182.91$.

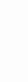




\section{ABSTRACT}

Objective: To determine the effects of a single course of maternally administered dexamethasone on preterm fetal sheep in utero.

Desigh Prospective randomised controlled trial.

Setting: University laboratory.

Sample: Pregnant sheep at 0.7 of gestation.

Methods: Pregnant ewes at 103 days of pregnancy (term $=147$ days) were given two intramuscular injections of vehicle $(\mathrm{n}=7)$ or $12 \mathrm{mg}$ of dexamethasone (DEX; $\mathrm{n}=8) 24$ hours apart. Fetuses were continuously monitored for five days.

Main outcome measures: Fetal mean arterial blood pressure, carotid and femoral arterial blood flow and vascular resistance, heart rate, heart rate variability, fetal plasma cortisol and ACTH and fetal body movements.

Results: DEX injections led to an acute increase in mean arterial blood pressure with a rise in carotid and femoral vascular resistance, a fall in femoral arterial blood flow, and a brief fall in fetal heart rate followed by significant tachycardia. From 24 hours after the injections, mean arterial blood pressure and vascular resstance retumed to control values, however, a mild tachycardia 200 (3) vs:184 (4) bpm, $P<0.05$ and loss of the circadian pattern of fetal heart rate variability persisted until the end of recording. Plasma ACTH and cortisol were markedly suppressed by DEX $(P<0.05)$, with values returning to control Jevels 32 and 72 hours after the first miection, respectively. There was no effect (x) on basal fetal heart ratevariability, body movements, warofid anterial blood low, or the circadian pattern 1.

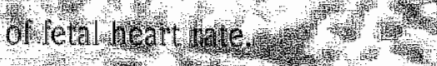
त)

Grichsion in contrast to previous experiments utilising direct fetal infusion of steroidsthaternal

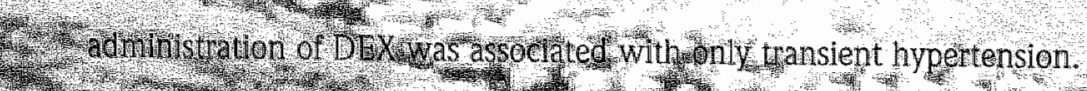

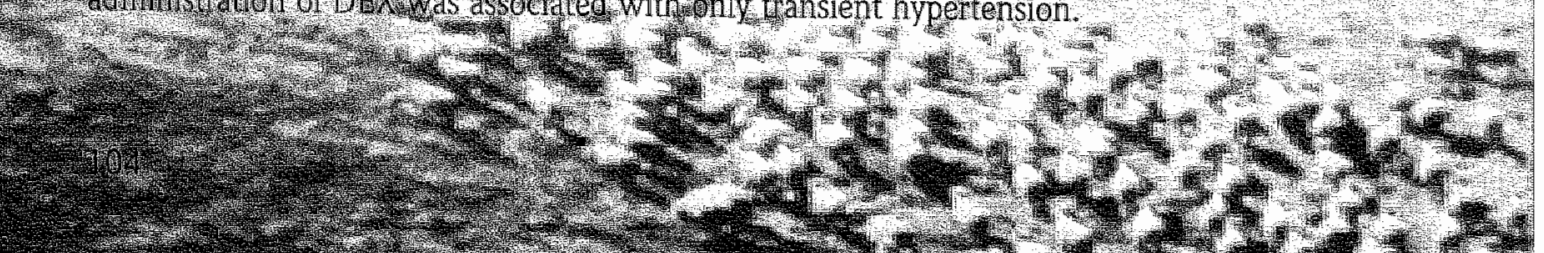




\section{INTRODUCTION}

The current recommended single course of ghucacorticoids has unequivacal benefits for the premature newborn that outweigh any short term risks for mother and newborn. 'However, as highlighted in the $1995 \mathrm{NIH}$ consensus statement, there is a need for further research on the longer term effects of both short and repeated courses. ${ }^{2}$ There is increasing interest in the role that antenatal steroid exposure may have in subsequent adult cardiovascular disease and whether these changes are already evident in utero. ${ }^{3}$ Currently, there are only limited and conflicting clinical data on the influence of antenatal steroids on adult cardiovascular function. ${ }^{4,5}$

Recent experimental data, however, suggest that even a single course of steroids may alter detrimentally fetal cardiovascular function. In near term fetal sheep, glucocorticoids have been reported to cause a significant reduction in cerebral blood flow, ${ }^{\circ}$ sustained elevation of blood pressure, 7,8 increased baseline cortisol but not ACTH levels 48 hours later, ${ }^{\circ}$ increased central and peripheral vascular resistance, ${ }^{6-8}$ and altered vascular sensitivity to endothelium-derived factors. 10,11 In late gestation rats, dexamethasone (DEX) results in altered cardiac innervation and B-adrenergic function. ${ }^{12.13}$ Further, there is experimental evidence to show that there are altered perinatal responses to hypoxia, which potentially could compromise adaptation to labour. ${ }^{14-16}$ It is of concern that there are also now data suggesting that infants exposed to a single course of corticosteroids more than seven days before birth may have increased perinatal mortality. ${ }^{17}$

While these data argue strongly that even a single course of steroids may cause significant and potentially harmful changes in cardiovascular function, interpretation of these studies is problematic due to a number of methodological considerations; in particular, the route of administration and degree of maturity. Many of the experimental studies, for example, utilised a direct infusion or injection to the fetus. This direct and constant exposure is quite different from the profile of clearance seen after maternal administration. $18-20$ Several studies have shown that the route of administration may be critical to how the fetus responds to glucocorticoids. Organ maturation is significantly different after maternal compared with direct administration to the fetus, ${ }^{21}$ and neonatal blood pressure changes after antenatal treatment have been shown to be both route and dose dependent. ${ }^{22}$ Maternal administration of DEX in late gestation induced only transient cardiovascular effects, ${ }^{10}$, while a lower dose in preterm sheep had no effect on blood pressure. ${ }^{23}$ In contrast, maternal betamethasone in the preterm baboon caused an acute elevation of fetal blood pressure for at least 24 hours, 24 although the subsequent changes are unknown. While there may be differences related to the type of steroid used, these and other clinical and experimental data, ${ }^{25,26}$ suggest that maturity at the time of exposure is important.

Thus, it is not known whether a single course of maternal treatment with synthetic glucocorticolds leads to prolonged hypertension or increased baseline cortisol levels in the preterm fetus. Therefore, it was the purpose of the current study to assess the cardiovascular responses, and associated endocrine and behavioural changes, in the preterm fetal sheep to a single course of DEX consisting of two maternal injections given 24 hours apart, ${ }^{27}$ with fetal follow up in utero for five days.

\section{METHODS}

All procedures were approved by the Animal Ethics Committee of The University of Auckland. Fifteen singleton Romney/Suffolk fetal sheep were instrumented at $97-99$ days of gestation (term $=147$ days) as previously described. ${ }^{28}$ This age approximates the 32 week human when comparing neuronal 
development. ${ }^{29}$ Food, but not water, was withdrawn 18 hours before surgery. Ewes were given $5 \mathrm{~mL}$ of Streptopen [Procaine Penicillin $(250,000$ lU) and Dihydrostreptomycin $(250 \mathrm{mg}) / \mathrm{mL}$, PitmanMoore, Wellington, New Zealand] intramuscularly 30 minutes prior to the start of surgery. Anaesthesia was induced by an intravenous injection of Saffan [Alphaxalone and Alphadolone; $3 \mathrm{mg} / \mathrm{kg}$, ScheringPlough Animal Health, Wellington, New Zealand), and general anaesthesia was maintained using $2-3 \%$ halothane in oxygen.

Using sterile techniques, the uterus was exposed via a midline incision and the fetal hind limbs and abdomen were exteriorised. Polyvinyl catheters were placed in the left femoral artery and vein to measure fetal arterial and venous blood pressure. A 2R ultrasound blood flow probe (Transonic Systems, Ithaca, New York, USA) was placed around the right femoral artery to measure femoral blood flow. The uterus was then closed in layers and the upper body of the fetus was exteriorised via a second uterine incision. A polyvinyl catheter was placed in the right brachial artery for pre-ductal blood sampling. Electrodes (Cooner Wire, Chatsworth, California, USA) were placed in the nuchal muscle to measure nuchal EMG activity as an index of fetal body movements, and ECG electrodes were sewn across the chest to record fetal heart rate. A multiperforated catheter was placed in the amniotic sac to record intra-amniotic pressure. A 35 ultrasound blood flow probe was placed around the left carotid artery to measure carotid artery blood flow. This measurement is an index of cerebral blood flow, with a strong correlation with direct microsphere measurements. ${ }^{30}$ All fetal leads were exterionised through the maternal flank and a maternal long saphenous vein was catheterised. Antibiotics were administered into the amniotic sac $180 \mathrm{mg}$ Gentamicin, Pharmacia \& Upjohn, Rydalmere, NSW, Australial prior to closure of the uterus.

After surgery, sheep were housed together in the vivarium in separate metabolic cages with access to water and food ad libitum. They were kept in a temperature-controlled room $\left[16^{\circ} \mathrm{C}\left(1^{\circ} \mathrm{C}\right)\right.$, humidity $50 \%(10 \%)$, in a 12 hour light/dark cycle. A period of four days post-operative recovery was allowed, during which time antibiotics were administered intravenously daily to the ewe $(600 \mathrm{mg}$.Crystapen, Biochemie, Vienna, Austria, for four days and $80 \mathrm{mg}$ Gentamicin, daily for the first two days). Catheters were maintained patent by continuous infusion of heparinised saline $(20 \mathrm{U} / \mathrm{mL}$ at $0.2 \mathrm{~mL} / \mathrm{h})$.

Experiments were conducted at 103 days (0.7) of gestation. Fetal arterial and venous blood

Table 1. Fetal arterial $\mathrm{pH}$, blood gas, glucose and lactate data for control (C) and DEX (D) groups.

Time is taken from injecion one.

\begin{tabular}{|c|c|c|c|c|c|c|}
\hline & & Con & 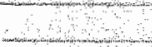 & & $D E X-1$ & \\
\hline & & & $3 \mathrm{~h}$ & $6 h$ & 81 & $235 \mathrm{~h}$ \\
\hline phl & $C$ & 739000 & $740(0.0)$ & $7.40(00)$ & $7,40(0.0)$ & $737(0: 0)$ \\
\hline & 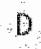 & $739(0.01)$ & $738(0.02)$ & $738(0.02)$ & $739(0,02)$ & $739(0.01)$ \\
\hline $\mathrm{PaCO}_{2}$ & $c$ & $6.4(02)$ & $6,6(0.2)$ & $6.5(0.2)$ & $6.5(0.2)$ & $67(02)$ \\
\hline$(\mathrm{KPa})$ & $D$ & $6.5(02)$ & $6.8(0.2)$ & $67(0.2)$ & $6.7(0.2)$ & 63102 \\
\hline $\mathrm{PaO}_{2}$ & $C$ & $3.4(0.1)$ & $35(0.2)$ & $34 / 01$ & $33(01)$ & $3.4(02)$ \\
\hline (KPa) & $D$ & $31(0,1)$ & $3.1(0.2)$ & $32(0.2)$ & $28(01)$ & $32(0.2)$ \\
\hline Glucose & $C$ & $09(01)$ & $0.9(0.4)$ & $10(01)$ & $1.0(0)$ & $10(0.1)$ \\
\hline (nimoll) & D & 0.7011 & $13(0,1)^{*}$ & $21(03)^{1}$ & $17(0,2)^{\circ}$ & $12(0.1)^{\circ}$ \\
\hline Lactate & $c$ & $0.6(0.1)$ & $0.6(0)$ & $07(0.1)$ & $07(0,1)$ & $06(0,1)$ \\
\hline nomolls & D & $0.5(0.1)$ & $0.9(0.2)^{\circ}$ & $1,4(0.2)^{\circ}$ & $13(0.2)^{7}$ & $07(0,1)^{\star}$ \\
\hline
\end{tabular}

$\mathrm{P}<0.65$. Data are mean'(sem) 
pressure, corrected for amniotic fluid pressure, fetal heart rate, femoral arterial blood flow and carotid artery blood flow were recorded continuously from 6 hours before the first DEX injection to 120 hours afterwards. Data were stored to disk by custom software for offine analysis (Labview for Windows, National Instruments, Austin, Texas, USAl.

Fetuses were randomly assigned to either the DEX group $(n=8)$ or the control group $(n=7)$. Following baseline recording, the ewes [weighing $60.5(1.0) \mathrm{kg}$ ) received an intramuscular injection of either DEX (DEX-1; $12 \mathrm{mg}$ in $3 \mathrm{~mL}$ saline, DEX sodium phosphate, DBL, David Bull Laboratories, Mulgrave, Victoria, Australia) or vehicle ( $3 \mathrm{~mL}$ isotonic saline) at 11.00 hours, which was repeated after 24 hours (DEX-2). No ewes in either group went into labour. Fetal arterial blood $(350 \mu \mathrm{L})$ was taken from the brachial artery for pre-ductal $\mathrm{pH}$ and blood gas determination (Ciba-Corning Diagnostics 845 blood gas analyser and cooximeter, Massachusetts, USA) and for glucose and lactate measurements (YSI model 2300, Yellow Springs, Ohio, USA) 30 minutes before each injection, and 30 minutes, 1, 3, 6 and 8 hours following each injection, then $48,72,96$ and 120 hours following the first injection. Fetal arterial blood samples (1 mL) were taken for ACTH and cortisol measurements at the same time points. Blood was transferred immediately upon collection to chilled test tubes and spun at $4^{\circ} \mathrm{C}(3000 \mathrm{rpm})$ for 15 minutes. Plasma was stored at $80^{\circ} \mathrm{C}$ for subsequent analysis. On completion of the experiment at 120 hours after DEX-1 the fetuses and ewes were killed by sodium pentobarbitone $(9 \mathrm{~g}$ iv to the ewe: Pentobarb 300 , Chemstock International, Christchurch, New Zealand). Fetal body and organ weights were measured.

Immunoreactive cortisol concentrations were determined after extraction with diethyl ether by a modified radioimmunoassay validated for use with maternal and fetal ovine plasma. ${ }^{31}$ The antiserum to cortisol was raised in rabbits against Cortisol 3-CMO/BSA and was used at a final dilution of $1: 19,200$. The cross-reactivity of the antiserum at $50 \%$ binding with other relevant steroidrelated compounds was $3.3 \% 11$ deoxycortisol, $0.18 \%$ cortisone, $0.5 \%$ corticosterone, $0.015 \%$ progesterone and $0.002 \% 11$ a-hydroxyprogesterone (Steraloids, Newport, USA). No detectable cross-reactivity was observed for 17ahydroxypregnenolone, pregnanediol, 21-deoxycortisone, aldosterone, cholesterol or DEX (Steraloids). The lower limit of detection was $10 \mathrm{pg} /$ tube $(0.13 \mathrm{ng} / \mathrm{mL}$ ); samples containing $<0.13 \mathrm{ng} / \mathrm{mL}$ were given this value for the purposes of analysis. The intra- and inter-assay coefficients of variations were $3.68 \%$ and $3.97 \%$, respectively, at the cortisol concentrations determined in plasma.

Immunoreactive concentrations of ACTH were measured using a commercially available 1251 radio-immunoassay kit (24130, DiaSorin, Stillwater, Minnesota, USA) previously validated for use with both fetal and maternal ovine plasma. The intra-assay and inter-assay coefficient of variation were $9.7 \%$

$D E X 2$

\begin{tabular}{|c|c|c|c|c|}
\hline $27 \mathrm{~h}$ & $30 h$ & 324 & $48 \mathrm{~h}$ & $120 \mathrm{~h}$ \\
\hline $739(00)$ & $737(0.0)$ & $738(0.0)$ & 73610.01 & $738(0.0)$ \\
\hline $737(001)$ & $739(0001)$ & $739(0,01)$ & $736(001)$ & $7.37(0.00)$ \\
\hline $6.6(0.2)$ & $6.8(01)$ & $67(0,2)$ & $6.6(0.2)$ & $6.4(0.1)$ \\
\hline $65(0.2)$ & $6.4(0.1)$ & $6,4(02)$ & $6.4(0.2)$ & $6.6(0.1)$ \\
\hline $3.4(0.2)$ & $3.3(0.1)$ & $33(0.1)$ & $3.4(0.2)$ & $3.3(0.1)$ \\
\hline $3.3(02)$ & $3.3(0.2)$ & $3.1(0.2)$ & $20(0.2)$ & $3.0(02)$ \\
\hline $10(01)$ & $1.1(0,1)$ & 09000 & $0.9(0.1)$ & $0.9(00)$ \\
\hline $17(0,2)^{*}$ & $2010,3)^{\circ}$ & $20(03)$ & $1.3(0.1)^{*}$ & $0.9(0.1)$ \\
\hline $07(0,1)$ & $0.7(0.1)$ & $07(01)$ & $0.7(0.1)$ & $0.7(0.0)$ \\
\hline $0.9(0.1)^{*}$ & $1,(01)^{\prime}$ & $1.090 .1)^{2}$ & $07(0.0)^{*}$ & $0.8(0.1)^{\circ}$ \\
\hline
\end{tabular}


and $12.8 \%$, respectively. The mean sensitivity of the ACTH assay was $9.7 \mathrm{pg} / \mathrm{mL}$; samples containing $<9.7 \mathrm{pg} / \mathrm{mL}$ were given this value for the purposes of analysis.

The mean fetal arterial blood pressure corrected for amniotic pressure (Novatrans II, MX860; Medex; Hilliard, Ohio, USA) and ECG readings were recorded continuously. The blood pressure signal was collected at $64 \mathrm{~Hz}$ and low pass filtered at $30 \mathrm{~Hz}$. The nuchal EMG signal was bandpass filtered between $100 \mathrm{~Hz}$ and $1 \mathrm{kHz}$, the signal was then integrated using a time constant of 1 second. The raw ECG reading was analogue filtered between 0.05 and $80 \mathrm{~Hz}$ and digitised at $512 \mathrm{~Hz}$. ${ }^{32}$ Fetal heart rate was measured using the ECG signal. Fetal heart rate variability was calculated by the method described by Dawes et all, ${ }^{33}$ to obtain the mean minute range (the difference between the maximum and minimum RR intervals every minute). Fetal heart rate variation was not measured during accelerations or decelerations of $\geq 10 \mathrm{bpm}$ for 1 minute or $\geq 20 \mathrm{bpm}$ for $>30$ seconds. ${ }^{33}$ Offline analysis of the phystological data was performed using customised Labview programmes (National Instruments).

Vascular resistances for the femoral and carotid beds were calculated using the formula (mean arterial pressure mean venous pressure)/absolute blood flow ( $\mathrm{mmHg} / \mathrm{mL} /$ minute). Statistical analysis was performed using SPSS (SPSS, Chicago, Llinois, USA). The effect of DEX on physiological, blood gas and hormonal variables was tested by analysis of covariance, with time treated as a repeated measure to allow for repeated sampling. For continuous variables, the baseline period was taken as the mean of the 6 hours before injection. The effects of DEX on the acute treatment period up to 48 hours after DEX-1 and for the remainder of the study were evaluated separately. If a significant treatment effect or an interaction between treatment and time was found, individual time points were compared by analysis of covariance. Statistical significance was accepted when $P<0.05$. Data are mean (SEM).

\section{RESULTS}

DEX injections led to a prolonged increase in fetal plasma glucose and lactate, but no significant overall change in fetal $\mathrm{pH}$ and $\mathrm{PaCO}_{2}$ (Table 1). Some time points, in which there were no significant changes, have been omitted for brevity. There was a significant interaction between treatment and the time course of changes in $\mathrm{PaO}_{2}$, with a small fall in fetal $\mathrm{PaO}_{2}$ at 8 hours after DEX-1 $2.8(0.1) \mathrm{kPa}$ vs. 3.3 (0.1) $\mathrm{kPa}$ in controls; $P<0.05$.

Fetal body weight $\left[1613\right.$ (54) $\mathrm{g}$ in controls $v S_{.} 1627$ (57) $\mathrm{g}$ in the DEX groupl and organ weights, including the heart, lungs, kidney, adrenal gland and spleen, were not significantly different between the control and DEX groups.

After DEX-1, there was a significant increase in mean arterial blood pressure for 50 hours $(P<0.05$, Fig. 1). Following DEX 1 , mean arterial blood pressure rose markedly, peaking at around 3 hours $[43.9$ (1.3) mmHg vs. $35.7(0.7) \mathrm{mmHg}$ in controls; $P<0.00 \%$. Mean arterial blood pressure was then attenuated, but remained significantly elevated by the time of the second DEX injection (Fig. 1). Following DEX 2, there was a similar rise in mean arterial blood pressure superimposed on an elevated pre-injection baseline, again peaking at 3 hours $146.1(1.1) \mathrm{mmHg}$ vs. $36.0(0.7) \mathrm{mmHg} ; P<0.001]$.

Fetal heart rate showed a similar biphasic response to both DEX injections (Fig. 1). Initially, there was a significant fall in fetal heart rate during the first 3 hours $(P<0.05)$, corresponding with the marked rise in mean arterial blood pressure. Although following DEX-2 this fall was not significant compared with the control group, it was significant compared with the period immediately preceding DEX 2 injection $(P<0.05\}$. Following this brief bradycardia, the fetal heart rate response was variable, with a transient period of tachycardia observed following DEX-1 between 19 and 24 hours $(P<0.05)$, whereas a sustained tachycardia was seen after DEX $2(P<0.05)$. 


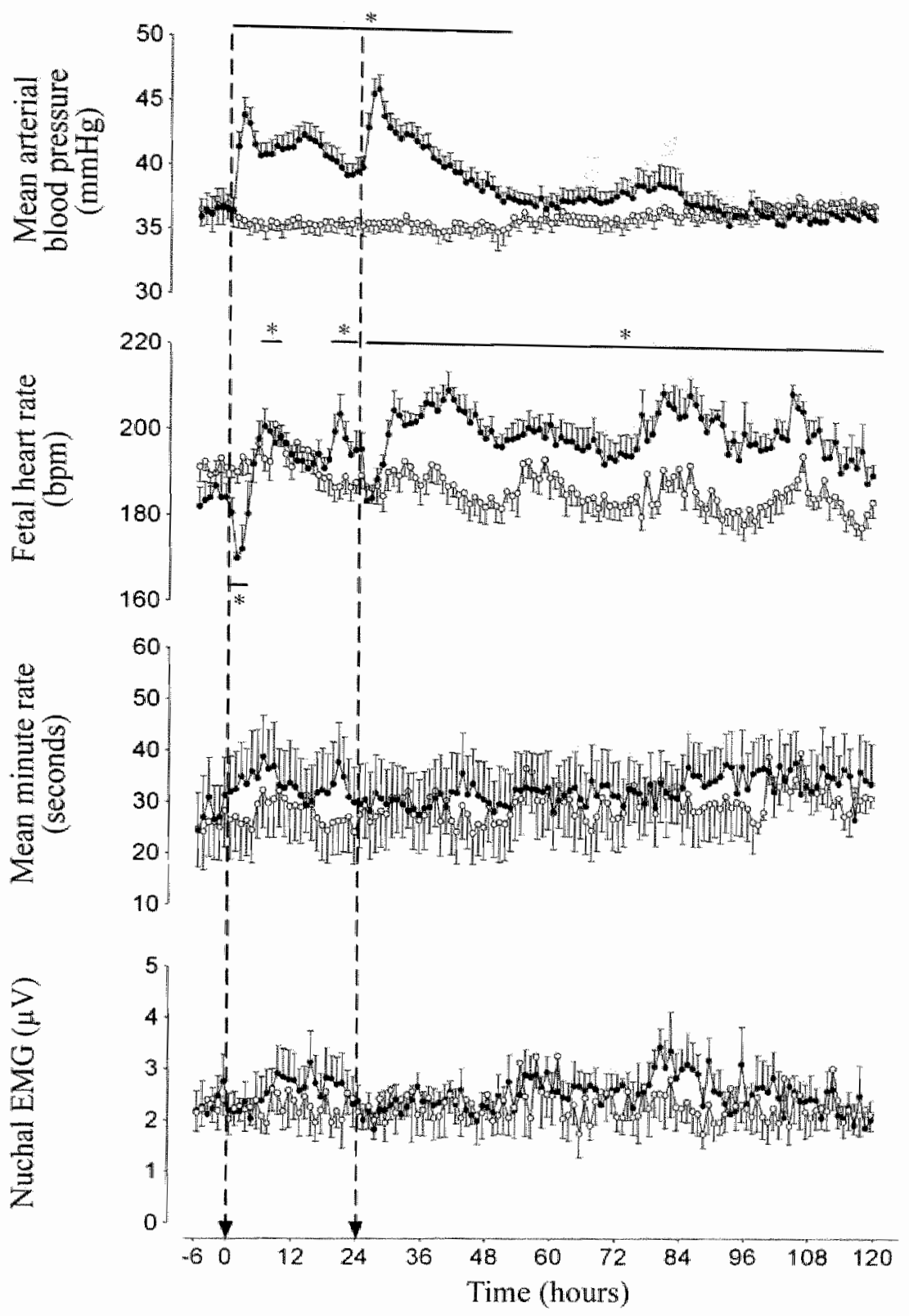

Fig. 1 . Time sequence of changes in feta! mean arterial blood pressure and heart rate, felal heart rate vartability (mean minute ratel and nuchal muscle EMG activity. Controls lopen circles, $n=7$ and fethses whose mothers rectwed wo DEX injections 24 hours apart (filled circles, $n=8$ ] are showh from o hours before the first injection, to 120 hours afterwards. The dashed arrows show the timing of injections. Data ate one hour averages, mean (SEM). *P< $<0.05$, DEX versus controls, analysis of covariance. 

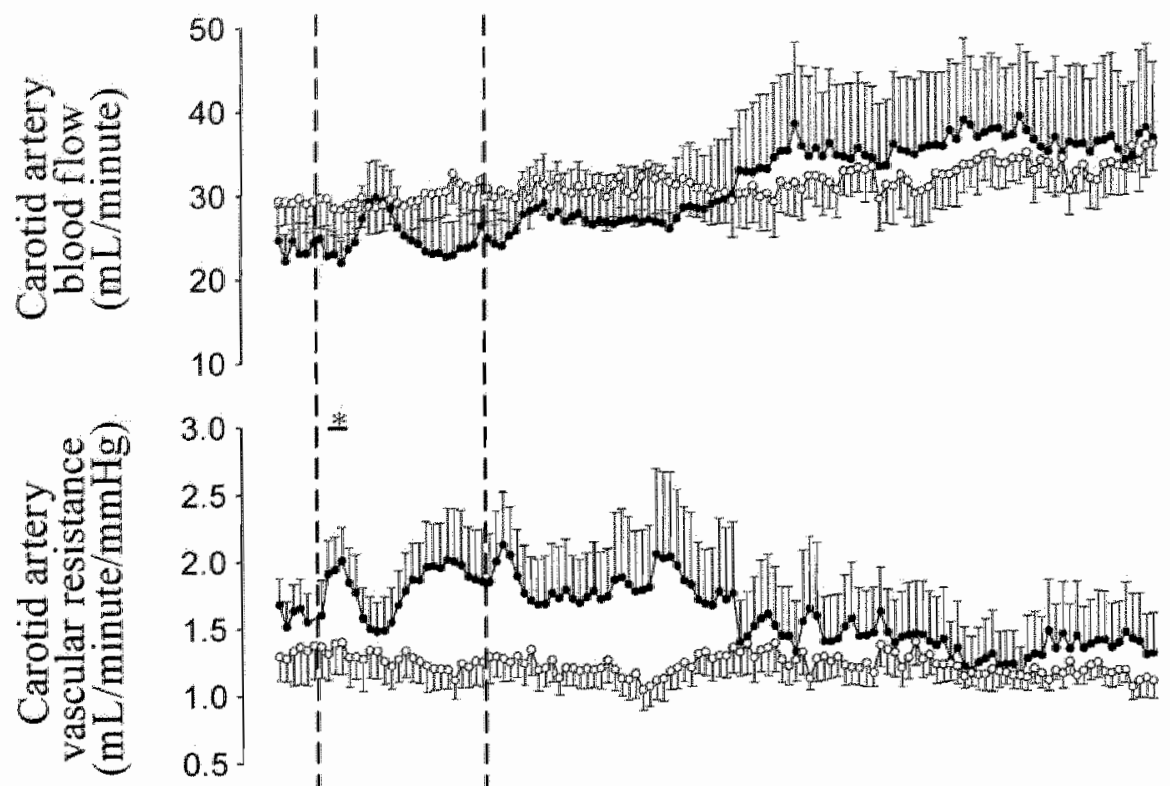

20
10<smiles>IC1CCCCC1</smiles>

3.0
2.5
2.0
1.5
1.0
0.5
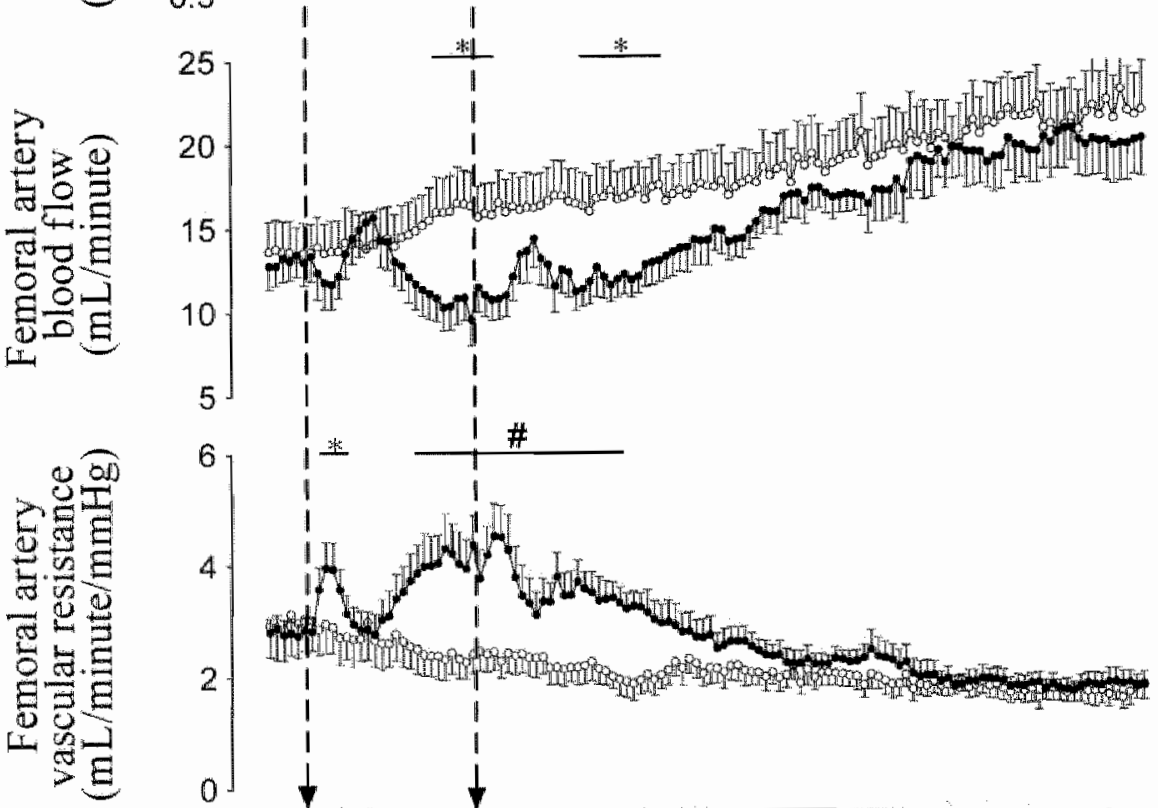

10
5
6
4
2
0 1.

MI

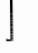




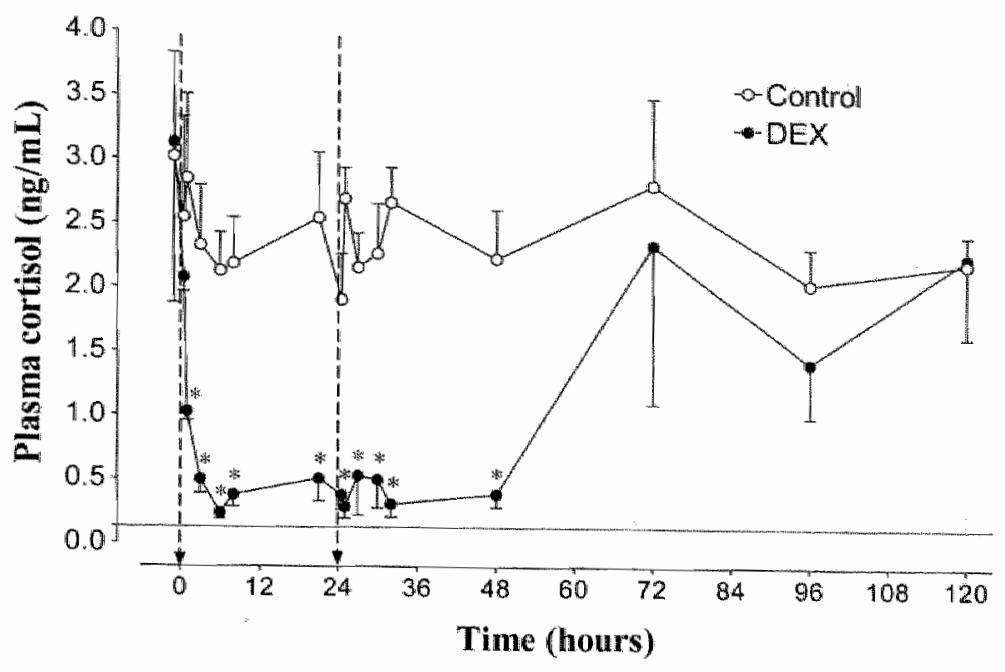

Fig. 3. Time sequence of changes in fetal plasma cortisol concentrations, showing fetuses whose mothers received either vehicle injection fopen circles, $n=7$ ) or two DEX injections 24 hours apart (closed circles, $n=8$ ). The vertical dashed arrows show the timing of two injections. The horizontal dashed line denotes the level of detection for the assay. Data are mean $(S E M),{ }^{*}<<0.05$, DEX versus controls, analysis of cowariance.

While there was a tendency for mean minute range to be elevated after DEX-1, there was no significant difference between groups throughout the study (Fig. 1). Similarly, there were no differences between groups in fetal body movements (Fig. 1).

Treatment with DEX was associated with a significant effect on carotid artery blood flow and carotid artery vascular resistance in the first 48 hours, as shown by significant interactions between treatment and time for both parameters $(P<0.05)$; in particular, there was a rise in carotid artery vascular resistance from 2 to 4 hours after DEX-1 (Fig. 2). While there was a trend for carotid artery vascular resistance to be elevated at later time points, this was not significant. There was no significant overall change in carotid artery blood flow.

Femoral arterial blood flow showed a modest fall after the first injection (Fig. $2, P<0.05$ ). A transient return to control values was followed by a much longer fall that was signiffcant between 18 and 29 hours and again between 38 and 51 hours $(P<0.05)$. Thereafter, there were no differences between groups. There was a similar biphasic pattern of changes in femoral artery vascular resistance following both DEX injections, which was superimposed on an elevated baseline following DEX-2 (Fig. 2). After injection one, femoral artery vascular resistance rose between 2 and 5 hours $(P<0.05)$, transiently normalised, then became significantly elevated again from 14 to 51 hours $(P<0.001$ ).

Plasma cortisol levels were rapidly suppressed following DEX-1 to a minimum of $0.24(0.04) \mathrm{ng} / \mathrm{mL}$. at 6 hours $\mid v s .2 .13(0.30)$ in controls, $P<0.001]$ and did not recover until 72 hours after DEX-1 (Fig. 3). For the remainder of the study, plasma cortisol leveis were not different between groups.

Similarly, plasma ACTH levels fell to below the detectable level from 6 hours after DEX-I injection |detection level $9.7(0.0) \mathrm{vs} .12 .9(5.0) \mathrm{pg} / \mathrm{mL}$ in controls] until DEX-2 $[9.70(0.0) \mathrm{vs} .10 .5(2.2) \mathrm{pg} / \mathrm{mL}$ in controls, $P<0.05]$. ACTH levels returned to control values by 48 hours after DEX-1 $\| 10.6(0.9\}$ vs. $14.3(2.8) \mathrm{pg} / \mathrm{mL}, \mathrm{N} . \mathrm{S} .1$, and were not different from the control group for the remainder of the study $[13.6(3.0)$ vs. $10.4[0.7] \mathrm{pg} / \mathrm{mL}$ at 120 hours after DEX-1]. 


\section{DISCUSSION}

This study demonstrates that maternal administration of a single course of DEX in sheep at 0.7 of pregnancy is associated with only a transient increase in blood pressure which was mediated by both changes in peripheral and central vascular resistance and fetal heart rate. Further, there were no significant changes in brain perfusion, basal fetal heart rate variability, the diurnal pattern of fetal heart rate or body movements. Although the suppression of the hypothalamic-pituitary-adrenal axis resolved by two days after the second injection, there was a sustained increase in fetal heart rate after the second injection and a loss of diurnal rhythm in fetal heart rate variability.

A key linding of the current study is the observation that blood pressure and vascular resistance changes after DEX were relatively transient. These data are in contrast to the sustained increase in pressure and vascular resistance that was observed for at least 48 hours after short term fetal intravenous infusion. 7,8 The data in the current study are, however, consistent with the long term normal blood pressure observed after varying maternal glucocorticoid treatments at 0.4 and 0.7 gestation. ${ }^{26,34}$ Further, in the 0.7 gestation baboon, although fetal blood pressure was still elevated 24 hours after matemal treatment, mean arterial blood pressure appeared to be falling towards baseline at that time, consistent with the present study. ${ }^{24}$ In the near term fetus, the transient increase in blood pressure resolved more quickly than seen in present study, ${ }^{18}$ suggesting a maturational influence. Overall, however, these data suggest that differences in the profile of plasma DEX levels between regimens are a more important factor.

The experimental approach of constant low dose fetal infusion of long-acting synthetic glucocorticoids leads to constant direct fetal vascular exposure at relatively stable leveis, whereas after a single injection there are very high levels initially followed by rapid clearance. ${ }^{18,20}$ The model of fetal intravenous infusion was created to avoid potential confounding influences of differences in transplacental passage between individual animals to facilitate direct assessment of the effects of glucocorticoids on the fetus and to avoid interspecies differences. 7,8,35 Interestingly, such studies have suggested that levels as low as one-fifth of those measured in umbilical arterial blood samples taken from human infants at caesarean section, 12 hours after the completion of a maternal course of glucocorticoids, appear to be effective, ${ }^{20,30}$ raising the possibility that current regimens could be optimised. ${ }^{35,36}$ The current study, however, highlights potential limitations of this approach when extrapolating to the clinic, such as the greater fetal cardiovascular perturbations after fetal administration.

During fetal infusion of glucocorticoids, blood pressure is primarily elevated by increased peripheral and central vascular resistance. $0,7,30$ Mechanisms of the sustained increase in fetal peripheral resistance may include changes in circulating levels of vasoconstrictor agents $7,11,36$ and up-regulation of receptors to many vasoconstrictors and down-regulation of potential vasodilators. ${ }^{10} \mathrm{In}$ particular, fetal infusion of glucocorticoids elevates fetal plasma adrenaline and NPY concentrations during and after infusion, as well as increasing endothelin $\mathrm{ET}_{\mathrm{A}}$ subtype receptors and contractility in fetal femoral, but not cerebral, arteries. " Further, the increased fetal mean arterial blood pressure could be related in part to an increase in the set point of the hypothalamic-pituitary-adrenal axis, with a sustained increase in baseline cortisol levels 48 hours after the infusion in near term fetal sheep, but normal ACTH levels. ${ }^{9}$ However, there was no evidence of an altered set point in the present study with simple normalisation of fetal ACTH and cortisol levels within 48 hours after DEX-1. Alternatively, the effect of glucocorticoids on blood pressure may, in part, be secondary to activation of the fetal renin-angiotensin system as seen with hypercortisolaemia. ${ }^{37,38}$ Consistent with this hypothesis, early glucocorticoid exposure in utero (around 0.2 of gestation but not later) is known to cause adult hypertension that may also be related to changes in the renin-angiotensin system. ${ }^{39}$ 
Iit is interesting to note that in the current study, in contrast to fetal infusion experiments, the acute changes in fetal mean arterial blood pressure were mediated by changes in combined ventricular output, as determined by fetal heart rate, 40 in addition to increased vascular resistance. Vascular resistance briefly returned to control values after both injections around 6 to 8 hours after injection; at this time, blood pressure was then supported by a marked increase in fetal heart rate. This variable control of blood pressure at different times may reflect the temporal clearance of DEX after maternal administration. While we have not evaluated the role of vasoconstrictors and vasodilators in this study, given that fetal mean arterial blood pressure did not remain elevated, it is likely that such endocrine changes were also transient. Consistent with this suggestion, in the present study, cortisol and ACTH suppression resolved in parallel with the resolution of DEX-induced hypertension.

We do not know, however, if endothelial sensitivity to vasoconstrictors has been modified and we cannot rule out more prolonged changes in sympathetic activity in cardiovascular control given the modest but sustained tachycardia we observed after injection two and the loss of the diurnal rhythm in fetal heart rate variability. Increased fetal heart rate has also been observed after the end of fetal infusion of DEX 15 and after both maternal and fetal injection in the late gestation sheep fetus. 18,41 A recent clinical study found a similar pattern after maternal injection at preterm gestations of initial bradycardia followed by a mild tachycardia. 42

The mechanisms mediating this tachycardia are unknown. One factor may simply be the increase in fetal plasma glucose. Glucose infusions increase fetal heart rate, ${ }^{43}$ probably secondary to increased basal metabolic rate. However, because blood glucose levels returned to control values at a time when fetal heart rate was still raised, this cannot be the only mechanism. Hypoxia can increase fetal heart rate, ${ }^{44}$ however, there were only transient changes in fetal $\mathrm{PaO}_{2}$. Alternatively, glucocorticoids are known to have direct chronotropic effects, mediated by augmented coupling of the S-adrenoreceptors to cellular postreceptor signal transduction 12 and potentially by augmenting sympathetic responses. 45,46 Furthermore, Padbury et al. ${ }^{41}$ have shown that newborns who had received antenatal betamethasone had significantly elevated blood pressure, cardiac output and cardiac contractility, despite similar preload (as assessed by left ventricular end-diastolic pressure). In part, this may be due to a significant increase in B-adrenergic receptor-dependent myocardial cyclic adenosine monophosphate generation. ${ }^{47}$ The physiological meaning of these cardiac observations cannot be determined from the current study. Experimentally, although adult sheep previously exposed to DEX near mid-gestation are normotensive with normal cardiac output, they have altered baroreceptor -heart rate responses. 48

It was also notabie that despite the immaturity of the fetuses in the present study there was a marked diurnal rhythm in fetal heart rate, which was not affected by DEX treatment after injection two. In contrast, there was a loss of the more modest circadian pattern seen in fetal heart rate variability. A diurnal rhythm in fetal heart rate and fetal. heart rate variability has also been observed in the preterm human fetus, ${ }^{49}$ and limited data suggest that the circadian pattern in mean fetal heart rate is not affected by betamethasone or maternal cortisol levels. ${ }^{50}$ The current study also suggests that it is not mediated by changes in fetal cortisol. The reason for the differential effect of DEX on the diurnal rhythms of heart rate and its variation is not clear, but the presence of a continuing rhythm in fetal heart rate argues against a specific effect of DEX within the hypothalamus. Instead, the loss of the diumal fetal heart rate variability pattern may potentially relate to altered autonomic control. In the fetus, as in the adult, the control of heart rate variability is complex, resulting from the cyclic interplay of sympathetic and parasympathetic branches of the autonomic nervous system and modified by fetal behaviour, chemoand baroreflexes. ${ }^{51-53}$ The synchrony of diurnal fluctuations in fetal heart rate variability is reflective of fetal autonomic nervous system regulation. ${ }^{5+4}$ Thus, speculatively, changes in both resting fetal heart 
rate and the loss of diumal thythm could be medated by an altered autonomic balance. Whether this cardiac change would have corrected over time remains to be determined.

We have previously reported that maternal DEX produces a marked biphasic time-dependent response in fetal heart rate variability in the nearterm fetal sheep. ${ }^{18}$ In contrast, in the present study. the same regimen produced only negligible effects on basal fetal heart rate variability in pretem fetuses. We observed no decrease with either injection and only a modest trend to increase with the fitst injection. Similatly, we observed no significant effect on body movements, which in part may account for these fetal heart rate warlability observations. Clinically, DEX has been reported to have a variable effect on body movements and generally produces either relatively small increases in fetal heart rate variability, a small increase followed by a decrease or no changes at all. "The differences in the current data compared with our previous findings at term suggest that differences in maturation may contribute to the apparent variability of fetal responses to glucocorticoids.

Finally, this is the first report of longitudinal effects of maternal administration of DEX on preterm fetal cerebral perfusion. Our data show that while there was a marked increase in carotid vascular resistance in the 24 hours after each injection, carotid artery blood flow was not significantly reduced and in the longer term there was a trend for blood flow to increase. These blood flow responses are consistent with those observed experimentally, 55 and clinically in the fetus, 56,57 and in newborms after antenatal treatment. ${ }^{58}$ These data are in contrast, however, to findings by Schwab et al. ${ }^{6}$ using fetal betamethasone infusion where a significant reduction in cerebral blood flow was observed, secondary to a marked increase in cerebral vascular resistance. It is unlikely that this simply reflects a difference between betamethasone and DEX since cinically, betamethasone leads to either no effect or increased perfusion, similarly to DEX. ${ }^{59,60}$ Again, these conflicting data suggest a differential impact of direct fetal exposure to steroids versus matemal administration.

\section{CONCLUSIONS AND PERSPECTIVES}

In the current study, a single course of matemal DEX led to only a transient increase in blood pressure in the preterm sheep fetus, with no sustained changes in vascular resistance. These findings are in contrast to previous studies of prolonged fetal infusions. However, while the cardiovascular data in the current study were on the whole reassuring, there were nonetheless some persistent changes in cardiac function which merit furthel" study.

In recent years, consistent reports of negative outcomes after repeated courses of steroids have led to emphasis on the importance of using only a single course of treatment. Yet there still remains a significant need for further systematic research on both short and long term outcomes after a single course of treatment. There is also, as suggested recently by Wijland, ${ }^{35}$ a need to assess what the optimal dosing regimen should be. The current study highlights some limitations of direct fetal infusion or injection for studies of the potential clinical impact of antenatal treatment with long-acting corticosterolds, and the importance of maturation in evaluating these issues.

\section{ACKNOWLEDGEMENTS}

This study was supported by grants from the Health Research Council of New Zealand, Auckland Medical Research Foundation and the Lottery Grants Board of New Zealand, and UPHS grant HD32752. 10 was supported by the Foundation 'De Drie Lichten' in The Netherlands. The authors would like to thank Davanea Forbes for her technical assistance, and Prof Dr J. de Haan for his helpful comments. 


\section{REFERENCES}

1. Dudley DI, Waters TP, Nathanielse PW. Current status of singlecourse antenatal steroid therapw. Chin Obstet Gmecol $2003 ; 46: 132-149$.

2. NHC Consensus. Effect of corticosteroids for fetal maturation on perinatal outcomes. NHH Consensus Development Panel on the Effect of Corticosteroids for Fetal Maturation on Perinatal Outcomes. /AMA 1995;273:413-418.

3. Newnham JP. Is prenatal glucocorticoid administration another origin of adul disease? Chin Exp Phatmacof phosto: 2001;28:957-961.

4. Doyle LW, Ford GW, Davis NM, Callanan C. Antenatal corticosteroid therapy and blood pressure at 14 years of age in preterm children. Clin Sci (Lond) 2000;98:137-1.42.

5. Dessens $A B$. Has HS, Koppe IC. Twentyear follow-up of antenatal conticosteroid treament. Pedatrics 2000:105:E77.

6. Schwab M, Roedel M, Anwar MA, er al. Effects of betamethasone administration to the feral sheep in late gestation on fetal cerebral blood llow. / Physio 2000,528:619-632.

7. Derks JB, Gussani DA, Jeakins SL, et al. A comparative study of cardiowascular, endocrine and behavioural effects of betamethasone and dexamethasone administration to fetal sheep. / Physiol 1997;499:217-220.

8. Fetcher A], McGarrigle HH, Eowards CM, Fowden AL, Gussani DA. Effects of low dose dexamethasone treatment on basal cardiovascular and endocrine function in fetal sheep duing late gestation. I physiol 2002,545:649-660.

q. Fetcher AJ. Ma XH, Wu WX, et al. Antenatal glucocorticoids reset the level of baselme and hypoxemia induced pituitary-adrenal activity in the sheep fetus during late gestation. Am/ Physol Endochinol Metab2004;286:6311E319.

10. Arwar MA, Schwab M, Poston L, Nathanielsz PW. Betamethasonemediated vasculat dysfunction and changes in hematological profile in the owine fetus. Am Physiol 1999;270:H1137-H1143.

11. Docherty CC, Kalmar Nagy I, Engelen M, Nathanielsz PW. Development of Fetal vascular responses to endothelin1 and acetylcholne in the sheep. Am J Physiol Regul hteg Comp Physlol 2001;280: R554 R562.

12. Bian X, Seidler F, Olsen $C$, Raymond $\ R$, Slotkin TA. Effects of fetal dexamethasone exposure on postnatal control of cardiac adenylate cyclase: beta adrenergic receptor coupling to $G$ segulatory protein. Teratolog $1093,48: 169$ 177 .

13. Bian $\mathrm{X}$, Seldlew $\mathrm{G}$, Slotkin TA. Fetal dexamethasone exposure interferes with establishment of candiac noradrenergic inmervation and sympatheic activity. Teratology 1993;47:109-117.

14. Ervin MO, Padbury JF, Polk DH, Vkegami M, Bery LM, Jobe AH. Antenatal glucocorticoids alter premature

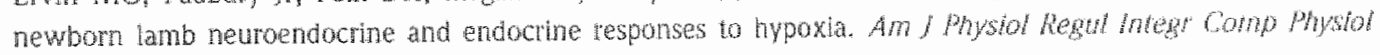
2000;279:R830-R838.

15. Fetcher Al, Gardner DS, Edwards CM, Fowden AL, Ciussani DA, Cardovasculat and endocrine responses lo acule hypoxaenia during and following dexamethasone infusion in the orine fotus $/$ fhysol $2003 ; 549: 271-287$.

16. Kaufman KS, Seider F, Sotkn TA. Prenatal dexamethasone exposure causes loss of neonatal hypokia tolerance: ceilular mechanisms. Pediats Res 1904:35:515-522.

17. Mclaughin K, Crowher CA, Walker N, Harding JE. Effects of a single course of conticosteroids given more than 7 days before birth: a systematic review. AUst NZJ Obster Oyneco 2003;43:101-106.

18. Bennet $L$, Kozuna $S$, McCarigle HHG, Hanson MA. Temporal changes in fetal cardiovascular, behavioural, metaboic and endocrine responses to matemaly administered dexamethasone th the late gestation fetal sheep. $B r$ J Obste Graecol 1990:100:331-339.

19. Anderson DF, Stock MK, Rankin JH. Placental transer of dexamethasone in neartem sheep. / Dev physol $1979 ; 1 ; 31-436$

20. Kream I, Mulay S, Fukushima DK, Solomon S. Determination of plasma dexamethasone in the mother and the newbon after administation of the hortuone in a clincal trial. / Cin Endocrinol Metab $1083 ; 56: 127-133$. 
21. Newham JW, Evans SF Godfey M, Hung W, Ikegam M, Jobe A. Matenal, but not fetal, administration of cortucosteroids festicts fetal growth. J Matem Fetal Med 1999;8:81-87.

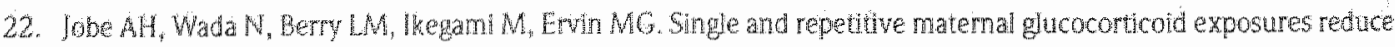

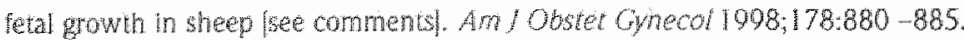

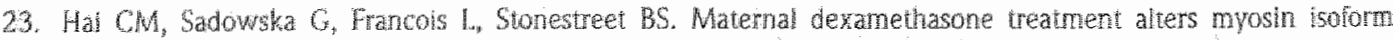

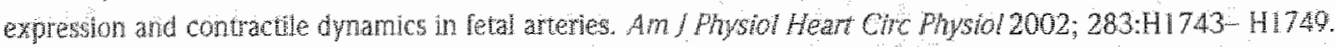

24. Koenen SV, Mevenas CA, Smith GS, Jenkins S, Nathaniesz PW. Eftects of maternal betamethasome adminstration on fetal and maternal blood pressure and heart rate in the baboon at 0.7 of gestation. Am / Obstet Checol $2002 ; 186: 812-817$

25. Mulder El, Koenen $\mathrm{SW}$, Dhom 1, Visser $\mathrm{GH}$. The effects of antenatal betamethasone administration on fetal heart rate and behayour depend on gestational age. Early Hum Dev 2004;76:65-77.

26. Dodic M, May CN, Whitou EM, Coghlan JP. An early prenatal exposure to excess glucocorticold leads to hypertenswe offspring in sheep. Chn Scl /Colch 1098;94:149-155.

27. Dawes $\mathrm{CS}$, Sermasera $\mathrm{V}$, Mouden M, Redman CW. Dexamethasone and fetal heart rate variation. Br I Oostet Graced 1994; 101:075-679.

28. Bentet $L$, Quaedackers $I S$, Gunn $A$, Rassenrode $S$. Heineman $E$. The effect of asphyxia on superior mesenteric artery blood flow in the premature sheep fetus. J Pedat Surg 2000;35:34m 40.

29. Barlow rM. The foetal sheep: morphogenesis of the nervous system and histochemical aspects of myelination. $f$ Comp Neurol 1969;135: 249-262.

30. Grafton R, Garmichael L, Homan I. Richardson B. Carotid arterial blood flow in the ovine fetus as a continuous measure of cerebral blood flow. I Soc Cynecol hwestig 1996;3:60-65.

31. Fraser M, Mathews SG, Braems G, Jeffay T, Challis JR. Developmental regulation of preproenkephalin [PENK] gene expression in the adrenal gland of the ovine fetus and newbom lamb: effects of hypaxemia and exogenous corisol infusion. I Endocmino 1997 ; $155: 143-149$.

32. Westgate IA, Bennet L, Gun AJ. Fetal heart rate variability changes during brief repeated umbilical cord occiusion in near tert fatal sheep. Br J Obster Cynaecol 1990;106:604-671.

33. Dawes GS, Moulden M. Redman CW. Systen 8000: computerized antenatal FHR analysis. I Perinat Med $1901 ; 19: 447-51$.

34. Moss TJ, Soboda DM, Gurrin LC, Harding R, Challis JR, Newnham JP. Progamming effects in sheep of prenatal growth festriction and glucocorticoid exposure. Am, f Physiol Regul Integr Comp Fhysho/2001;281:R960-R970.

35. Nijland Mil. Fetal exposure to conticosteroids: how low can we go? I Physio 2003;549:1.

36. Hetcher A, Goodellow $\mathrm{NR}$, forhead $\mathrm{A}_{\text {. }}$ et al. Low doses of dexamethasone suppress pitunary-adrenal runction but aughent the glycemic response to acute hypoxemia in fetal sheep during late gestation. Pediat: Res $2000 ; 47: 684-601$.

37. Forhead A, Cillesple CF, Fowden AL. Role of cortisol in the ontogenic control of putronary and renal angiotensinconverting enzyme in fetal sheep near term. J Phwsio 2000;5201P 21:400- 416.

38. Limmemann H, Gardne DS, Jellyman JK, Fowden AL, Gussan DA, Forhead AJ. Effect of dexamethasone on pulmohary and renal angiotensin-converting enzme concertration in fetal sheep during late gestation. Am / Obxter Geacol 2003;189:1467 1.4671.

39. Whtour EM, Johnson $\mathrm{K}$. Koukoulas I, Monirz K, Tersteeg M, Dodic M. Programing the cardiowascular system, kidney and the brain-- a review. Placenta $2003 ; 24$ Suppl A $1565-571$.

40. Thomburz KL, Reller MD. Coronary llow regulation in the fetal sheep. An f Phyol 1909;277:R1240-R1200.

41. Padhury IE Polk DH, Eryin MG, Berry LM, Ikegami M, Jobe AH. Postnatal Cardiovascular and metabolic responses 10 a single intramuscular dose of betamethasone in fetal sheep bon prematurely by cesarean section. Pediatr Res $1905 ; 38: 700-715$ 


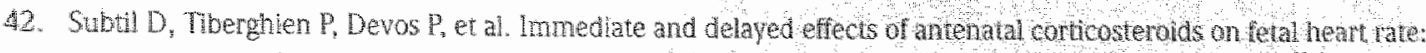
a randomized trial that compares betamethasone actate and phophate betamethasone phosphate, and dexamethasone. Am J Ostet Gnecol $2003 ; 188: 524-531$

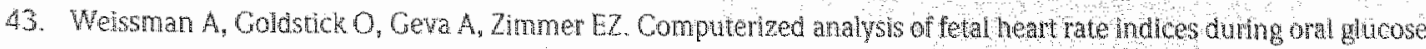
tolerance test. Peninat Med 2003;31:302 - -306.

44. Gulusan DA, Spencer JA, Moore PI, Bennet L, Hanson MA. Afferent and efferenteomponent of the cardiovascular reflex responses to acute hypoxia in term fetal sheep. J Physiol Lond 1993,401:431-440.

45. Chan MY, Dai S, He JH, Ogle CW. Invivo and in witro sudies on the effect of chronic dexamethasone treatment on cardiovascular responses to sympathebic stimulation. Arh In Phystol Brochm Bophys 1091:99:323-329

46. Segar IL, Bedell KA, Snitr OJ. Glucocorticoid modulation of cardiowascular and autonomic hinction in preterm lambs: nole of ANG Il. Am J Physol Regul integr Comp Phystol 2001;280:R640-R654.

47. Stein HM, Oyama $K$, Marunez $A$, et al. Effects of corticosteroids in preterm sheep on adaptation and sympathoadrenal mechanisms at birh. Am / Physion 1993;264:563-5769.

48. Dodic M, Peers $A$, Coghlan IP, et al. Altered cardiowascular haemodynamics and barorecepto - heart rate rele $\mathrm{x}$ in adult sheep after prenatal exposure to dexamethasone. Cin Sc/ Colch 1099;07:103-105.

49. Lunshof $\mathrm{S}$, Boer $\mathrm{K}$, Wolf $\mathrm{H}$, van Hofen $\mathrm{G}$, Baytam $\mathrm{N}$, Mirmiran M. Fetal and matemal ditmal rhythms during the thind trimester of nomal pregnangy: outcomes of computerized analys sf of contunous twenty-foumour fetal heart rate recordings. Am / Obstet Ohecol 1998; $178: 247-254$

50. Lunshof $S$, van Someren EJ, Kortes-van Hoffen $G$, Wolf $H$, Boer $K$. Lack of relationship between diumal mythms in letal heart rate and matemal cortisol concentration. Am J Obstet Gynecol 2000;183:460-461.

51. Datton KI, Dawes GS, Patrick JE. The autononic nerwous system and fatd heart rate variabilly. Am fobstet Gyecol $1983 ; 140: 450-462$

52. Dalton K, Dawes GS, Patrick JE. Diumal, respiratory, and other rhythms of fetal heart rate in lambs. Am/ Obstet Gnecol 1977:127: 414-424.

53. Wu $2 Y$, Lumbers ER. Measurement of baroreceptormediated effects on heart rate variability in fetal sheep. Pediat Res $2000 ; 47 \cdot 233-239$.

54. Stark RI, Garland M, Daniel S5, Tropper P. Myers MM. Diumal mythms of fetal and maternal heart rate in the baboon. Eary Hum Dev 1990,55:195-209.

55. Eltt CM, Sadowsika GB, Stopa EG, Pinar H, Petersson KH. Stonestreet BS. Effects of antenatal stenoids on ischemic brain injury in nearterm ovine fetuses. Early Hum Dev 2003;73:1-15.

50. Onlsson A, Botud, Govan ], Ryan ML, Mybr T, Fong K. The effect of deramehasone on time averaged mean welocity in the middle cerebral artery in wey low hirth weight infants. Fur f Pedat $1904 ; 153,363-300$

57. Chitrit Y, Cabel P, Herrero R, Schwinte AL, Gullwumin D, Boulanger MC. Elects of maternal dexamethasone

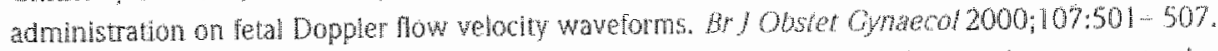

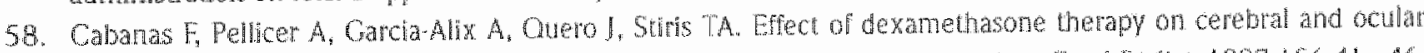

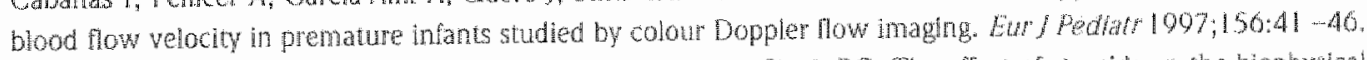

59. Deren O, Karaer C. Onderogu L, Yigh N, Dunikan T, Bahado-Singh RO. The effect of steroids on the biophysical profle and Doppler indices of umbilcal and midale cerebral arteries in healthy preterm fetuses. Eun / Obster Onecol Reprod Bol $2001,99: 72-76$.

60. Kahter C. Schleussner E, Moller A, Sewald Hy. Doppler measurements In fetoplacental vessels after maternal betamethasone administration Fetal Dagn Ther 2004:19:52-57. 
(1)

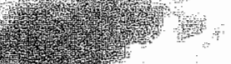

16y

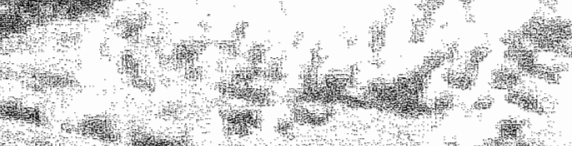

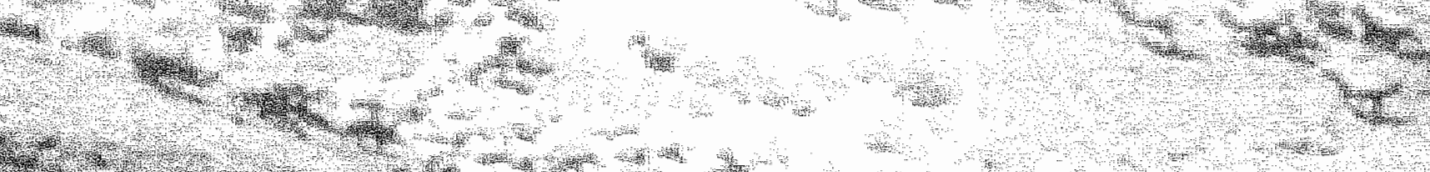

1. What

$4+$

3.

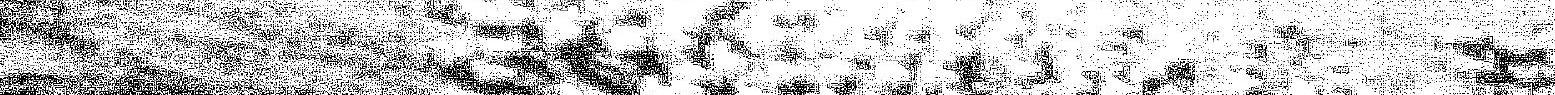

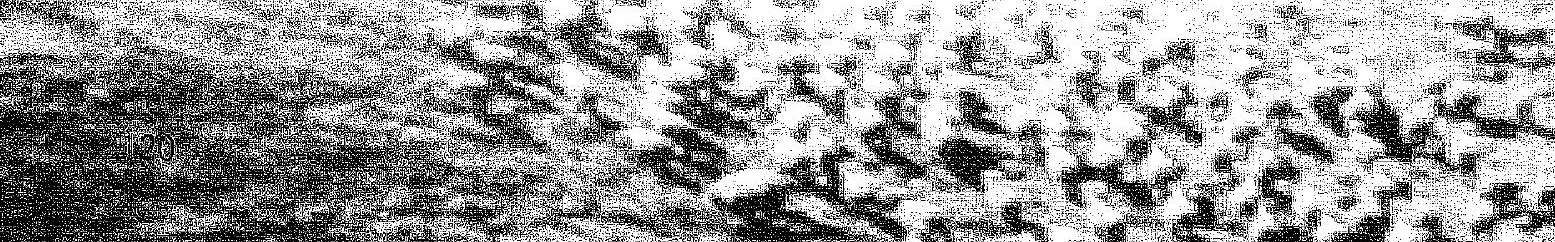

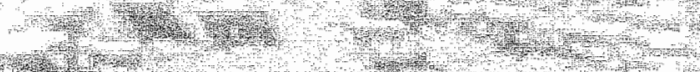

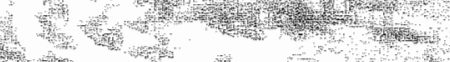




\section{THE MECHANISMS OF HYPOPERFUSION: THEORETICAL AND PRACTICAL CONSIDERATIONS}

Low blood flow to organs, i.e. poor organ perfusion, is a function of two main factors: perfusion pressure (the difference between arterial and venous blood pressures) and peripheral vascular resistance, as defined in the classic equation, below. Since venous pressure is typically much less than arterial blood pressure, in most situations arterial. pressure can be taken as a close estimate of perfusion pressure, and thus:

\section{Blood flow = arterial blood pressure $/$ wascular resistance}

\section{Blood pressure in the preterm infant}

In the first few hours of life it is common for preterm neonates to suffer from hypotension, especially those that have been exposed to perinatal asphyxia and develop hyaline membrane disease $(1,2)$. Hypotension in the preterm is a much debated topic. Many neonatal intensive care unit (NICU) guidelines set $30 \mathrm{mmHg}$ as the 'normal' blood pressure (BP) for preterm infants, which has been argued to be a completely arbitrary value that is not supported by experimental proof (3). Alternatively, the guidelines set out by the British Association of Perinatal Medicine and the Royal College of Physicians suggested keeping neonatal BP above the value of their gestational age in weeks (1). Whether this or $30 \mathrm{mmHg}$ is too high for a 'normal' BP for preterm neonates remains unclear, but at least some pretern neonates fall below these arbitrary walues.

One explanation for the frequency of hypotension in preterm infants is that it is due to the immaturity of the circulatory system in the preterm infant (4). After preterm birth there is often delayed closure of the key fetal vascular shunts; the ductus arteriosus and foramen ovale $(4,5)$. These shunts are fundamental for the fetal circulation, involving redistribution of oxygenated blood from the placenta away from the lungs, to the upper body. After birth however, they cause bi-directional flow of blood, when the placenta is removed and gaseous transfer is taken over by the lungs (4). This results in inefficient distribution of oxygenated blood. Some investigators suggest that immaturity of the cardiac tissue, with limited ability to increase cardiac output to meet increased systemic demand (4), plays a more important role than the ductal shunts in compromising perfusion in preterm infants, because of the largely mixed evidence of the outcomes from closure of patent slunts (6). Given that there is only a weak relationship between blood pressure and left ventricular output in preterm infants, several additional factors have been proposed including increased systemic resistance (7), positive pressure ventilation and high airway pressure (7). Since the latter interventions must increase mean intrathoracic pressure, we may speculate that their effect is also mediated by impaitment of filling pressure and reduced cardiac output.

The low blood pressure often observed in the preterm infant has led to the hypothesis that low blood pressure results in low blood flow and therefore poor organ perfusion (1). This theory has supported the clinical practice of increasing mean arterial blood pressure of preterm infants to the previously stated 'normal' BP of $30 \mathrm{mmHg}$ and has resulted in volume loading being one of the most commonly used therapies in NICU $(7,8)$. Other common therapies used for preterm cardiovascular support are inotropic agents (such as dopamine and dobutamine) infusion and corticosteroids $(9)$. Although it is widely used, there is no evidence that volume expansion improves the outicome of the majority of preterm infants, as revealed by a Cochrane Database Systematic Review in 2004 of five clinical trials of volume expansion (9).

Indeed, there is increasing evidence that increased blood pressure does not necessarily lead to 
increased blood flow (4). For example, Bauer et al found that in preterm infants hypotension (between 2 and 48 hours) did not necessarily indicate hypovolaemia as systemic blood pressure did not increase over a large range of volume infusions (10). In addition, Barr et al (2) found that in a study of hypotensive compared to normotensive preterms, volume loading was not effective in resolving low $\mathrm{pH}$ (suggested to be a result of metabolic acidosis), or in significantly increasing pressure above 30 mmHg for over half the preterm infants. In a recent study by Hunt et al (11), when confounding factors of gestational age, use of postnatal steroids and maternal education were taken into account there was no significant correlation between neurodevelopmental problems and mean arterial pressure. These data further contradict the focus on blood pressure as the key to outcome. It is clear from cohort studies that at least some infants do have very low blood pressure and poor perfusion; this subgroup are simply in uncompensated shock. However, there is a larger subgroup of preterm neonates with 'normal' blood pressure but low systemic blood flow $(3,12,13)$.

\section{Vascular resistance in the preterm infant}

If it is not changes in central arterial blood pressure that are mediating the reduction in blood flow, then our focus must be redirected to the other factor controlling perfusion: vascular resistance. Vascular resistance is inlluenced by a range of central and local mechanisms. Autoregulation is one of the local mechanisms of vascular control. Under myogenic control, the arterioles of a systemic bed contract. when blood pressure increases, reducing flow and therefore preventing damage of downstream capillaries and the opposite occurs with decreased blood pressure (14). It has been suggested that there is a loss of autoregulation in the sick preterm infant $(1,3)$. This hypothesis has been strongly contested by other studles, such as the report from Tyszczuk et al(15), which showed no relationship between cerebral blood flow and mean arterial pressure over a range of 23.7 to $39.3 \mathrm{mmHg}$ indicating that autoregulation was intact, and effective. Munro et al (1) suggested that there may be a loss of dynamic autoregulation but a preservation of static autoregulation in neonates that have suffered an asphyxic insult (i.e. adaptation to steady-state change versus rapid change in blood pressure, as described in adults (16)). Thus, despite enthusiastic advocacy of this hypothesis (17], it remains unclear whether impaired autoregulation is a major factor in sick preterm neonates.

Another proposed local mechanism of increased vascular resistance is so called "endothelial dysfunction". Some investigators have suggested, mainly from studies in adult animals, that increased vascular tone after ischaemia could be a result of changes in the ability of the endothelium to respond to neural control, due to factors such as reduced local production of nitric oxide synthase or altered receptor activity $(18,19)$. If correct, we would predict that the reduction in blood flow would be 'passive', i.e. independent of control by the autonomic nervous system.

Finally, changes in vascular resistance are often of course actively mediated by altered activity of endocrine and autonomic systems, and in particular, increased SNS activity leads to hypoperfusion. AS discussed below, the results of chapters 4 to 6 suggest the concept that in at least some preterm infants exposure to external events such as severe hypoxia (asphyxia) can trigger an active, neurally mediated increase in vascular resistance.

\section{POST-HYPOXIC SYSTEMIC HYPOPERFUSION IS ACTIVELY MEDIATED BY THE SNS}

As discussed above, secondary hypoperfusion is known to develop in many vascular beds after hypoxic. ischaemic insults both pre- and postnatally (19), and it has been unclear whether the causes are 
primarily related to impaired autoregulation, endothelial dysfunction (i.e. disturbed blood - vessel wall interactions) or centrally mediated (20-22). In our studies in chapters 4 to 6 we found that the changes in blood flow in the gut and kidney in the first few hours after severe asphyxia were both relatively rapid in onset (and resolution) and surprisingly variable over time. In particular, SMA blood flow showed a transient reduction in vasoconstriction between two and four hours post-asphyxia. These observations very strongly argue against the reduction in blood flow being due to passive vascular dysfunction. Further, since arterial blood pressure was normal or elevated through out this period, impaired autoregulation could not possibly be a factor. Thus these data strongly suggest that for the preterm fetal sheep, hypoperfusion of the gut and kidney after asphyxia is primarily related to an active increase in vascular resistance. This has simply not been adequately examined in the preterm infant to date, but our findings may explain the remarkably inconsistent effect of 'hypotension' in preterm infants, and at least a subset of the large group of infants with impaired systemic perfusion despite normal arterial pressure.

Although multiple systems help determine vascular tone, the speed of the changes pointed to a neural mechanism, which, we then confirmed in chapter 5, primarily involves increased alpha adrenergic sympathetic nervous system activity. At this time we cannot of course rule out a contribution from other vasoactive mediators. It is notable, however, that we found in chapter $\sigma$ that the acute increase in renin levels during asphyxia resolved rapidly after release of cord occlusion, and thus the renin-angiotensin system does not seem to contribute to delayed systemic hypoperfusion in this setting.

\section{MESENTERIC ARTERY HYPOPERFUSION IS ESSENTIAL FOR CARDIO- VASCULAR SUPPORT}

The pattern of blood flow changes after hypoxia in the mesenteric bed is much more complex than in the femoral / renal beds. Normalisation of delayed SMA hypoperfusion by alpha-adrenergic blockade in chapter 5 significantly impaired fetal blood pressure during the early recovery phase after asphyxia. Thus our data suggests the hypothesis that the 'purpose' of secondary hypoperfusion of the gut is at least in part to maintain systemic perfusion pressure. Consistent with this, in the adult under conditions of decreased cardiac output caused by cardiogenic or hypovolaemic shock, selective vasoconstriction of the afferent mesenteric arterioles is reported to be crucial in sustaining total systemic vascular resistance, thereby maintaining systemic arterial pressure $(23,24)$. Under these conditions, while there is some degree of wasoconstriction in other peripheral systems, it is disproportionately greater within the mesenteric circulation, and thus perfusion of non-mesenteric organs is maintained at the expense of the gut $(23,24)$. Further, given the strong postnatal link between feeding tolerance and gut perfusion in preterm and growth retarded infants reviewed in chapter 1 , we may speculate that the development of ileus following exposure to severe hypoxia may reflect such a reduction in blood flow to support other systems.

It is worth noting that no intestinal injury was seen after 3 days recovery from severe asphyxia in chapter 5 . It is highly likely that this tolerance reflects a combination of the relatively low metabolic demand of the fetal gut, and as we discuss in chapter $I$, the lack of the remaining factors known to be central to the clinical pathogenesis of NEC: feeding and exposure to bacteria (25-27). The immature intestine has been proposed to be more sensitive to ischaemic injury, based on studies in neonatal piglets $\{28,29\}$. However, in practice, the data do not conflict. Firstly, these studies were carried out at full-term, in contrast with our very preterm model. Secondly, the studies from Nowicki and 
colleagues did not report increased histological injury per se, but rather examined the effect of ischaemia-reperfusion on vascular tone. They found a greater increase in vascular resistance after hypotension in 3 day old piglets compared with 35 day old piglets (30), consistent with our findings.

\section{ACUTE RENAL FAILURE: OFTEN POLYURIC}

Premature infants frequently develop an early phase of intense polyuria with salt wasting after birth, which resolves over the first week $(31,32)$. The aetiology is very poorly understood. Our study in chapter 6 highlights two relevant aspects of preterm renal injury: firstly that at least experimentally the immature kidney is relatively resistant to injury even after severe ischaemia or asphyxia $\{33,34\}$, and secondly that milder post-asphyzial renal dysfunction may be manifested by polyuria and natriuresis, rather than oliguria (35). We found no evidence of renal injury after 3 days recovery, as shown by normal predominantly basolateral cytoskeletal anchorage of $\mathrm{Na}, \mathrm{K}$-ATPase on immunohistochemistry, and normal histologic examination of $\mathrm{H} \& \mathrm{E}$ stained sections by light microscopy. Therefore despite evolving hypoperfusion during recovery from a severe asphyxial insult there appears to be no lasting structural injury. This finding of no structural renal injury 3 days after asphyxia is consistent with the observation that, in the rat, the immature kidney has much greater tolerance for ischaemia-reperfusion than the adult rat (33).

There is now increasing evidence from early electrophysiological and hemodynamic recordings that many preterm infants are exposed to significant events either in the immediate perinatal period or shortly after birth $(36,37)$; as illustrated by the present study adaptation to such events can lead to significant changes in systemic or regional perfusion (38-40). These intriguing observations raise the possibility that the early, transient phase of polyuria commonly seen in preterm infants may be a consequence of early hypoxic events and thus reflect reversible renal compromise rather than purely immaturity.

\section{LIMITED ROLE OF PRE-RENAL MECHANISMS IN ACUTE RENAL FAILURE IN THE PRETERM FETUS}

We found only a mild reduction in the clearance of creatinine at 48 hours of recovery from severe hypoxia in our studies (chapter 6 ) corresponding in time with the most pronounced decrease in renal blood flow in the chronic recovery phase. Within subjects regression analysis demonstrated a positive relationship between RBF and creatinine clearance in all but one subject. However, since this relationship accounted for less than $20 \%$ of variance and the effect of impaired RBF on creatinine clearance appeared to be significant only with substantial reductions in blood flow, additional factors are likely to be more important particularly within the normal blood pressure range. There are limited data on the determinants of changes in renal blood flow after premature birth, however, Doppler flow measurements suggest that renal vascular resistance is initially elevated shortly after birth and progressively falls with time $(41,42)$. Consistent with our findings, these studies found only a weak relationship between renal blood flow velocity and urine output (43), and olliguria was typically seen only with marked reductions in renal blood flow velocity. Thus, these clinical data and our experimental findings, do not support the hypothesis that the glomerular filtration rate in the preterm kidney is more dramatically affected by small reductions in renal perfusion than at later ages (44). 


\section{PRENATAL EXPOSURE TO GLUCOCORTOIDS}

The currently recommended single course of glucocorticoids is well proven to have unequivocal benefits for the premature newborn (45). In recent years consistent reports of negative outcomes after repeated courses of steroids have led to re-emphasis on the importance of using only a single course of treatment. Yet there still remains a significant need for further systematic research on both short and long-term outcomes after a single course of treatment. In particular, it has been suggested on the basis of experimental studies that antenatal steroid exposure might cause a long lasting risk of hypertension (46). As discussed in some detail in chapter 7 however, the concern that glucocorticoid treatment may have cardiovascular complications is actually based on limited information. A major problem has been inadequate periods of follow up, for example elevated blood pressure was found for 24 hours after maternal betamethasone treatment in the preterm baboon - but blood pressure appeared to be falling towards baseline at that time (47). Other studies used sustained direct fetal infusions, which produces a constant exposure that is quite different from the profile of clearance seen after maternal administration (48-50). Currently there are only limited and conflicting clinical data on the influence of antenatal steroids on adult cardiovascular function $(51,52)$.

Our study highlights the limitations of direct fetal infusion or injection for studies of the potential clinical impact of antenatal treatment with long-acting corticosteroids, and the importance of maturation in evaluating these issues. In the study described in chapter 7 a single course of maternal dexamethasone led to only transient hypertension and increased vascular resistance, resolving within $24 \mathrm{~h}$ of the last injection. There was, however, a sustained increase in FHR and a loss of diurnal FHRV activity. Speculatively these changes may reflect altered autonomic function; a longer-term follow-up would be required to determine whether these relatively subtle changes resolve with time, or affect cardiovascular responses in the long-term.

An important issue, which we did not examine, is whether prenatal glucocorticoids affect cerebral maturation. There is now extensive imaging data that prolonged post-natal steroid thetapy for lung disease reduces long-term brain growth $(53,54)$. Repeated prenatal betamethasone treatment in fetal sheep reduced adult brain weight by $7 \%$ to $8 \%$ [55]. Despite the well established beneficial effects of a single course of treatment, there are some short-term data, in term equivalent fetal sheep and the preterm fetal baboon suggesting that there maybe functional changes including a reduction in cortical cytoskeletal proteins and presynaptic terminals $(56,57)$. Further investigation of the neural impact of current treatment prenatal treatment schedules is important, and thus there is, as suggested recently by Nijland (58), a critical need to further assess what the optimal dosing regimen should be.

\section{CONCLUSIONS}

The present studies have elucidated the significance and mechanisms of systemic hypoperfusion after exposure to asphyxia and antenatal steroids. Hypoperfusion was actively mediated, particularly by activation of the sympathetic nervous system. In part, it likely reflects decreased metabolism, however, in part increased vascular resistance in the gut also seems to play a vital role in supporting cardiovascular function after hypoxia. These findings are consistent with the highly equivocal effects of many clinical interventions such as a volume expansion, administration of inotropes and closure of the ductus arteriosis after birth. Focused, physiolologically oriented studies are required in the future to evaluate if, when and how promotion of blood flow should be considered. 


\section{REFERENCES}

1. Munro M, Waker AM, Barfield CP. Hypotensive extremely low bith welght infans have reduced cerebral wlood low Pediatrics 2004:11460):1591-6.

2. Barr PA, Bailey PE, Sumners J, Cassady G. Relation between arterlal blood pressure and blood volune and effect of infused albumin in sick pretem infants. Pedothics 1977,001312829 .

3. Evans $\mathrm{N}$. Management of hypotension and circulatory assessment on NCU. Farl Hum Dev 2005;81 [51:307-8.

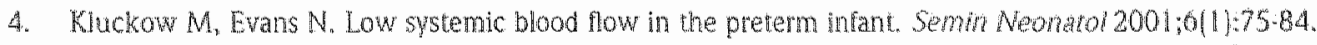

5. Evans N, KJuckow M. Early determinants of right and left ventricular output in ventiated preterm infants Arch Dis Child Fetal Neonatal Ed 1990;742]: F88-04.

6. Kuckow M, Evans $M$. Low superior vena cava flow and intraventricular hatemorrhage in preterm infants. Arch Dis Child Fetal Neonatal Ed 2000;82131:F188-94.

7. Kuckow $M$, Evans $N$. Relahonship between blood pressute and cardiac output in pretem intants requing mechanical wentiation. J Pediatr" $1996 ; 129(4): 500-12$.

8. Evans N. Volume expansion during neonatal intensive care: do we know what we are doing? Semin Neonatot $2003 ; 8[4]: 315 \cdot 23$.

9. Osbom DA, Evans N. Early volume expansion for prevention of mobidity and mortality in very preterm infants. Cochrane Database Syst Rev 2004(2):CD002055.

10. Bauer K, Linderkamp O, Versmold HT. Systolic blood pressure and blood volume in pretem infants. Amch Dis Chid $1993 ; 09(5$ Spec Nol:521:2.

11. Hunt RW, Evans N, Rieger I, Kluckow M. Low superior vena cava fiow and neurodevelopment at 3 years in very preterm indants. J Pedlat 2004;145(5):588-92.

12. Osborn DA. Diagnosis and treatment of preterm unsifional circulatory compromise. Eary Hum Dew $2005 ; 81(5): 413-22$.

13. Noori $S$, Seri 1. Pathophysiology of newbom hypotension outside the transitional period. Earty Hum Dew 2005;81:(5):390:404.

14. Berne R, Lewy M. Physiology. Fourh ed. Missouri: Mosby Inc; 1998.

15. Tyszczuk L, Meek J, Elwell C, Wyat JS. Cerebral blood how is independent of mean arterial blood pressure in pretern infants undergoing intensive care. Pediattos 1908;102(2 Pt 1):337-41.

16. Tiecks FP, Lam AM, Aaslid R, Newell DW. Comparison of static and dynamic cerebral autoregulation measurements. Stroke 1905,20101:10140.

17. Lou MC. The "losit autoregulation hypothesis" and bran lesions in the newborn an update. Brath bev $1988: 10[31: 143 \cdot 140$.

18. Karmova A. Pinsky DJ. The endothelial response 10 owgen deprivation: biology and clincal implications. Intenshe Care Med $2001 ; 2711: 19-31$.

19. Conger $1 \mathrm{D}$, Wei JV. Abnomal vascular functon following ischemateperfusion infury. Investg Mad $1095,4315): 431 \cdot 42$

20. Hosmann KA. Reperfusion of the brin after gubal ischemia: hemodyamic disturbances. Shock 1997,80121:95-101.

21. Ten VS, Pusky DI. Endotheliad response to hypoxia: physiologic adaptation and pathologic dysfunction. Cur Opin Corit Care 2002;813:242.50.

22. Reber KM, Nankervis CA. Nowicki PT. Newbom intestinal circulation. Physiology and pathophysiology. Chi Perinatol 2002;29:1!23-39.

23. Reilly PM, Wukns $\mathrm{KB}$, Fun $\mathrm{KC}$. Haglund $\mathrm{U}$, Bukley $\mathrm{GB}$. The mesenteric hemodynamic response to circulatory shock: an averview Shock $2001 ; 15151: 32043$.

24. Ceppa EP. Fuh KC, Bukley GB. Mesenteric hemodynamic response to circuatory shock. Cum Oph Cril Care $2003 ; 9(2): 127-32$. 


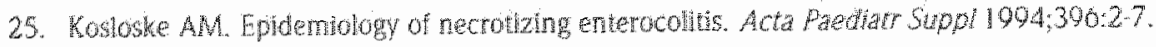

20. Capan MS, Mackndrick Wectowing enterocoltis: a review of pahogenetic mechamins and inphications for prevention. Pediat Pahor $1093 ; 1363$ m 35769 .

27. Claud EC, Walker WA. Hypothesis: inapproprate colonizaton of the premature intestine can cause neonatal

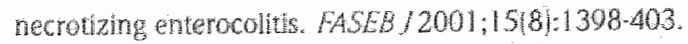

28. Nowick Pr. Effecs of sustaned flow reduction on posthatal hintestinat circulation. Am/ Physol $1908,275(4 \mathrm{Pr}$ 11.075868

29. Nowick PT, Nankervis CA, MAler $\mathrm{CE}$. Effects of ischemia and reperfusion on Ininicic vascuar reguation in the postratal intestnal circulation. Pediatr Res 1993,3344 Pt 1 j:400-4.

30. Nowck PT, Miler CE. The effects of systemic hypotension on postnatal intestral hemodynamics and oxygenation. Pudiat Res $1996,30(1): 105-11$.

31. Bidiwala KS, Lorenz JM. Keinman LI. Renal function conelates of postnatal diuresis in preterm infanis. Pedathos $1088 ; 82(1): 50 \cdot 8$

32. Galini $F$, Maggio $L$, Romagnoli $G$, Marrocco $G$, Tortorolo $G$. Progression of renal function in preterm neonates with gestational age $c$ or $=32$ weeks. Pedat Nephrol $2000 ; 15(1 \cdot 2): 11924$.

33. Vicencio A, Bidmon B, Ryu I, Reidy K, Thulin G, Mann A, et al. Developmental expression of HSP.72 and ischemic tolernce of the immature kidney. Pediatr Mephrol 2003; 18/2):85.91.

34. OConnel AE, Boyce AC, Lumbers ER, Gibson KI. The effects of asphyxia on renal function in fetal sheep at midgestution. J Hystol (Lond) 2003 in press.

35. Karlowicz MG, Ademan RD. Nonoliguric and oliguric acute enal failure in asphyxiated term neonates. Pediat Nepirrol $1905,9(6): 71822$.

30. Takura A, Kurauchi O, Hayakawa F, Matwizawa K, Mizutani S, Tomoda Y Tining of perivenuicular leukomalacia

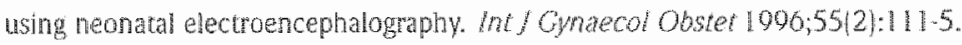

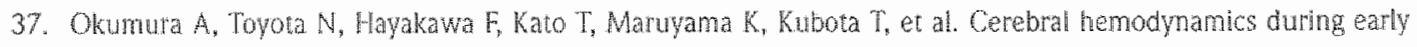
neonatal period in preterm infants with periventricular leukomalacia. Bram Dev 2002:24171:693.7.

38. Luchano R, Gallini F, Romagnoli C, Papacoi P, Tortorolo G. Dopples evaluation of renal blood fow velocty as a predictive index of acute renal failure in perinatal asphyxia. En f Pediat 1008; 157:81:656-60.

39. Akimbi H, Abbasis, Hilpert PL, Bhutani VK. Gastrointestinal and renal blood flow velociv profile in neonates with birth asphyxia. Pediatr 1904:125:41:025-7.

40. Combs RC, Morgan ME, Durbin OM, Bonth IW, MeNeish AS. Abnormal gut blood flow velocities in neonates at risk of necousing enterocolits. / Pediat Gastroenterol Nur 1092:15(1:13-9.

41. wan de Bor M. Renal blood blow velocty in nondistressed preterm infants during the first 72 hours of life. Bhot Nomate 1905,67(5):340.51.

42. Ceary CM, Higgins ST, Merton DA, Culden IA, Gotheb RP, Bangart S. Developmental changes in renal attery

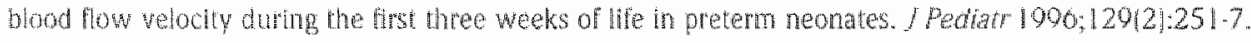

43. Kusuda S, Kim TJ, Myagl N, Shishida N, Jitani H, Taraka $Y$, er al. Postnatal change of renall artery blood Iow velocty and its relationship wh urne volume in very low bith weight infans during the first month of life. Permat Mod 1990;27(2):107.11.

44. Toth Heyn P. Drukker A, Guignard IP. The stressed neonatal kidney: from pathophysiology to clinical management of neonatal vasomotor nephropathy Pedatr Nephol 2000; 1431:227-39.

45. Dudley DI, Waters TP, Nathanelsz PW. Current status of single course antenatal steroid therapy. Cin Obstet Gyecol $2003,4011: 132-40$

46. Newham IP. Is prenatal glucoconticoid administration another origin of adult disease? Cin Exp Phamacol Physiot $2001: 28(11), 057.61$ 


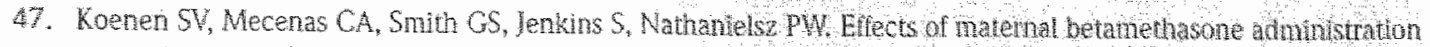

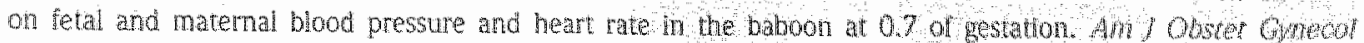
$2002 ; 180[4] 8127$.

48. Bennet $L_{\text {, Kozuma }} \mathrm{S}$, McGarrigle $\mathrm{HHG}$, Harson MA Temponal changes in fetal cardovascular behawoural, metabolic and endocrine responses to maternally admmisered dexamethasone in the late gestaton fotal sheep. $B_{r}$ J Obstet Gyarecol 1999;100(4):331-339.

49. Anderson DF, Stock MK, Rankin IH. Placental transler of dexamethasone in neatern sheep. J Der phosht $1979: 16: 431-6$.

50. Kream J, Mulay S, Fukushima DK, Solomon S. Determation of plasma dexamethasone in the mother and the

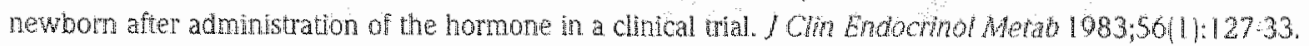

51. Doyle $\mathrm{WW}$, Ford GW, Davis NM, Callanan C. Antenatai corticosterotd theraps and blood presure at 14 years of age in preterm chudren. Cin $5 \mathrm{c}$ (Lond) 2000,98(2):137-42.

52. Dessens $A B$, Has HS, Koppe 16 . Twentyear follow-up of antenatal corticosteroid treatment. Pedthtors $2000 ; 10516): 177$.

53. van der Heide-Jalving $M$, Kamphuis PI, van der Lan M, Bakker JM, Wegan VM, Hejnen CI, et al. Short- and longterm eflecis of neonatal gicoconticoid therapy: is hydrocortisone an altemative to dexanehasone? Ach Paediat $2003 ; 9217): 827-35$.

54. Murphy BP, Inder TE, Huppi PS, Warfield S, Zientara GP, Kikinis R, et al. Impaired cerebrai contical gray inatter growth after weatment with dexamethasone for neonatal chronic lung disease. Pediatrics 2001;107/21:217-21.

55. Moss T], Doherty DA, Nitsos I, Sioboda DM, Harding R, Newnham IP. Fffects into aduthood of single or repeated antenatal corticosteroids in sheep. Am J Obstot Ghecot 2005;19211):140.52.

56. Schwab M, Antonow-Schlorke 1 , Kuhn B, Multer T, Schubert $H$, Walter B, et al. Effect of antenatal betamethasone

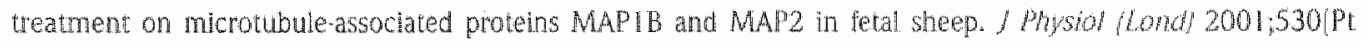
$3,407-500$.

57. Antonow-Schlorke I, Schwab M, Li C, Nathanielsz PW. Gucocorticoid exposure at the dose used cincally aiters

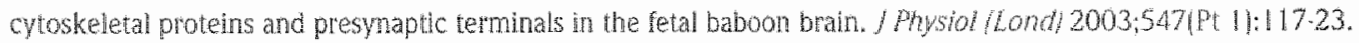

58. Nilland M. Fetal exposure to conticosteroids: how low can we go? / Physid / ond $2003 ; 549$ (Pt 1 ): 1 . 
rent 


\section{SUMMARY}

The overall goal of the studies described in the present thesis "Systemic complications in the preterm fetus after asphyxia. Studies of cardlovascular and blood flow responses" was to gain more insight into the mechanisms and significance of impaired systemic perfusion in the premature fetus.

In chapter 2 we explored in depth the remarkable tolerance of preterm animals to hypoxia/ asphyxia, and the implications for understanding complications of prematurity. In this review we refuted the existing hypothesis that the premature fetus is more vulnerable to injury foliowing these insults due to immaturity of its cardiovascular response. Instead, we proposed the hypothesis that paradoxically, the greater ability of the preterm animal to survive profound hypoxia, actually exposed it to more prolonged hypotension and hypoperfusion. This analysis critically underpinned the design of subsequent studies. Because one of the goals of the thesis was to examine the impact of asphyxia on the preterm gut, in chapter 3 we undertook a systematic evaluation of different systems of histological grading of intestinal injury, examining inter-observer and inter-method variance, and presented evidence to support the system of Chiu and Park for general purpose use.

In chapters 4 to 6 we dissected the impact of changes in blood pressure and vascular resistance during and after severe asphyxia on gut and kidney blood flow. Because these studies suggested that posthypoxic hypoperfusion was actively mediated, we specifically tested in chapter 5 whether it was mediated by endogenous sympathetic activation. This study confirmed our hypothesis, and suggested that the gut has a particular role in supporting fetal arterial blood pressure during the early phase of recovery, likely compensating for reversible cardiac dysfunction. Strikingly, we found that the short infusion with a well known alpha-adrenergic antagonist was associated with persistent changes in blood flow well after the end of the infusion, and altered the blood flow responses to secondary seizures.

Finally, in chapter 7 we examined for the first time the cardiovascular impact of a widely used clinical protocol of treatment with the long-acting glucocorticoid dexamethasone in our preterm fetal model. This study was extremely reassuring, showing that although steroids were associated with marked but transient haemodynamic effects, these all resolved by $72 \mathrm{~h}$ after the first injection. Thus, the data suggest that, contrary to the implications of previous studies using fetal infusion treatment, it is improbable that clinical treatment would have longlasting impact. Intriguingly, we did find persisting subtle changes in the diurnal rhythm of fetal heart rate variability that raise the possibility of a longerlasting effect that merits further study. 

s.

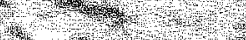
H. 


\section{SAMENVATTING}

De doelstelling van de studies beschreven in dit proefschrift geuteld "Systemic complications in the preterm fetus after asphyxia. Studies of cardiovascular and blood flow responses" was om meer inzicht te verkrijgen in de mechanismen en de consequenties van systemische perfusiestoomissen in de premature foetus.

In hoofdstuk 2 hebben wij in detail de uitzonderlijke tolerantie van premature dieren voor hypoxie/asfyxie geanalyseerd, alsmede de consequenties van deze toletantie bij het ontstaan van de complicaties van prematuriteit. In dit review verwerpen we de bestaande hypothese dat de premature foetus kwetsbaarder is voor dergelijke insulten ten gevolge van een immature cardiovasculaire respons. In plaats daarvan stellen wij de paradoxale hypothese voor dat het grotere vermogen van het premature dier om ernstige hypoxie te overieven, het dier tevens blootstelt aan langer durende hypotensie en hypoperfusie. Deze hypothese was een belangrijke maatstaf voor het ontwikkelen van de volgende studies. Een van de doelstellingen van dit proefschrift was om de impact van asfyxie op de premature darm te bestuderen. Derhalve hebben wij in hoofdstuk 3 systematisch de verschillende beschikbare histologische scoringssystemen voor ischemische darmschade geëvalueerd, lettend op inter-observer en inter-methode variatie. Onze data ondersteunen het systeem van Chiu en Park voor algemeen gebruik.

In hoofdstuk $4 \mathrm{t} / \mathrm{m}$ o bestudeerden wij de impact van veranderingen in bloeddruk en vaatweerstand zowel tijdens als na afloop van ernstige asfyxie op de doorbloeding van darmen en nieren. Deze studies suggereerden dat post-hypoxische hypoperfusie actief gemedieerd wordt. Derhalve hebben wij in hoofdstuk 5 specifiek onderzocht of post-hypoxische hypoperfusie wordt gemedieerd door endogene sympathische activatie. Deze studie bevestigde onze hypothese, en suggereerde dat de darm een belangrijke rol speelt bij het op peil houden van de foetale arteriële bloeddruk tijdens de vroege herstelfase na asfyxie, en daarbij waarschijnlijk compenseert voor omkeerbaar cardiaal dysfunctioneren. Het was opvallend dat kortdurende infusie met een alfaadrenerge antagonist leidt tot veranderingen in doarbloeding van de darm, welke geruime tijd persisteren na stoppen van de infusie, en dat tevens de effecten van epileptische insulten op intestinale perfusie veranderen.

Tenslotte onderzochten wij in hoofdstuk 7 voor de eerste keer de cardiovasculaire effecten van een veelvuldig gebruikt klinisch protocol voor toediening van het langdurig werkende glucocorticoid dexamethason in ons premature foetale schapen model. Deze studie was zeer geruststellend en toonde aan dat hoewel steroïden duidelijk hemodynamische effecten hebben, deze van tijdelijke aard zijn en 72 uur na de eerste injectie genormaliseerd zijn. In conclusie tonen deze data aan dat in tegenstelling tot eerdere studies waarbij foetale infusie plaatsvond, het onwaarschijnlijk is dat klinische toediening via maternale injectie langdurige effecten op de hemodynamiek zal hebben. Wij vonden daarnaast persisterende subtiele veranderingen in het dag nacht ritme van de variabiliteit van foetale hartfrequentie. Dit wekt de suggestie dat er een langduriger effect op deze variabiliteit bestaat dat verder onderzoek zal vergen. 


\section{PAPERS PRESENTED IN THIS THESIS}

Gunn A, Ouaedackers J5, Guan I, Heineman E, Bemnet L.

The prenature fetus: no as defenseless as we though, but still paradoxicaly wherable?

Developmental newosicience. 2001;23(3):1759.

Quaedackers 15, Beuk RJ, Bennet L, Charton A, oude Egbrink MG, Gunn A, Heineman E.

An evaluation of methods for grading histologic injury following ischemia/reperfusion of the small bowel.

Transplandaton proceedings. 2000 Sep; 326 [6]:1307-10.

Bennet L, Quaedackers $I S$, Cumn A, Rossentode S, Heineman E.

The effect of asphyxia on superior mesenteric artery blood flow in the premature sheep letus.

jounat of pediaric surgery 2000 jan:35[1]:34440.

Quaedackers IS, Roelisema V, Heineman E, Gunn Al, Bemet $L$.

The role of the sympathetic nervous system in postasphyral intestinal hypoperfusion in the pretem sheep fetus.

The joumat of physiology (London). 2004 jun $15,557(\mathrm{Pt} 3$ ):1033-44.

Quaedackers JS, Roelfsema V. Hunter C., Heineman E, Gunn AJ, Bennet L.

Polyuria and impaired renal blood flow atter asphyxia in pretem fetal sheep.

Anerican joumat of physiology. Reguleroy, integrative and comoatatue physiology 2004 Mar;28613!:2576-83.

Ouaedackers IS, Roeffsema V, Fraser M, Gunn A, Bennet $\mathbb{L}$.

Cardiovascular and endoctine effects of a single course of maternal dexamethasone treatment in preterm fetal sheep.

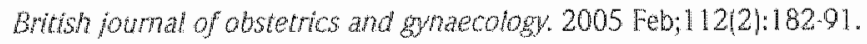

\section{OTHER PAPERS}

Bennet L, Roelfsema V, Pathipati P. Cuaedackers $1 S$, Gunn AD

Relationship beween evolwing epleptifom activity and detayed loss of witochondrial activity after asphyxh measured by nearinfrared spectroscopy in pretem feital sheep"

The jounat of physiogy flondon. In Press.

Bennet L, Booth L, Mapas SC, Quaedackers IS, Jensen E, Dean IM, Gun Al.

Acute systemic complications in the preterm letus ater asphyxia: the role of cardiovascular and bood flow respones.

chincal and Experinenal Phamacology who physology in press.

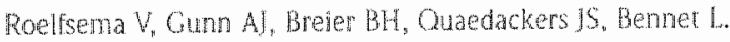

The effect of mild hypothermia on insulin like growh faciors ater severe asphyxia in the pretern fetal sheep. Journal of the Society for Grnecological investigation. 2005 May 121412327 .

Roelsema V, Gun A. Fraser M, Quaedackers 15 , Bennet L.

Cortisol and ACTH responses ro severe asphyxin in preterm fetal sheep.

Experimental Physology. 2005 Ju!,90/4]:54555. 


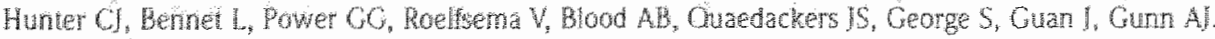

Key newoprotecture role for endogenous adenosime Al receptor activation during asphyata in the fetal sheep.

Stroke. 2003 separ 340$): 2240: 5$.

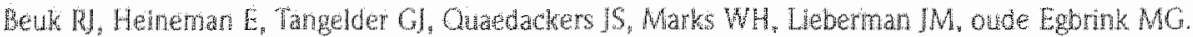

Total wam ischeria and repertumin impairs flow in all rat gut layers but increases leukocyteressel wall interactions in the subnucosa only.

Annals of surgety, 2000 Jan,23111:90-104.

\section{PARTICIPATION}

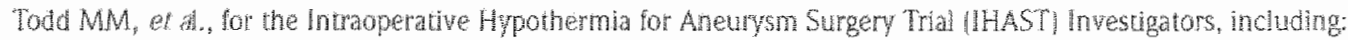
1.S. Quadackers (2005).

Mid intaperative hypothesmid during subgery for intracranial aneurym.

New England fou hal of Medicine 2005; $352(2): 135.45$. 



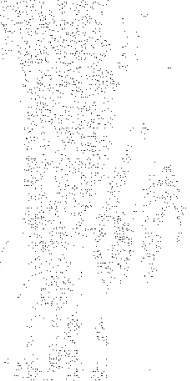

W

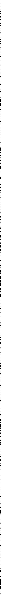


Josine Quaedackers was born on 26 January 1976 in Heerlen. She graduated from high school. (gymnasium-ß, ) at the St.Janscollege in Hoensbroek in 1994 and subsequently started her medical training at Maastricht University. During her studies she got acquainted with scientific research at the microcirculation laboratory of the Physiology department, working as a "student assistant" to PhD student $R$. Beuk, studying the effects of intestinal ischemia on leukocyte-vessel wall interactions, supervised by Dr. M. oude Egbrink en Prof. Dr. E. Heineman. She also participated in the organisation of the Maastricht Medical Student Reseach Conference (MMSRC). Josine spent her scientific internship in 1998 at the Starship Childrens Hospital in Auckland; New Zealand on a project with Prof. Dr. E. Heineman. She began her studies in fetal physiology supervised by associate professors Dr. L. Bennet en Dr. A.J. Gunn. They offered her the chance to come to the Liggins Institute at the University of Auckland for a PhD project, in collaboration with Prof. Dr. J. de Haan from GROW at Maastricht University. After finishing her masters degree in Medicine in Maastricht she left for New Zealand together with Vincent Roelfsema. Her studies into the cardiovascular effects of asphyxia in the preterm sheep fetus resulted in this thesis. After 4 years in Auckland, Josine returned to Maastricht and graduated from Medical School "Cum Laude" in July 2004. In September 2004 she began working as a surgical registrar at the Maasland Hospital in Sittard, where she started her speciaity training in surgery in January 2005.
Awards
1999: research grant, Ter Meulen Foundation, The Netherlands
2000: research grant, De Drie Lichten Foundation, The Netherlands
2000: travel grant, Maurice \& Phyllis Paykel Trust, New Zealand
2000: Prize for best poster presentation, Postgraduate Students' Poster Day,
School of Medicine and Health Sciences, The University of Auckland
2002: Prize for best poster \& mini presentation,
29th Annual Meeting of the Fetal and Neonatal Physiological Society,
Prague.
2003: Prize for best poster \& mini presentation, Chirurgendagen,
Nederlandse Vereniging voor Heelkunde, Veldhoven. 
Josine Quaedackers werd geboren op 26 januari 1976 te Heerlen. In 1994 behaalde zij Maar gymnasium-B, diploma aan het St.Janscollege te Hoensbroek en begon aan de opleiding Geneeskende aan de Universiteit Maastricht. Tijdens haar studie maakte zij kemis met wetenschappelik onderzoek op het microcirculatie laboratorium van de vakgroep fysiologie. Zij was enkele jaren student assistent bij het promote-onderzoek van Drs. R. Beuk, naar de effecten van darmischemie op leukocyt-vaatwand interacties, onder begeleiding van Dr. M. oude Egbrink en Prof. Dr. E. Heineman Daarnaast nam zij actief deel aan het bestuur van het Maastricht Medical Student Reseach Conference (MMSRC). Voor haar wetenschapsstage ging zij in 1998 naar het Starship Childrens Hospital in Auckland, Nieuw Zeeland voor een project bij Prof Dr. E. Heineman. Hier zette zij de eerste stappen op het gebied van de foetale fysiologie onder supervisie van associate professoren Dr. L. Bennet en Dr. A.J. Gunn. Zij boden haar de kans om aan het Liggins Institute van de Uniwersity of Auckland promotie-onderzoek te doen, in samenwerking met Prof. Dr. J. de Haan van GROW aan de Universiteit Maastricht. Na het behalen van het doctoraal examen onderbrak Josine haar studie Geneeskunde en vertrok samen met Vincent Roelfsema naar Nieuw Zeeland. Haar onderzoek naar de cardiovasculaire effecten van asfyxie in de premature foetus resulteerde in dit proefschirift. Na een verblijf van 4 jaar in Auckland, keerde zij terug naar Maastricht en behaalde in juli 2004 het artsexamen met het predikaat "Cum Laude". Sinds september 2004 werkt Josine als assistent chirurgie in het Maasland Ziekenhuis te Sittard, waar zij in januari 2005 aan de opleiding tot chirurg begon.

\section{Beurzen/prijzen}

1.999: onderzoeksbeurs, Ter Meulen Fonds, Nederland

2000: onderzoeksbeurs, Stichting De Drie Lichten, Nederland

2000: reisbeurs, Maurice \& Phyllis Paykel Trust, Nieuw Zeeland

2000: Prijs voor beste poster presentatie, Postgraduate Students" Poster Day, School of Medicine and Health Sciences, The University of Auckland

2002: Priis voor beste poster $\&$ mini presentatie, 29 th Annual Meeting of the Fetal and Neonatal Physiological Society, Praag

2003: Prijs voor beste poster \& mini presentatie, Chirurgendagen, Nederlandse Vereniging voor Heelkunde, Veldhoven 
.

sषे

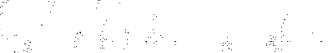

औ

$\therefore:-$ 


\section{DANKWOORD}

Na enkele jaren als student assistent bij de vakgroepen fysiologie / chirurgie aan de Universiteit Maastricht, wilde ik voor mijn wetenschapsstage iets anders doen, en wel lets chirurgisch en in het buitenland. Het was een mooie bijkomstigheid dat mijn begeleider Prof. Dr. E. Heineman, chirurg, voor enkele jaren naar Nieuw Zeeland zou gaan: ik kon mitn wetenschapsstage daar doen. In Auckland, Nieuw Zeeland, introduceerde associate Prof. Dr. L. Bennet mij tot het foetale schapen model. De combinatie van foetaal intestinaal onderzoek ên foetale operaties wekte mijn interesse voor de foetale fysiologie. Toen na deze stage het onderzoek uitgebreid kon worden tot een promotie project was de verhuizing naar Nieuw Zeeland samen met Vincent al snel een feit. Op deze plaats wil ik iedereen bedanken die een steentje heeft bijgedragen tot het uiteindelijke resultaat, dit proefschrift.

Allereerst mijn promotor Prof. Dr. E. Heineman. Beste Erik, ik ben erg blij dat iij mijn promotor bent. Jouw vermogen tot het inspireren en motiveren wan mensen is zeer bijzonder. Het is dan ook erg prettig om met jou samen te werken. Je was onmisbaar voor het vasthouden van de klinische link. lk heb veel van je geleerd, ook dat het belangrijk het is om je werk in perspectief te zien van je sociale leven. Bedankt voor je begeleiding, niet alleen op het wetenschappelijke pad, maar ook bij de organisatie van een studie-stop en het emigreren naar Nieuw Zeeland.

Prof. Dr. J. De Haan, promotor. U hebt vanuit Nederland de progressie van miln onderzoek met interesse gevolgd. Mijn dank voor onze gesprekken in Maastricht en op congressen. Uw begeleiding bij de laatste loodjes hebben ertoe geleid dat dit proefschrift is afgekomen zonder al te veel bloemlezingen.

Associate Professor Dr. L. Bennet, co-promotor. Dear Laura, little did I know what would come of my elective in Auckland. Thank you for giving me the opportunity to explore the effects of asphyxia on peripheral organs in a lab that was mainly focussed on the brain. You taught me the ins and outs of the fetal sheep model and how to run the lab. You were never lost for ideas for new studies. I think back with great pleasure to the many dinners at "the house", and sampling fine New Zealand wine. Organising the FNPS conference with you was great fun.

Associate Professor Dr. A.J. Gunn, co-promotor. Dear Alistair, in addition to all of your scientific input you were always a great help when performing statistics on thousands of minutes of data. Aiso, once I was able to decipher your comments on my manuscripts they were excellent, but computen: writing will always work better!

I would like to thank Prof. Dr. P.D. Guckman for enabling me to do my studies at the RCDMB and later the Liggings institute.

Thank you to Sherly George and Michelle McAnulty-Smith for their help with processing tissues for histology and working out immuno-histochemical techniques and your company in the lab. Steve Fischer for the PRA and ANP analysis. Also to all lab technicians for their contributions to the experiments.

Furthermore I would like to thank my fellow PhD students at the Liggins institute for the fun times inside and outside the institute: Tanja Moderscheim and Paul, Andrew Baker and Sasha, Justin Dean, 
Tim Sato, Simon, Elicla, Susan, Nina, Frank, Ross, Bert, Christian, Bettina and others. It is amazing how so many PhD's together won so few pub quizzes!

Daarnaast waren er de fellow. Dutchies die (al dan niet bij ons) op stage zijn geweest in Auckland en met wie we Nieuw Zeeland hebben verkend: Niek en Ebtisam, Martijn, Marije; Ralph, Hja, Femke en anderen. Ook jullie bedankt voor de gezelligheid! Niet te vergeten de familie Heinebots. Simone je regelde voor ons een prachtig huisje en boot in Devonport; zo dicht bij het strand zullen we niet gauw meer wonen. Jullie waren voor ons home-away-from-home, en toch zijn we met zijn allen heuse Kiwi's geworden!

In dit dankwoord horen ook de mensen van het microcirculatie lab thuis, het lab waar ik begonnen ben. Roland, Mirjam, Erik, Dick en Sabrina bedankt voor jullie bijdrage aan hoofdstuk 3. Roland, je adverteerde voor een student assistent en lokte met een opleidingsplek chirurgie. We hebben samen soms latte avonden op het lab gemaakt, met speciale Beuk-humor altijd een belevenis. Gelukkig is het met die opleidingsplek ook goedgekomen.

Chirurgen, collega arts-assistenten uit het Maaslandziekenhuis te Sittard, en speciaal mijn opleider Dr. Ton Hoofwijk, bedankt voor jullie ondersteuning.

Dr. Esther Lutgens. Beste Esther, dat jij mijn paranimf zou worden stond lang vast voordat dit proefschrift werd geschreven. We kennen elkaar vanaf de eerste dag van onze studie geneeskunde en zijn altijd vriendinnen gebleven. In jaar 2 begonnen we allebei als student assistent op het microcirculatielab. Al gauw vertrok jij naar de pathologie om je eigen onderzoek te gaan doen, waarop je inmiddels bent gepromoveerd en wat je als post-doc voortzet naast je opleiding tot patholoog. Bij jouw promotie kon ik niet aanwezig zijn, de volgende grote gebeurtenis in jouw leven volg ik gelukkig van dichtbij!

Dr. Imke Veltman. Beste Imke, vriendin vanaf de middelbare schooltijd. Daarna gingen we aan een andere kant van het land studeren. Samen met Gwen en Kathy hebben we altijd gezellig contact gehouden. Van de landbouw universiteit switchte jij naar het medische onderzoek, dat was voor mij beter te volgen. Ik vind het erg leuk dat jij nu mijn paranimf bent. En dames, we spreken snel weer eens af!

Lieve familie, vrienden en kennissen, hoewel het voor jullie soms moeilijk te begrijpen was waar ik mee bezlg was, hebben jullie vanuit Nederland altijd interesse getoond in het onderzoek en leven in Nieuw Zeeland. Het was heerlijk om jullie allemaal weer te zien tijdens onze kerst-tournees door Nederland. En om sommigen van jullie op bezoek te krijgen was helemaal super: Albert, Liesbeth en Edwin, Jorgen, Gwen en Cyriel, Pam en Pieter, AnneMarie. Allemaal bedankt voor jullie begrip en steun.

Lieve Vincent, samen begonnen we aan dit avontuur en samen ronden we het af. Eindelijk zijn we klaar met de laptops, laat die toekomst zonder boekjes nu maar komen! 